Competence Modelling for Export Performance Improvement in Ethiopia

Worku Tuffa Birru 


\section{Thesis committee}

\section{Promotor}

Prof. Dr M. Mulder

Professor of Education and competence studies

Wageningen University

\section{Co-promotors}

Dr P.R. Runhaar

Assistant professor, Education and Competence Studies Group

Wageningen University

Dr T. Lans

Assistant professor, Education and Competence Studies Group

Wageningen University

\section{Other members}

Prof. Dr S.W.F. Omta, Wageningen University

Prof. Dr M. Gessler, University of Bremen, Germany

Prof. Dr S. Weber, Ludwig Maximilian University of Munich, Germany

Prof. Dr R. Ruben, Wageningen University

This research was conducted under the auspices of the Graduate School of Wageningen School of Social Sciences (WASS). 


\title{
Competence Modelling for Export Performance Improvement in Ethiopia
}

\author{
Worku Tuffa Birru
}

Thesis

submitted in fulfilment of the requirements for the degree of doctor at Wageningen University by the authority of the Rector Magnificus

Prof. Dr A.P.J. Mol, in the presence of the Thesis Committee appointed by the Academic Board to be defended in public on Friday 2 September 2016 at 8:30 a.m. in the Aula. 
Worku Tuffa Birru

Competence Modelling for Export Performance Improvement in Ethiopia 146 pages.

$\mathrm{PhD}$ thesis, Wageningen University, Wageningen, NL (2016)

With references, with summary in English

ISBN: 978-94-6257-899-9

DOI: http://dx.doi.org/10.18174/388093 


\section{Contents}

Chapter 1 General introduction 1

Chapter 2 International business competence essential to export: a systematic 14 literature review

Chapter 3 International business competence needs of the Ethiopian export sector: 44 experts' view

Chapter $4 \quad$ Explaining organizational export performance by single and combined 64 international business competencies

Chapter 5 Explaining export performance: an examination of the roles of 87 international business competencies and organizational learning orientation

Chapter 6 General conclusions and discussion

References

Summary (English)

Appendix 


\section{CHAPTER 1}

\section{GENERAL INTRODUCTION}

\subsection{Introduction}

The identification of competencies required for accomplishing tasks in a specific context or for a specific purpose and the corresponding performance outcomes has become the subject of sizeable empirical research. To mention some of these studies: Lans (2009) studied how entrepreneurial competence is characterized and identified, how it develops and how it is fostered in small agricultural firms; Du Chatenier (2010) identified competencies for professionals in open innovation teams; Karbasioun et al. (2007) worked on competency profile for agricultural extension instructors; Awuah (2007) studies on the competence development of professional services firms. Likewise, firms involved in exporting need to have certain competencies, which are fundamental building blocks of competitive advantage in the foreign markets and subsequently, leading to successful export performance (Knight and Kim, 2009; Chetty and Hamilton, 1993). This thesis examines the relationship between firms' competencies and performance outcomes within the context of export.

Export represents a viable strategic option for firms to internationalize and has remained the most frequently used foreign market entry mode (Manolova et al., 2010; Lee and Makhija, 2009; Pangarkar, 2008). From a macro-economic perspective, the expansion of a country's export can enhance the accumulation of foreign exchange reserves, raise the level of employment, increase national productivity, and drive economic growth (Ural, 2009). A country's ability to compete successfully in the world markets, ability to maintain a favourable balance of trade, and ability to control its external payment situation reflect the economic strength of the nation. From a company perspective, selling in international markets benefits firms through enhanced revenues and greater productivity owing to the learning effects associated with exporting (Manolova et al., 2010; Martins and Yang, 2009; Fryges and Wagner, 2008; Greenaway and Kneller, 2008). Studies stressed that engaging in export helps firms improve the utilization-rate of production capacity, develop superior management capabilities, enhance innovation in product and process, and consequently, strengthen financial performance (Damijan and Kostevc, 2006). Besides, because of intensifying globalization of the world's economies, exporting activities have become increasingly important for the survival, growth and long-term viability of firms (Knight and 
Kim, 2009; Muzychenko, 2008; Dana and Wright, 2005). In view of this, exporting is seen as an entrepreneurial act in the sense that firms make a strategic shift from potentially slumping domestic markets to growing overseas ones (Kaleka, 2012; Lee and Makhija, 2009; Knight and Kim, 2009).

Firms' survival and expansion in export markets, and the consequent economic growth of many countries, is strongly dependent on a better understanding of the determinants that influence their export performance. The key issue is how to be a successful exporter. In response to this question, an influential research stream - specifically by researchers in the field of international business, international marketing, and international entrepreneurship has explored the factors that are critical to firms' export success (e.g., Brouthers et al., 2015; Kaleka 2012; Murray et al., 2011; Cadogan et al., 2009; Wu et al., 2007). In this context, international business competence (IBC), which Knight and Kim (2009: 255) described as "intangible, overarching firm resource that engenders superior international performance" appears to be an important determinant of export performance (e.g., Nalcaci and Yagci 2014; Boso et al., 2012; Sørensen and Madsen, 2012; Lisboa et.al., 2011). While there has been a great deal of research efforts in identifying IBCs essential for export and the corresponding export performance, most of these studies have been primarily conducted in the West. Given the significant difference between developed and developing countries in terms of contextual factors determining the development and use of IBCs necessary for exporting activities, undeniably, there is a knowledge gap in the understanding of these issues in the Global South developing countries contexts (Boso et al., 2012; Kabagambe et al., 2012; Okpara, 2009). The purpose of this thesis is to contribute to the literature by addressing these issues within the context of a developing economy, Ethiopia. This chapter presents an overarching introduction to this research objective. It does so by describing the specific characteristics of the Ethiopian export sector, elaborating the key concepts and theoretical foundations of the research topic, and outlining problem statements, research questions and overview of the thesis.

\subsection{Ethiopian export sector at a glance}

Ethiopia is a developing East African country going through political, economic, social and technological transitions. The country's development strategy has the objectives of promoting rapid economic growth with a stable macro-economic environment, and enhancing the 
integration of the country's economy with the world economy. In this endeavour, due emphasis has been given to the promotion of exports. Accordingly, an export development strategy has been devised to increase and diversify the country's exports, by focusing on those labour-intensive products that give Ethiopia a competitive edge.

Ethiopia's potential for export of manufactured goods lies in textile, leather and leather products, as well as products of agro-processing. Clothing offers a good possibility of increasing export due to availability of all the essential ingredients for a competitive textile industry in the country: raw materials, low wages and low energy costs. This gives the country a comparative advantage over other countries and regions. Likewise, Ethiopia has a resource advantage in export of semi-processed leather, and has a potential competitive advantage in export of leather garment, shoes, bags, and articles in the same sense as textile clothing. Ethiopia's export of products of agro-processing is dominated by the food and beverages industry. The export potential of this sector, like textile and leather, is linked with the availability of agricultural raw materials and abundant and cheap labour.

Notwithstanding the fact that the Ethiopia's economy has seen tremendous growth over the past decade - averaging $10.8 \%$ per year in the period between 2003 and 2014, as compared to the regional average of $4.8 \%$ - statistics indicate that Ethiopia lags behind in Global Competitiveness Rankings and its export performance has recently taken a downwards turn (World Bank Group [WBG], 2014). The structure of Ethiopian export has been and still is dominated by agricultural products, and the share of manufactured exports has remained marginal, averaging far below the already very low median for Africa. Few studies on export of developing countries attributed such poor performance on the fact that many firms exporting from developing economies often perform poorly, in part because of a failure to identify prioritize and develop the required competencies for sustained export (Kabagambe et al., 2012; Boso et al., 2012; Ibeh, 2003). In view of this, the identification of competencies essential for export and investigation of the relationship between those competencies and export performance in the specific context of Ethiopia provides important insights for the export promotion activities both in Ethiopian and other developing countries. 


\subsection{Theoretical underpinnings}

\subsubsection{Approach to the concept of competence}

Although competence is viewed in this thesis as an organizational construct, its origin can be traced back to psychology where it was seen as a driver of performance (White 1959). As such, it was a construct at the individual level. According to more recent scholars on competence, there are three dominant approaches to the concept of individual - or professional - competence: the behaviourist, generic and comprehensive approaches (Mulder 2014; Le Deist and Winterton 2005).

The Behaviourist approach defines competence based on detailed lists of fragmented and assessable behavioural elements related to job performance and primarily focuses on the actual tasks that must be performed, and/or the challenges that must be overcome (McClelland 1973). It has been criticized for: being reductionist in nature; equating task to competence; ignoring the influence of contextual and group factors; and for assuming that the aggregation of various atomized tasks was sufficient for their integration (Cheetham and Chivers 1996; Eraut 1994).

In contrast, the Generic approach considers competence a general, relatively stable and context-independent attribute underlying effective performance (Eraut 1994). However, this approach was criticized for assuming that generic situation-independent competencies exist, and it has been argued that expertise is highly domain specific (Bereiter and Scardamalia 1993; Gonczi 1994).

By integrating the behaviourist and generic approaches, the Comprehensive approach views competence as an integrated performance-oriented capability necessary for reaching specific achievements (Mulder, 2014; Baartman and Bruijn, 2011; Le Deist and Winterton, 2005; Biemans et al., 2004; Eraut, 1994). The term 'integrated' refers to clusters of knowledge, skills and attitudes necessarily conditional for task performance and problem solving (Mulder 2007). A competency, in this approach, is therefore comprehended as a situated element of competence which can be either behaviour-oriented or task-oriented and that has meaning only in specific context. A key strength of this approach is that it incorporates the underlying attributes of the practitioner with the context in which these attributes may be applied (Wesselink et al., 2010; Hager et al., 1994). 
In this thesis, we employ the definition of competence as a functionally linked complex of knowledge, skills, and attitudes that enable a person (or an organization) to act effectively in a job or situation (Baartman and Bruijn, 2011; Mulder, 2007; Baartman et al., 2007).

\subsubsection{The concept of organizational competence}

As stated before, from the start, competence was conceived as a concept at the level of the individual. It was defined as a set of skills, knowledge and characteristics an individual must possess in order to be capable of adequately performing a specified job. Consistent with this view, individual employees were seen as the source of an organization's competence. Consequently, the core competencies of individuals were seen as giving an organization competitive advantage. In practice, the concept of competence was widely used in human resource management to refer to the universe of employee skills that the company must have in order to successfully achieve their goals (Boyatzis, 1982; McClelland ,1973).

Through the 1990s, competence gained a lot of attention as a concept at the organizational level in the field of strategic management (Barney, 1991; Prahalad and Hamel, 1990). It has been argued that since it is the organization as a whole that performs - not just an individual employee - organizational competence should be viewed as more than the sum of the individual competencies of an organization's employees (Sanchez and Heene, 2004; Boreham 2004). In accordance with this view, organizational competence reflects fundamental capabilities embedded in a firm's structure, technology, processes, and interpersonal and intergroup relationships (Autio et al., 2000; Barney, 1991; Prahalad and Hamel, 1990).

The notion of organizational competence is in line with basic thinking on the Resource-Based View (RBV) of the firm (Barney, 1991) and Dynamic Capability View (DCV) of the firm (Teece et al., 1997). The RBV posits that firms can only achieve sustainable competitive advantage if they possess valuable, rare, inimitable, and non-substitutable resources (Barney, 1991). As work on this view has progressed, it has become clear that the RBV extends not only to the physical and financial assets of an organization but also to its competencies (e.g., De Vita et al., 2011; Javalgi and Todd, 2011; Day, 1994; Henderson and Cockburn, 1994). Organizational competence represents an organization's intangible resources, i.e. those knowledge intensive and performance-enhancing business activities at which the organization has become particularly skilled (Murry et al., 2011; Wu et al., 2007; Teece et al., 1997). 
Because competence is embedded in the specific context in which it was created, it is very difficult to imitate and can become the basis for sustained competitive advantage (Knight and Kim, 2009; Van de Ven, 2004).

An important aspect of firm competence is the notion that these competencies are not fixed structures but dynamic capabilities that can be improved through learning efforts and experiences (Prahalad and Hamel, 1990). The DCV addresses such dynamic nature of organizations' competence (Barrales-Molina et al., 2014; Helfat and Peteraf, 2003; Eisenhardt and Martin, 2000; Teece et al., 1997). According to this view, not only organizations' external environment, but also the competence that enables them to respond effectively to their changing environments are conceptualized as being dynamic and flexible (Vogel and Güttel, 2013; Eisenhardt and Martin, 2000; Teece et al., 1997). The concept of organizational competence therefore not only includes a stable asset but also continuously changing skills or even a process (Helfat and Peteraf, 2003; Montealegre, 2002).

\subsubsection{Organizational competence in the domain of international business}

A model of competencies relevant for internationalization is grounded in the above-discussed approaches to and notions of the concept of competence in general and organizational competence in particular. As it applies to international business, competence are comprehend as organization's fundamental capabilities that account for international business success (Knight and Kim, 2009; Autio et al., 2000). According to Knight and Kim (2009: 255), those competencies that are essential for the internationalization of firms can be conceptualized as International Business Competence (IBC) and are defined as "an intangible, overarching firm resource that engenders superior international performance". In accordance with this definition, IBC measures a multidimensional concept that reflects the extent to which the firm adopts bundles of international competencies in multiple areas in order to effectively carry out international business activities in foreign markets (Brouthers et al., 2015; Murray et al., 2011; Knight and Kim, 2009). Such bundles comprise a number of more specific competence domains the importance of which depends on the specific contexts in which they are used (Shavazi et al., 2015; Hutzschenreuter et al., 2015; Lisboa et al., 2011; Knight and Kim, 2009).

Specific to exporting, the notion of firm IBCs entails processes by which organizational resources are developed, combined and transformed into value offerings for the export 
market (Kabagambe, 2012). In line with the RBV of the firm, this means that firm's success in exporting is positively associated not only with its tangible resources, but also with its possession of competencies that provide guidance for how a firm should use its resources and interact with contextual forces to transform resources into successful export performance (Sørensen and Madsen, 2012; Boso et al., 2012; Murray et al., 2011; Knight and Kim, 2009 Wu, et al.,2007; Knight and Cavusgil, 2004; Autio et al., 2000). In other words, successful performance in exporting denotes possession of enhanced capabilities to identify, create and deliver customer value in export markets (Knight and Kim, 2009; Morgan et al., 2004; Piercy, Kaleka, and Katsikeas, 1998). As such, the scarcity of financial, human, and tangible resources, are no longer major impediments to the large-scale internationalization and global success of the firm. In turn, this suggests that in order for effective export performance, firms need to prepare for international ventures by developing appropriate sets of competence necessary for their internationalization process (Knight and Kim, 2009; Knight and Cavusgil, 2004; Chetty and Hamilton, 1993).

It has been asserted in the literature that competence gets meaning only in a certain context (Mulder, 2014; Le Deist and Winterton, 2005; Eraut, 1994), and that contextual embeddedness matters in interpreting how competencies of the firm play out to influence its performance (Okhmatovskiy, 2010; Dacin et al., 1999; Granovetter, 1985). These views suggest that the integrated set of a firm's IBCs that are prerequisite for effective export performance dynamically emerges from the context in which it is applied. Context is here defined as: "situational opportunities and constraints that affect the occurrence and meaning of organizational behaviour as well as functional relationships between variables" (Johns, 2006: 386). In the literature, three contexts are regarded to be of crucial importance for internationalization competence identification, definition, development, and assessment: environmental, institutional, and organizational contexts (Murray et al., 2011; Peng et al., 2008; Zhou, et al., 2007). The environmental context reflects the turbulence of international environments and may include market dynamics, competitive intensity, technological change, and cultural diversity (Murray et al., 2011; Javalgi and Todd, 2011; Cadogan, Kuivalainen, and Sundqvist, 2009). Institutional contexts refer to regulatory, normative and cultural arrangements that engender, enforce, and limit economic and social activities (Scott, 1995). Organizational context refers to factors that are internal to an organization size and experience in export; prior international experience; and their attitudes towards internationalization (Zhou et al., 2007; Reuber and Fischer, 1997). 


\subsubsection{Export performance}

Export performance represents the extent to which a firm's objectives, both strategic and financial, with respect to exporting a product to a market are achieved via the execution of the firm's export marketing strategy (Navarro et al., 2010; Papadopoulos and Martín, 2010; Cavusgil and Zou, 1994). In the export marketing literature, researchers have used both financial and strategic measures for export performance, and measures of satisfaction with the export venture (Rodriguez et al., 2013; He and Wei, 2011; Zou and Stan, 1998). The Financial performance dimension measures the extent to which firms achieve their results relative to their competitors in terms of financial measures such as sales, market share, profitability, and sales revenue etc. (Lisboa et al., 2011; Murray et al., 2011; Morgan et al., 2004). The Strategic performance dimension of export performance captures firms' strategic goals in the export market, such as, competitiveness, strategic position, global market share, and maintenance of good relationships with the importer in the foreign market (Cavusgil and Zou, 1994). And, finally, the Satisfaction-related dimension of export performance captures the extent to which managers were satisfied with their firms' performance in terms of certain specified indicators and/or satisfaction with overall export performance (Cadogan et al., 2002). Following the lead of recent studies (Zhang and Zhu, 2015; Julian et al., 2014; Kaleka, 2012), we employ in this thesis both financial and strategic measures of export performance.

\subsection{Problem statement, research questions and overview of the thesis}

Given the importance of exporting to both nations and firms, an array of international research has focused on understanding the factors that determines successful performance in export. In particular, recent years have seen increasing attention being given to the identification and assessment of international business competencies that underpin export performance of the firms (Kaleka, 2012; Knight and Kim, 2009; Wu et al., 2007). However, previous studies have examined different sets of IBCs in isolation (e.g., Murray, Gao, and Kotabe, 2011; Okpara, 2009); thereby, offering little information about the various combinations of IBCs that firms can pursue in order to boost their EP. Moreover, majority of prior studies in this direction were focused on Western and advanced economies, hence, an understanding of the relationship between such competencies and export performance in the developing economies' contexts is still lacking (Boso et al., 2012; Kabagambe et al., 2012). Considerable evidence from prior studies points to differences between advanced and 
developing economies in factors important for export. More importantly, exporting firms operating from developing economies have to manage multiple export market challenges, such as, resource constraints (Boso et al., 2012; Tesfom and Lutz, 2006), little international experience (Gries and Naude, 2010), lack of marketing knowledge and information (Tesfom and Lutz, 2006), complex regulatory system and underdeveloped institutions and structures supporting international operations (Global Entrepreneurship Monitor, 2014; Boso et al., 2012; Bianchi, 2010); and significant tariff and non-tariff barriers applied to their manufactured exports (Korneliussen and Blasius, 2008). Given these differences, more study and data is needed from the context of developing economies to broaden knowledge on the subject (Boso et al., 2012; Kabagambe et al., 2012; Okpara, 2009). This thesis, therefore, generates better understanding by step-by-step disentangling the complex relationship between IBCs and export performance in a developing economy context, Ethiopia. The main research question of the thesis is, therefore, 'What is the relationship between international business competencies and export performance in developing economies?' This main research question is addressed in three studies presented in chapters 2 to 5 . These studies investigate specific or a combination of sub research questions that are described below. Each of these chapters is written as a stand-alone academic paper, with its own specific contributions to the literature; thus, there is some overlap between chapters. As such, the introductory sections of each chapter may contain repetitions of the concepts and theoretical linkages presented in the previous chapter. Figure 1.1 illustrates how the three studies of this thesis come together.

First, despite growing amount of academic exchange on IBC that underpin a firm's export performance, the literature has been criticized for focussing only on a narrow set of such competencies and for not being able to develop a comprehensive framework for investigating the relationship between IBC, export performance, and contextual factors. A major reason for that, in spite of the growing volume of published studies, was the lack of synthesis and assimilation of the fragmented knowledge on the subject (Sousa et al., 2008). Consequently, there is no comprehensive framework for studying how exactly IBC relates to export performance and contextual factors. In the light of this, the objective of the first study of this thesis is to synthesizing the literature on IBC essential for export - and its associated factors into an overarching framework, and suggests areas in which more research is required. This objective is to address three specific research questions: 1) What does IBC, which is essential 
for export performance consist of? 2) How does it influence export performance? 3) Which context factors influence the IBC-export performance relationship?

These research questions are addressed in chapter 2. A systematic research strategy was used based on the study's three main concepts: international business, competence, and export performance. Three bibliographical databases (Web of science, Scopus, and Google scholar) were searched and the relevant publications selected based on specific inclusion criteria. Furthermore, the snowball method was used to identify additional relevant publications. Overall, 58 publications dating from 2000 through early 2015 were studied. Based upon the substantive conceptual meanings of the underlying constructs extracted from a content analysis of the literature, a framework comprising of four main components: IBC leading to successful export performance; mediators, i.e. variables that carry the influence of IBC on export performance forward; outcome, i.e. the firm's export performance; and contextual variables, i.e. factors that either inspire IBC development or moderate IBC's influence on export performance was built. More importantly, research gaps for the empirical studies were identified.

Secondly, the importance of IBCs to a large degree depends on the specific situation of each company, the institutional contexts in which it is operating, and the effects of domestic and international environmental factors (Lisboa et al., 2011; Knight and Kim, 2009). As opposed to their counterparts in developed economies, exporting firms operating from developing countries are mostly small to medium-sized enterprises that have: a myriad of resource constraints (Boso et al., 2012; Tesfom and Lutz, 2006), little international experience (Gries and Naude, 2010), lack of marketing knowledge and information (Tesfom and Lutz, 2006), and are heavily dependent on the export of primary commodities (World Bank Group, 2014). In view of this, the objective of the second study of this thesis is to validate and expand the literature-based IBC framework in the specific context of Ethiopia and identify those sets of IBC, which are considered most important for Ethiopian exporting firms. This objective is to address five specific research questions: 1) To what extent do Ethiopian experts recognize $I B C s$, which were extracted from the literature, as an important factor which influences export performance? 2) Which other competence domains experts think are important for enhancing export performance? 3) Which IBCs are considered to be most important for export performance in the Ethiopian context, according to experts' perceptions? 4) How do experts characterize the process through which IBCs, which are chosen as being most 
important, influence export performance? And 5) what other factors help or hinder firms to achieve higher export performance?

Towards addressing these research questions, in-depth experts' interview method was used. A total of 24 (15 male and 9 female) experts, who were selected on the basis of their experience in international business activities within an Ethiopian export organizations or various areas such academia, ministry of trade, chamber of commerce and international trade associations, consultants, and research institutes were participated in this study. A framework of literature based IBC developed in Chapter 1 was used as a starting point for the empirical exploration of the Ethiopian export sector and identifying the types of IBC firms need for successful export performance. Based on the results of these expert interviews, a much clearer IBC framework for use in Ethiopia and other developing countries with similar contextual characteristics was developed.

Third, based on the literature review and the results of the exploratory study, the objective of the third study of this thesis is to investigate the relationship between the identified IBCs and their interaction - and export performance as well as the role that organizational learning orientation plays in that relationship. To this end, a quantitative research method was employed and the analysis was based on data from on-site structured interviews with 159 owners and managers of exporting firms from different economic sectors in Ethiopia. The results of this empirical study are presented in chapter 4 and Chapter 5.

Chapter 4 explores the direct and interaction effects of IBCs. The reasoning for such analysis is that in accordance with the competence-based strategic management theory (Sanchez and Heene, 2004) a firm's competencies are interdependent and likely to interact to influence the firm's performance. Recent studies drawing on the RBV and its extension 'Dynamic Capabilities View' (DCV) of the firm also address the notion of interdependence of organizational resources and capabilities (e.g. Sørensen and Madsen, 2012; King, et al. 2008; Tanriverdi and Venkatraman, 2005). Accordingly, although different sets of a firm's IBC can drive export success individually, they also complement each other and their synergetic effects bring more positive outcomes to firms (Boso et al., 2012; Sørensen and Madsen, 2012). Thus, to increase our understanding of the interplay between different sets of IBCs and their effect on export performance, more research focusing on identifying and specifying their interaction effects is needed, as despite decades of research conducted in the different streams of international business literature, the potential interactive effects of IBCs have not 
been sufficiently explored within the exporting literature (Boso et al., 2012; Sørensen and Madsen, 2012). Accordingly, the objective of this chapter of the thesis is to explore relationships between export performance and IBCs and their interactions. In view of this, three sets of IBC that are identified as most relevant for Ethiopian exporting firms, namely international orientation, export market orientation, and international entrepreneurial orientation were examined. This objective of the third study of this thesis is to address two specific research questions: 1) To what extent are international orientation, export market orientation, and international entrepreneurial orientation related to export performance? And 2) To what extent and in what ways do these IBCs interact in realizing export performance?

Chapter 5 extends the results presented in Chapter 4 and explores the role of organizational learning orientation, which is known as a set of organizational values that influence the firm's propensity to generate and use new knowledge (Rhee et al, 2009; Sinkula et al., 1997) in strengthening the export performance impact of the aforementioned three IBCs. The rationale for this analysis is that exporting firms' strategic resources such as IBCs are learning constructs that can be improved through a firm's learning efforts and experiences (Huang and Wang 2011; Baker and Sinkula, 2009; Wang, 2008; Slater and Narver, 1995). The firms' propensity to gather, accumulate, and use knowledge determine the level of manifestation of a firm's competencies and facilitate their impact on performance (Huang and Wang 2011; Newbert et al., 2008). This further means that the performance impact of a firm's competencies is contingent on the level of its learning-oriented values (Huang and Wang 2011; Newbert et al., 2008). However, thus far, the number of empirical studies examining the role of such values in the relationship between IBCs and export performance has been rather limited. Above all, there are no studies that attempted to look into the role of organizational learning orientation in enhancing the performance effects of different interactions between IBCs. In light of this, the second objective of the third study of this thesis was to examine the extent to which organizational learning orientation strengthens the different interactive effects of international orientation, export market orientation, and international entrepreneurial orientation. This objective of the third study of this thesis is to address a specific question: To what extent does an organizational learning orientation strengthen the effect of the various interactions between international orientation, export market orientation, and international entrepreneurial orientation on export performance? 
Finally, in the last chapter of this thesis the overall conclusions are described and discussed. The chapter opens with a summary of the main findings followed by the main conclusions. Next, the strength and weaknesses of the studies are discussed along with methodological and theoretical issues and suggestions for future research are given. The chapter ends with outlining implications of the findings for policy and practice.
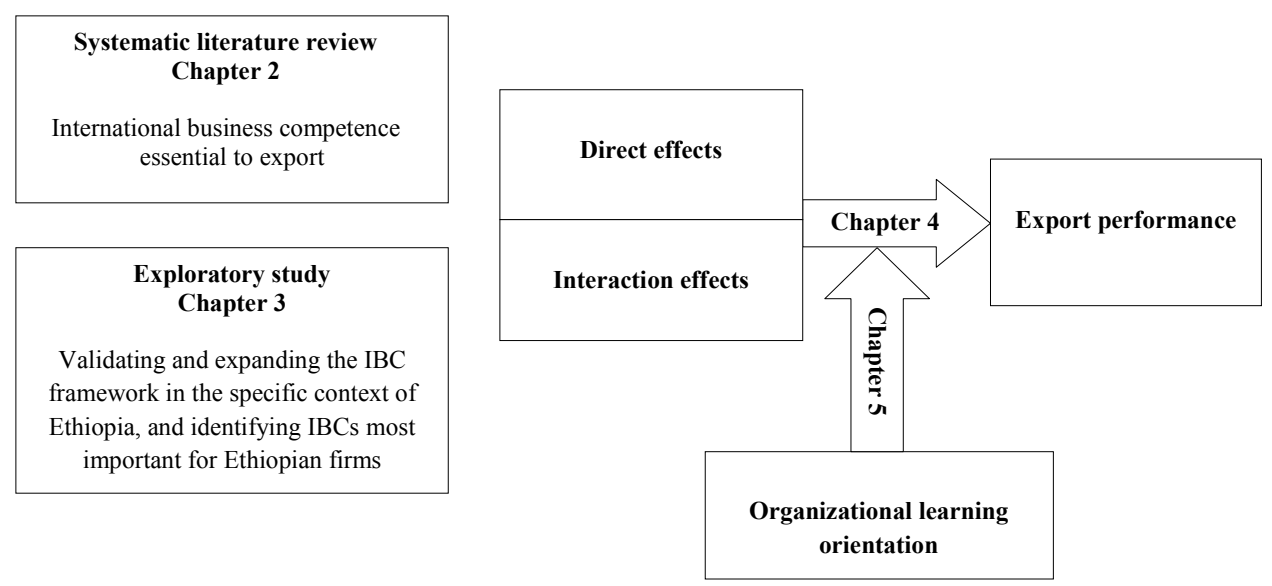

Figure 1.1: Structure of the thesis 


\title{
CHAPTER 2
}

\section{INTERNATIONAL BUSINESS COMPETENCE ESSENTIAL TO EXPORT: A SYSTEMATIC LITERATURE REVIEW}

\begin{abstract}
The increasing amount of research conducted on the link between different sets of international business competence (IBC) and export performance (EP) in recent years invites an analysis of the scholarly conversations taking place. This article provides an integrative review of extant knowledge on the subject, based on input received from 58 articles. The results reveal that: a) eight different but related sets of IBCs have been shown to positively influence firms' export performance, of which Export Market Orientation and International Entrepreneurial Orientation have emerged as the ones studied most; b) researchers tend to use different names and labels for conceptually corresponding IBCs; c) most recent studies have drawn on the Resource-Based View to explain firms' IBC as an important intangible resource leading to success in export; and, d) there is a growing trend to include context and mediating factors when examining the IBC-EP relationship. The study concludes with the identification of research foci whose pursuit promises to advance knowledge on IBC and corresponding performance outcomes.
\end{abstract}

This chapter is based on Birru, W.T., Runhaar, P. Lans, T., and Mulder, M. (submitted). International business competence essential to export: a systematic literature review. 


\subsection{Introduction}

Export is regarded as the most common international market entry mode (Murray et al., 2007) and increasingly seen as an important route for entrepreneurial firms to take, in order to realize their growth potential (Manolova et al., 2010). The extant studies - specifically by researchers in the field of international business, international marketing, and international entrepreneurship - indicate that improved Export Performance (EP) is associated with organizational competencies that facilitate foreign market entry and operations; suggesting that firms who have better developed such competencies perform better in export (Brouthers et al., 2015; Yi et al., 2013; Kaleka, 2012; Murray et al., 2011; Tang, 2011; Knight and Kim, 2009; Wu et al., 2007; Autio et al., 2000). A lot of literature concerning export has also addressed the notion of organizational competence as an important predictor of successful EP (Acikdilli, 2015; Nalcaci and Yagci 2014; Boso et al., 2012; Sørensen and Madsen, 2012; Cadogan et al., 2009; Baldauf et al., 2000). According to Knight and Kim (2009: 255), those competencies that are essential for the internationalization of firms can be conceptualized as international business competence (IBC) and are defined as "an intangible, overarching firm resource that engenders superior international performance". In accordance with this definition, IBC measures a multidimensional concept that reflects the extent to which the firm adopts bundles of international competencies in multiple areas in order to effectively carry out international business activities in foreign markets (Brouthers et al., 2015; Murray et al., 2011; Knight and Kim, 2009). Such bundles comprise a number of more specific competence domains the importance of which depends on the specific contexts in which they are used (Shavazi et al., 2015; Hutzschenreuter et al. 2015; Lisboa et al., 2011; Knight and Kim, 2009). This further highlights the importance of a better understanding of the role contextual factors play in the IBC-EP relationship (Murray et al., 2011; Cadogan et al., 2009).

The notion of organizational competence is in line with basic thinking on the Resource-Based View (RBV) of the firm (Barney, 1991) and Dynamic Capability View (DCV) of the firm (Teece et al., 1997). The RBV shows us the determinants of organizations' performance and the competitive heterogeneity among them, based on the premise that organizations differ in their resources and capabilities (Andersén et al., 2015). A firm's resources consist of all assets, both tangible and intangible, that it possesses and permit it to create and apply valueenhancing strategies (De Vita et al., 2011; Javalgi and Todd, 2011; Day, 1994). Organizational competence represents an organization's intangible resources, i.e. those 
knowledge intensive and performance-enhancing business activities at which the organization has become particularly skilled (Macpherson et al., 2015; Murry et al., 2011; Wu et al., 2007; Teece et al., 1997). The DCV, on the other hand, addresses the evolutionary nature of firms' resources (Teece et al., 1997). This view sustains that it is not only organizations' external environment, but also the competence that enables them to respond effectively to their changing environments are conceptualized as being dynamic and flexible (Barrales-Molina et al., 2014; Vogel and Güttel, 2013; Helfat and Peteraf, 2003; Eisenhardt and Martin, 2000; Teece et al. 1997). The concept of organizational competence therefore not only includes a stable asset but also continuously changing skills or even a process (Montealegre, 2002). In accordance with the notion of organizational competence, IBC represent intangible firmspecific resources out of which the firm's competitive advantage in foreign markets emerges (Knight and Kim, 2009; Wu et al., 2007). It reflects competence in multiple areas that provides guidance for how a firm should use its resources and interact with contextual forces to transform resources into successful international market performance (Kabagambe et al. 2012; Sørensen and Madsen, 2012; Boso et al., 2012; Murray et al., 2011; Knight and Kim, 2009).

While the number of academic exchanges on IBCs that underpin a firm's EP is growing, studies have commonly focused on a specific set of such competencies; disregarding other possible competence domains (Sousa et al., 2008). Some examples of said competencies studied in isolation include: international orientation (Javalgi and Todd, 2011; Knight and Kim, 2009); export market orientation (Zhang and Zhu, 2015; Murray et al., 2011; He and Wei, 2011; Miocevic and Crnjak-Karanovic 2011); international entrepreneurial orientation (Gerschewski et al., 2015; Fernández-Mesa and Alegre, 2015; Lisboa et al., 2011; O'Cass and Weerawardena, 2009); network competence (Tang 2011); and international marketing skills (Acikdilli, 2015; Nalcaci and Yagci, 2014; Knight and Kim, 2009; Mavrogiannis et al., 2008). Moreover, while the construct IBC has only relatively recently been introduced in literature (Knight and Kim, 2009), it remains unclear what constitutes IBC and how exactly it relates to EP and contextual factors. Given the increased interest in the subject and the diversity of conversations taking place, we believe it is time to review the extant knowledge and offer suggestions for advancing knowledge on the subject. Towards these ends, this article provide an overview of the state of research on the link between IBCs that are associated with successful export performance. Reviewing and synthesizing the literature on IBC essential for export - and its associated factors - into an overarching framework is a 
matter of some interest, from a scientific as well as a practical point of view. To start with the first, if there was no ambiguity about the identification of this IBC that enhances organizations' EP, the learning process that underlies its development in an organization could be studied into more detail; as could the link between competence development and organization performance in export. However, despite the claim that the future of export competence lies in the concept of IBC (Knight and Kim, 2009), as of yet there is no specific framework for exploring how a firm's IBC materializes within it; neither as a culture nor as a behavioural tendency. This study therefore provides a basis for future research on the concept of IBC. In practice, a deeper understanding of this competence will serve to guide business practitioners in determining the appropriate set of competencies firms will need to develop to successfully boost their EP. Furthermore, it will also serve policy-makers in developing national export promotion programs.

The research questions underlying this study are, therefore. What does $I B C$, which is essential for export performance consist of? How does it influence export performance? And which context factors influence the IBC-export performance relationship? As there seems to be no specific framework available for analysing and synthesizing research on IBC and its influence on EP, we followed the lead of previous reviews (Keupp and Gassmann, 2009) and built a framework based upon the substantive conceptual meanings of the underlying constructs extracted from a content analysis of the literature. Our framework consists of four main components: IBC leading to successful EP; mediators, i.e. variables that carry the influence of IBC on EP forward; outcome, i.e. the firm's EP; and contextual variables, i.e. factors that either inspire IBC development or moderate IBC's influence on EP.

\subsection{Review Methodology}

To provide a broad overview and evaluation of published research on IBC that are associated with high-level export performance, we followed procedures that are consistent with the recommendations of other reviews (e.g. Delgado-García et al., 2015; De Clercq et al., 2012; Jones et al., 2011). First, we formulated search terms based on the study's three main concepts: competence, international business, and export (including synonyms derived from literature and Merriam-Webster's Online Thesaurus). Based on Mulder's (2007) definition of competence - which was the basis for related empirical competence research (e.g. Wesselink et al., 2010; Karbasioun et al., 2007) - we augmented the search term 'competence' with the 
synonymous capabilities, knowledge, attitude, and skill. To the search term international business were added synonyms like foreign business, international trade, overseas business, intercontinental business, world business, and global business. Similarly, export was joined by selling abroad, distributing abroad, trade abroad, market abroad, ship overseas, exportation, foreign sale, overseas shipment, international trade and foreign trade. Together these synonyms formed three domains of keywords; all words within each set were connected with 'OR' and the three domains were joined using 'AND'.

Secondly, we developed five selection criteria. To be considered relevant, an article had to: a) contain empirical evidence; b) be published in a peer-reviewed journal to ensure scientific quality; c) be published from the year 2000 up to the present - 2000 being the cut-off year for the period that produced the most IBC-research (Rialp et al., 2004); d) examine firms engaged in marketing and selling domestically produced goods to another country directly; e) contain - whether in its title, abstract, or full text - the search terms identified above.

Following the lead of earlier reviews (e.g. De Clercq et al., 2012; Jones et al., 2011; Keupp and Gassmann, 2009), we limited our review to non-invited peer-reviewed journal articles. We omitted material of an editorial nature, conference papers, books, book reviews, and book chapters; because journal articles best reflect existing original research. We also excluded reviews, commentaries from parent or related disciplines, introductions to special issues or articles (Short et al., 2010; Zahra, 2005) and studies on service firms due to their idiosyncratic characteristics (Zou and Cavusgil, 2002).

In order to ensure a reasonably complete coverage of the available literature, we searched three bibliographical databases: Web of science, Scopus, and Google scholar. This procedure yielded 985 articles. After eliminating redundancies, 889 articles remained for further investigation. Following that, two researchers independently checked the titles, abstracts, key words, and - where necessary - full text of the identified articles against the criteria for inclusion. This initial screening yielded 149 potentially relevant publications. After determining whether the link between IBC and EP was a central rather than a peripheral theme in the publication, 63 of them were deemed eligible for inclusion. Twelve studies were left out because they conceptualized IBC as an individual as opposed to an organizational construct. 
Agreement between the two researchers on inclusion of relevant and exclusion of irrelevant publications was sufficient (Cohen's Kappa $=0.84$ ) and discrepancies were resolved through discussion. Finally, following Short et al. (2010), we applied the snowball method to said articles' reference sections in order to identify other potentially relevant articles, which resulted in seven additional relevant publications. The final selection of 58 articles consists of a significant and sufficiently representative number of academic works that demonstrate the importance and, consequently, greater consideration currently given to this topic by researchers. Table 2.1 provides an overview of the reviewed articles by publication outlet.

Table 2.1: Overview of articles by journal

\begin{tabular}{ll}
\hline Journal & $\begin{array}{l}\text { Number of } \\
\text { publications }\end{array}$ \\
\hline Journal of International Marketing & 7 \\
Journal of World Business & 6 \\
International Business Review & 6 \\
International Marketing Review & 6 \\
Journal of International Business Studies & 4 \\
Journal of Business Research & 3 \\
European Journal of Marketing & 2 \\
Journal of Small Business Management & 2 \\
Entrepreneurship Theory and Practice & 2 \\
Other journals & 20 \\
\hline
\end{tabular}

\subsection{Results}

\subsubsection{General assessment of the reviewed studies}

The primary focus of our review is to unravel IBCs that are seen as instrumental in the successful EP of firms. Nevertheless, in view of the fact that empirical findings tend to be idiosyncratic in relation to the research method employed (Leonidou et al., 2002) - and following the lead of previous reviews on various aspects of international business (Kiss et al., 2012; Sousa et al., 2008) - this section provides the general characteristics of the reviewed studies. Table 2.2 summarizes the descriptive properties of the 58 studies selected.

Concerning the countries under study, most studies are based on the datasets of advanced and emerging economies. China was the most researched country $(\mathrm{N}=11)$, followed by the USA 
$(\mathrm{N}=8)$, the other 39 studies were distributed across a variety of countries. In terms of continental distribution, Europe was at the forefront $(\mathrm{N}=21)$, followed by Asia $(\mathrm{N}=20)$ and North America $(\mathrm{N}=10)$. Australia was researched least $(\mathrm{N}=3)$. We found no studies covering Latin America. Most studies only surveyed single countries, with the exception of three European studies that used cross-national data.

Of the 58 studies reviewed, 37 reported on the sort of firms studied. Of these, 30 focused on small to medium-sized firms (SMEs). Seven of those studies emphasized born-global SMEs, i.e. firms that entered the international market in a very early stage of their organizational existence; and seven other studies examined firms of all sizes. Criteria for measuring firm size differed between studies (e.g. number of employees, annual sales). Finally, depending on the geographic focus, there were some variations in the definitions of 'small', 'medium' and 'large'.

Around 71 percent of the articles reviewed were published during the last decade and over 39 percent have appeared in the last five years.

All but three studies used the survey method for data collection, a mail questionnaire survey being the most popular. In three cases, the information obtained from written questionnaires was supplemented by in-person and telephone interviews. Only two, small sample sized, studies employed in-depth personal interviews while another study with an extremely high sample size was based strictly on secondary data. The majority of studies $(\mathrm{N}=40)$ relied on just a single respondent per firm (usually the individual responsible for international marketing activities, like the export manager or CEO).

In the majority $(\mathrm{N}=37)$ of studies, the business firm was the unit of analysis. Six studies focused on export ventures and one combined both firm level and export venture analysis. One other study examined the firm's performance in a specific export market.

Authors employed various dimensions of EP. These were mostly assessed through perceived and self-reported financial, strategic, and satisfaction-related benchmarks. The most frequently used financial yardsticks for EP were: export sales growth (33); export profit level (29); export sales volume (16); export intensity (11); export market share (8); export profit contribution (7); and export market share growth (4). All remaining financial EP benchmarks appeared only once and we amalgamated these under the "other" category. Strategic benchmarks that were used in the reviewed studies included: export market entry (11); global 
competitiveness (4); strategic position (4); and six others, which appeared only once each. Finally, where it comes to satisfaction, 18 studies have either used managers' satisfaction with specified indicators or their overall satisfaction with export performance. Where it comes to the question whether studies have used single or multiple dimensions to measure $\mathrm{EP}$, we found that 26 of the studies reviewed here relied exclusively on a single dimension of EP. Of these, 23 studies only used perceived and self-reported financial criteria for EP. Eighteen studies used financial as well as strategic benchmarks; another 10 studies combined financial with satisfaction-related criteria. Only four studies combined all three dimensions of EP measurement presented above.

All of the 55 studies employing the survey method used Likert-type scales to develop the construct of choice, generally using previously validated benchmarks. In addition, 51 out of said 55 studies reported some validity or internal consistency reliability of data. Where it comes to validity: 37 studies reported some element of construct validity predominantly convergent and discriminant; 13 studies reported content validity; four studies reported face validity; and four studies reported both content validity and face validity. With regards to internal consistency reliability: 31 studies used Cronbach's coefficient; 16 studies used composite reliability; and two studies used both.

Finally, various theoretical perspectives have been used to study IBCs, such as RBV, DCV, social network theory, contingency theory, social exchange theory, and evolutionary economics theory. Most recent studies $(\mathrm{N}=21)$ drew on $\mathrm{RBV}$, while 5 others integrated $\mathrm{RBV}$ with other perspectives. On the other hand, 24 studies were not grounded in any kind of theoretical framework. 
Table 2.2: Descriptive properties of the reviewed empirical publications presented in reverse chronological order

\begin{tabular}{|c|c|c|c|c|c|c|c|}
\hline Article & $\begin{array}{l}\text { Country } \\
\text { under study }\end{array}$ & Firm size & $\begin{array}{l}\text { Sample } \\
\text { size }\end{array}$ & $\begin{array}{l}\text { Data } \\
\text { collection }\end{array}$ & $\begin{array}{l}\text { Unit of } \\
\text { analysis }\end{array}$ & $\begin{array}{l}\text { Theoretical } \\
\text { framework }\end{array}$ & Measure \\
\hline 1. Shavazi et al 2015 & Iran & SMEs & 120 & Survey & Firm & Not specified & Export si \\
\hline $\begin{array}{l}\text { 2. Ferna'ndez-Mesa and Alegre } \\
\text { (2015) }\end{array}$ & $\begin{array}{l}\text { Spanish and } \\
\text { Italian }\end{array}$ & SMEs & 150 & Survey & Firm & Not specified & Expor \\
\hline 3. Zhang and Zhu (2015) & China & Not specified & 220 & Survey & Firm & $\mathrm{RBV}$ & $\begin{array}{l}\text { Profita } \\
\text { introdu }\end{array}$ \\
\hline 4. Gerschewski et al (2015) & $\begin{array}{l}\text { Australian } \\
\text { and New } \\
\text { Zealand }\end{array}$ & SMEs & 310 & Survey & Firms & $\begin{array}{l}\text { RBV and } \\
\text { Network } \\
\text { perspective }\end{array}$ & $\begin{array}{l}\text { Sales, pr } \\
\text { profitabi }\end{array}$ \\
\hline 5. Brouthers et al (2015) & $\begin{array}{l}\text { U.S. and } \\
\text { U.K. }\end{array}$ & SMEs & 162 & Surveys & $\begin{array}{l}\text { Performance } \\
\text { in a specific } \\
\text { market }\end{array}$ & RBV & $\begin{array}{l}\text { Return o } \\
\text { performa }\end{array}$ \\
\hline 6. Acikdilli (2015) & Turkey & All-size & 416 & Surveys & $\begin{array}{l}\text { export } \\
\text { venture }\end{array}$ & Not specified & $\begin{array}{l}\text { Financia } \\
\text { specified }\end{array}$ \\
\hline 7. Hoang (2015) & Taiwan & SMEs & 142 & Survey & Firm & RBV & Export \\
\hline 8. Julian et al (2014) & Indonesian & All-size & 109 & Survey & Firm & Not specified & Financ \\
\hline 9. Nalcaci and Yagci(2014) & Turkish & All-size & 14 & Case study & Firm & RBV & Export \\
\hline 10. Navarro-García et al (2014) & Spanish & All-size & 212 & Survey & Firm & RBV & Expor \\
\hline 11. Singh and Mahmood (2013) & Malaysia & SME & 201 & Survey & Firm & RBV & Export \\
\hline 12. Al-Aali et al (2013) & Saudi Arabia & Not specified & 222 & Survey & Firm & Not specified & xpor \\
\hline 13. Rodriguez et al (2013) & Mexico & All-size & 119 & Survey & Firm & Not specified & Expor \\
\hline 14. Yi et al. (2013) & China & All size & 359,874 & $\begin{array}{l}\text { Archival } \\
\text { panel data }\end{array}$ & Firm & RBV and IBV & Expor \\
\hline 15. Sørensen and Madsen (2012) & Denmark & SMEs & 249 & Survey & Firm & RBV & Perceptu \\
\hline 16. Kabagambe et al. (2012) & Uganda & SMEs & 76 & Survey & Firm & RBV & Financ \\
\hline 17. Kaleka (2012) & UK & SMEs & 268 & Survey & $\begin{array}{l}\text { Export } \\
\text { venture }\end{array}$ & $\begin{array}{l}\text { Contingency } \\
\text { perspective }\end{array}$ & Market \\
\hline 18. Murray et al. (2011) & China & $\begin{array}{l}\text { Not } \\
\text { specified }\end{array}$ & 491 & Survey & Firm & RBV & $\begin{array}{l}\text { Profit le } \\
\text { competit }\end{array}$ \\
\hline $\begin{array}{l}\text { 19. Miocevic and Crnjak- } \\
\text { Karanovic (2011) }\end{array}$ & Croatia & SMEs & 125 & Survey & Firm & Not specified & $\begin{array}{l}\text { Profitabi } \\
\text { strategic } \\
\text { with ove }\end{array}$ \\
\hline
\end{tabular}




\begin{tabular}{|c|c|c|c|c|c|c|c|}
\hline 20. Lisboa et al. (2011) & Portugal & All size & 254 & Survey & $\begin{array}{l}\text { Export } \\
\text { venture }\end{array}$ & RBV and $\mathrm{OL}$ & Sales, $\mathrm{m}$ \\
\hline 21. Tang (2011) & China & SMEs & 210 & Survey & Firm & RBV & Export \\
\hline 22. Javalgi and Todd (2011) & India & SMEs & 150 & Survey & Firm & RBV & Expor \\
\hline 23. He and Wei (2011) & China & Not specified & 230 & Survey & Firm & RBV & Profita \\
\hline 24. Cadogan et al. (2009) & Finland & Not specified & 783 & Survey & Firm & RBV & Sales y \\
\hline 25. Okpara (2009) & Nigeria & SMEs & 89 & Survey & Firm & Not specified & Profita \\
\hline 26. Lages et al. (2009) & Portugal & Not specified & 419 & Survey & $\begin{array}{l}\text { Export } \\
\text { venture }\end{array}$ & RBV & $\begin{array}{l}\text { Sales, } 1 \\
\text { and rel }\end{array}$ \\
\hline 27. Knight andKim (2009) & USA & SMEs & 354 & Survey & Firm & RBV & Sales $g$ \\
\hline $\begin{array}{l}\text { 28. O'Cass and Weerawardena } \\
\text { (2009) }\end{array}$ & Australia & SMEs & 302 & Survey & Firm & Not specified & $\begin{array}{l}\text { Marke } \\
\text { propen }\end{array}$ \\
\hline 29. Blesa and Ripolle's (2008) & $\begin{array}{l}\text { Spain and } \\
\text { Belgium }\end{array}$ & Not specified & 2300 & Survey & Firm & $\mathrm{RBV}$ and $\mathrm{DCV}$ & $\begin{array}{l}\text { Profita } \\
\text { satisfac }\end{array}$ \\
\hline 30. Hartsfield et al. (2008) & USA & $\begin{array}{l}\text { Born-global } \\
\text { SMEs }\end{array}$ & 195 & Survey & Firm & Not specified & $\begin{array}{l}\text { Profita } \\
\text { perfor! }\end{array}$ \\
\hline 31. Mavrogiannis et al. (2008) & Greece & Not specified & 103 & Survey & Firm & Not specified & Market \\
\hline 32. Zhou et al. (2007) & China & $\begin{array}{l}\text { Born-global } \\
\text { SMEs }\end{array}$ & 129 & Survey & Firm & $\begin{array}{l}\text { Social network } \\
\text { theory }\end{array}$ & sales, \\
\hline 33. Racela et al. (2007) & Thailand & Not specified & 279 & Survey & Firm & $\begin{array}{l}\text { Social } \\
\text { exchange } \\
\text { theory }\end{array}$ & $\begin{array}{l}\text { Sale, } m \\
\text { satisfac }\end{array}$ \\
\hline 34. Kuivalainen et al. (2007) & Finland & $\begin{array}{l}\text { Born-global } \\
\text { SMEs }\end{array}$ & 185 & Survey & Firm & RBV & sales, 1 \\
\hline 35. Murray et al (2007) & China & Not specified & 491 & Survey & $\begin{array}{l}\text { Export } \\
\text { venture }\end{array}$ & Not specified & $\begin{array}{l}\text { Profit, } \\
\text { satisfac }\end{array}$ \\
\hline 36. Zhou (2007) & China & $\begin{array}{l}\text { Born-global } \\
\text { SMEs }\end{array}$ & 775 & Survey & Firm & EL & sales g \\
\hline 37. Kropp et al. (2006) & South Africa & Not specified & 396 & Survey & Firm & RBV & Profita \\
\hline $\begin{array}{l}\text { 38. Mort and Weerawardena } \\
\text { (2006) }\end{array}$ & Australia & $\begin{array}{l}\text { Born-global } \\
\text { SMEs }\end{array}$ & 6 & Case study & Firm & $\mathrm{DCV}$ & Entry $\mathrm{i}$ \\
\hline 39. Haahti et al. (2005) & $\begin{array}{l}\text { Finland and } \\
\text { Norway }\end{array}$ & SMEs & 149 & Survey & Firm & RBV & Expor \\
\hline 40. Brouthers and Nakos (2005) & Greece & SMEs & 112 & Survey & Firm & Not specified & Profita \\
\hline
\end{tabular}




\begin{tabular}{|c|c|c|c|c|c|c|c|}
\hline 41. Toften (2005) & Norway & SMEs & 125 & Survey & Firm & Not specified & $\begin{array}{l}\text { Growth } \\
\text { satisfact }\end{array}$ \\
\hline 42. Dimitratos et al. (2004) & Greece & $\begin{array}{l}\text { Born-global } \\
\text { SMEs }\end{array}$ & 152 & Survey & Firm & $\begin{array}{l}\text { Contingency } \\
\text { theory }\end{array}$ & $\begin{array}{l}\text { Export ir } \\
\text { perform }\end{array}$ \\
\hline 43. Knight and Cavusgil (2004) & USA & $\begin{array}{l}\text { Born-global } \\
\text { SMEs }\end{array}$ & 203 & Survey & Mixed & $\begin{array}{l}\text { Evolutionary } \\
\text { economics }\end{array}$ & $\begin{array}{l}\text { Market s } \\
\text { return on }\end{array}$ \\
\hline 44. Guan and Ma (2003) & China & Not specified & 213 & Survey & Firm & RBV & Export $\mathrm{r}$ \\
\hline 45. Zou et al. (2003) & China & Not specified & 50 & Survey & $\begin{array}{l}\text { Export } \\
\text { venture }\end{array}$ & RBV & $\begin{array}{l}\text { Profitabi } \\
\text { export } \mathrm{v}\end{array}$ \\
\hline 46. Akyol and Akehurst (2003) & Turkey & Not specified & 103 & Survey & Firm & Not specified & Export s \\
\hline $\begin{array}{l}\text { 47. Julien and Ramangalahy } \\
\text { (2003) }\end{array}$ & Canada & SMEs & 346 & Survey & Firm & RBV & Sales, p \\
\hline $\begin{array}{l}\text { 48. Balabanis and Katsikea } \\
(2003)\end{array}$ & UK & Not specified & 82 & Survey & Firm & Not specified & $\begin{array}{l}\text { Sales grc } \\
\text { satisfacti }\end{array}$ \\
\hline 49. Cadogan et al. (2003) & Hong Kong & Not specified & 137 & Survey & Firm & Not specified & Sales eff \\
\hline 50. Cadogan et al. (2002) & USA & Not specified & 206 & Survey & Firm & Not specified & Sales gi \\
\hline 51. Rose and Shoham (2002) & Israel & Not specified & 124 & Survey & Firm & Not specified & Sales, c \\
\hline 52. Prasad et al. (2001) & USA & SMEs & 381 & Survey & Firm & Not specified & Sales \\
\hline 53. Ibeh and Young (2001) & Nigeria & SMEs & 78 & Survey & Firm & Not specified & Market \\
\hline $\begin{array}{l}\text { 54. Ling-yee and Ogunmokun } \\
\text { (2001) }\end{array}$ & China & SMEs & 111 & Survey & $\begin{array}{l}\text { Export } \\
\text { venture }\end{array}$ & $\mathrm{RBV}$ and $\mathrm{KBV}$ & $\begin{array}{l}\text { Finan } \\
\text { develc }\end{array}$ \\
\hline $\begin{array}{l}\text { 55. Francis and Collins-Dodd } \\
(2000)\end{array}$ & Canada & SMEs & 88 & Survey & Firm & $\begin{array}{l}\text { Contingency } \\
\text { framework }\end{array}$ & Expor \\
\hline 56. Baldauf et al. (2000) & Austria & Not specified & 184 & Survey & Firm & Not specified & Expor \\
\hline 57. Calantone and Knigh (2000) & USA & Not specified & 1,300 & Survey & Firm & Not specified & Marke \\
\hline 58. Yeoh (2000) & USA & Not specified & 180 & Survey & Firm & Not specified & $\begin{array}{l}\text { Growth } \\
\text { sales }\end{array}$ \\
\hline
\end{tabular}




\subsubsection{Review of IBC in the literature}

We have organized our review of IBC into three parts: IBC leading to successful EP, mediating factors, and context factors. The schematic diagram shown in Figure 2.1 presents a framework, derived from content analysis of the reviewed literature. It shows how the different factors interact with each other. In classifying the factors within the framework, we made an effort to group some variables according to the underlying construct that they attempted to measure.

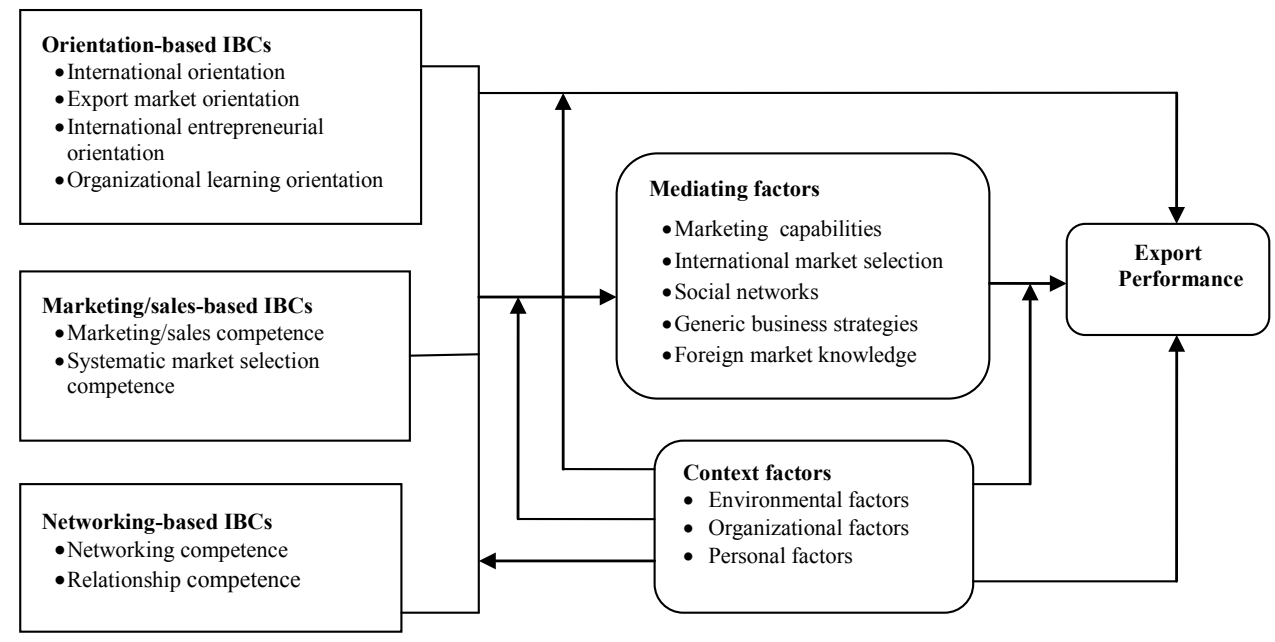

Figure 2.1: Organizing framework derived from content analysis of the reviewed literature

\subsubsection{IBC leading to successful EP}

Our review uncovered as many as eight different but related IBCs that have been found to have a direct or indirect positive influence on EP. Furthermore, going beyond merely extracting the IBCs examined in the reviewed studies, we attempted to cluster them into three interrelated groups - Orientation, Marketing/sales, and Networking competencies based on the substantive conceptual meanings of the underlying constructs examined in the studies. Orientation-based IBCs refer to the set of broad strategic choices implemented in the pursuit of sustainable superior performance, and are a predisposition for developing overall firm behaviour and activities for achieving superior performance (Liu and Fu, 2011; Zhou and Li, 
2007). Competencies in this domain serve as a platform for fostering effective managerial responses to changing international environments. Marketing/sales - based IBC refers to a firm's ability to: create value for foreign customers through key marketing elements (Lages et al., 2009); identify with the wants and needs of target customers; and communicate the company's brand image and product value so as to elicit favourable reactions from said target customers (Acikdilli 2015; Navarro-García et al., 2014; Knight and Cavusgil, 2004). Finally, Network - based IBC refers to a firm's ability to transcend its formal boundaries and reach out to other players during its internationalization process to improve international performance (Niesten and Jolink, 2015; Tang, 2011; Lages et al., 2009). It should be noted however that these categories are not mutually exclusive and, in some cases, overlap. For instance, a responsiveness dimension of a firm's export market orientation (EMO) - which, conceptually, falls in the orientation-based IBC category - is implementing responses to changing customer needs and competitors' actions; in which case it seems to be an element of marketing/sales-IBC as opposed to orientation -based IBC.

These IBCs and their description - in terms of how they are conceptualized, how they are measured, and how they influence EP - are presented below, based on the competence domain they emphasize. Table 2.3 presents -for each IBC - its underlying dimensions, the frequency of its presence, and a statistical summary of its impact on EP in the reviewed studies. Table 2.4, on the other hand, shows the use of names and terms by authors to refer to the IBC of their choice.

\section{Orientation-based IBCs}

International orientation (IO) - refers to the extent to which a firm's management has a favourable attitude towards, and is willing to expend the necessary resources for, internationalization efforts (Sørensen and Madsen, 2012; Knight and Cavusgil, 2004). In essence, it is whether managers see the world as their marketplace and how motivated they are to deal with international customers and partners. This entails that the management of an internationally oriented firm must be willing to spend the necessary resources and develop the organizational culture that motivates employee behaviour towards international activities (Sørensen and Madsen, 2012; Knight and Kim, 2009). IO also implies proactively motivating for international activities - instead of responding reactively to environmental changes - and the proactive seeking of market information and generating of sales (Baldauf et al., 2000). 
The contention that IO affects EP stems from the key role management plays in creating the values and orientation that members of a firm adhere to (Leonidou et al., 1998; Miesenböck, 1988). It has been argued that if a firm's management has an established and enduring commitment to the firm's export operations, the organization as a whole will recognize said commitment and a system of shared values and beliefs about export-viability and importance for organizational success is likely to thrive (Cadogan et al., 2005). This means that firms with an internationally oriented top management tend to possess distinctive competencies and outlooks that lead to an active exploration of new business opportunities abroad (Sørensen and Madsen, 2012; Mort and Weerawardena, 2006). However, organization-wide coordination of activities related to internationalization will be hindered in firms where the top management lacks IO (Francis and Collins-Dodd, 2000). Zhou and colleagues added that firms with a higher level of IO tend to develop home-based social networks, the information benefits of which leverage their EP (Zhou et al., 2007).

Eight of the studies examined the IO-EP relationship. All reported a significant and positive effect upon various facets of EP through the possession of IO. Yet, there is no consensus amongst studies regarding IO's exact role and the process through which it influences EP. Four studies reported a direct linear relationship between IO possession and EP, while one study provided evidence that IO affects EP indirectly through social networks (Zhou et al., 2007). Sørensen and Madsen (2012) report that IO is associated with EP both individually and in combination with Export Market Orientation (EMO). On the other hand, Miocevic and Crnjak-Karanovic (2011) and Blesa and Ripollès (2008) report that IO serves as a mediator in the relationship between EMO-EP and Marketing and Sales competence (M\&S)-EP respectively.

International entrepreneurial orientation (IEO) - Drawing on Lumpkin and Dess (1996), studies have understood IEO as being the behavioural elements of international orientation and it encapsulates a firm's propensity for innovativeness, proactiveness, and risk taking (Lisboa et al., 2011; Dimitratos et al. 2004). Innovativeness refers to supporting creativity, the introduction of new products and services, and the development of new processes. Proactiveness describes the characteristics of entrepreneurial actions to anticipate future opportunities, both in terms of products and technologies and in terms of markets and consumer demand. Risk-taking deals with tendencies in taking bold action, such as entering new foreign markets. Authors differ in the way they combine said dimensions into the overall 
IEO construct. Either using all three components (e.g. Gerschewski et al., 2015; Brouthers et al., 2015; Hartsfield et al., 2008), only one or two of them (e.g. Fernández-Mesa and Alegre, 2015; Yi et al., 2013), or even inserting new ones (e.g. Kuivalainen et al., 2007; Kropp et al., 2006).

While 14 studies used an aggregated one-dimensional benchmark for IEO - all reporting a significant positive impact of IEO on EP (e.g. Shavazi et al., 2015; Rodriguez et al., 2013; Javalgi and Todd, 2011) - three studies have examined the differential effect of IEO dimensions. In the latter case, Zhou (2007) found that innovative and proactive pursuit of entrepreneurial opportunities has a significant positive influence on a firm's EP; while the risk-taking dimension negatively influences performance. Likewise, Kuivalainen et al. (2007) found that the competitive aggressiveness dimension of IEO positively affects EP, whereas the risk-taking dimension even has a negative impact on performance. They connect the negative effects of a proclivity for risk-taking to managers' perception of the cost of internationalization. Kropp et al. (2006) dealt with the innovativeness and communication dimensions and found that a firm's innovativeness has a significant positive effect, while communication has been found to inversely relate to EP. Three other studies have examined only the innovativeness dimension of IEO and found its significant positive impact on firms' EP (e.g. Yi et al., 2013; Knight and Kim, 2009), while one study that has examined only the risk-taking dimension also reported its positive effect (Fernández-Mesa and Alegre, 2015).

Regarding the process through which IEO influence firms' EP, some studies have shown that IEO is directly associated with EP (e.g. Gerschewski et al., 2015; Brouthers et al., 2015; Javalgi and Todd, 2011). It has also been seen as a precursor to firms' development of business strategy, which in turn affects the marketing capabilities and EP of said firms (Lisboa et al., 2011). Knight and Cavusgil (2004), who said that having IEO supports the realization of key strategic initiatives that enhance a firm's international success, best explain the latter. Zhou (2007) shows that IEO influences EP through supporting the development of a firm's foreign market knowledge; while Fernández-Mesa and Alegre (2015) provided evidence that IEO influence EP when firms make efforts in organizational learning and innovation. On the other hand, Shavazi et al. (2015) demonstrate the mediating role of IEO in the EMO-EP and Organizational Learning Orientation (OLO)-EP relationship.

Export market orientation (EMO) - Kohli and Jaworski (1990) define market orientation as generating, disseminating, and responding to market intelligence. Said intelligence to be 
understood as pertaining to: current and future customer needs, competitor strategies and actions, and broad business environment. On the other hand, Narver and Slater (1990) view $\mathrm{MO}$ as an organizational culture and consequently conceptualize it in terms of three behavioural components, i.e. customer orientation, competitor orientation, and interfunctional coordination. In relation to internationalization, market orientation refers to the mind-set of a firm that stresses the development of customer value for foreign market customers through the organization's marketing practices (Shavazi et al., 2015; Murry et al., 2011; Cadogan et al., 2009; Racela et al., 2007).

Twenty one studies conceptualized EMO as a one-dimensional construct composed of Kohli and Jaworski's (1990) three information-based benchmarks or Narver and Slater's (1990) three behaviour-based ones. While five studies have examined the individual effects of EMO's components, two other studies investigated only the information search component. All studies have found positive and significant relationships between a firm's possession of EMO and its EP, while a further 15 studies found positive direct relationships between EMO and EP (e.g. Gerschewski et al., 2015; Julian et al., 2014; Singh and Mahmood, 2013; Cadogan et al., 2009). Six studies demonstrated that EMO enables firms to leverage EP through development of other export market capabilities. For instance, Murray et al. (2011) and Prasad et al. (2001) found that EMO affects EP through leveraging firms' marketing capabilities and Miocevic and Crnjak-Karanovic (2011) found that a managerial global mindset mediated the EMO-EP relationship. They argue that managerial characteristics, mind-set included, are important antecedents to an international marketing strategy and EP (Miocevic and Crnjak-Karanovic, 2011). Also, Julien and Ramangalahy (2003) and Calantone and Knigh (2000) revealed that EMO behaviour influences EP through the medium of generic business strategies. Four other studies have reported that EMO has both direct and indirect relationship with a firm's EP (e.g. Hoang, 2015; Navarro-García et al., 2014). Lastly, Acikdilli (2015) and Cadogan et al. (2002) saw the mediating role of EMO in the relationships between a firm's EP, its marketing capabilities, its export experience, and its export dependence and coordination, while Sørensen and Madsen (2012) saw its interaction effect when combined with a firm's IO.

Organizational Learning Orientation $(O L O)$ - refers to a cultural attribute reflecting the belief that learning is valued within an organization (Rhee et al., 2009; Sinkula et al., 1997). This especially reflects the values of a firm (i.e. commitment to learning, open-mindedness, 
and shared vision) that influence its propensity for creating and using knowledge of markets to give it a competitive advantage (Sinkula et al., 1997). These values guide a firm's

processes for acquiring information, developing a shared understanding of the information acquired, and then generating new knowledge or organizational insights based upon them (Rhee et al., 2009).

Five out of the 58 studies reviewed have investigated the impact of possession of OLO on a firm's EP. Two studies found that OLO positively influences economic EP through the firm's international entrepreneurial capabilities (Shavazi et al., 2015; Lages et al., 2009). While Gerschewski et al. (2015) and Kropp et al. (2006) found a direct and significant positive impact of OLO on a firm's EP, Fernández-Mesa and Alegre (2015) report the mediating role of OLO in the relationship between the firm's risk-taking abilities and its EP.

\section{Marketing and sales-based IBCs}

Marketing and sales competence $(M \& S C)$ - as it applies to firms' internationalization - refers to a firm's ability to create value for foreign customers through effective segmentation, targeting, and through integrated international marketing activities by planning, controlling, and evaluating how marketing tools are organized to differentiate from those of competitors (Acikdilli 2015; Al-Aali et al., 2013; Knight and Kim, 2009 ). Some studies argue that possession of M\&S competence determines the success of a firm's international marketing operations and allows it to choose the entry mode that best suits its strategy and goals (Blesa and Ripollès, 2008). M\&S competence also facilitates the acquisition of knowledge about export customers, product development and adaptation to overseas markets. More importantly, it allows meticulous manipulation of key marketing tactical elements to target customers through high quality and/or differentiated goods (Navarro-García et al., 2014; Nalcaci and Yagci, 2014; Barrales-Molina et al. ,2014; Lages et al., 2009).

Several dimensions underlying $M \& S$ competence in relation to export were documented in the studies reviewed. Prominent among them are: export marketing planning; control and evaluation of export marketing activities; skills to segment and target individual export markets; ability to use marketing mix tools (Navarro-García et al., 2014; Knight and Kim, 2009); ability to design, develop, and produce products that fulfil customer needs (Al-Aali et al., 2013; Lages et al., 2009); and developing and maintaining networks with partners (Hartsfield et al., 2008). 
Regardless of the measures used or dimensions examined, M\&S competence has been found to positively influence EP. Some studies showed a direct influence of M\&S competence on a firm's EP (e.g. Al-Aali et al., 2013; Knight and Kim, 2009), while some others have seen its influence on EP in the development of other capabilities. For example, Blesa and Ripollès (2008) show that international market entry mode and commitment to internationalization are determined by a firm's M\&S competence. Likewise, Knight and Cavusgil (2004) report that business strategies - such as the development of unique products, quality focus, and leveraging foreign distributor competence - which significantly influence EP, are a function of a firm's M\&S competence. In a similar vein, a firm's positional advantages - like low-cost advantage and branding advantages - stem from its M\&S competence, hence the influence on its EP (Zou et al., 2003). In addition, there are studies that consider M\&S competence a mediator between other IBC's, e.g. between IEO and EP (Hartsfield et al., 2008), and between EMO and EP (Navarro-García et al., 2014; Prasad et al. 2001).

Systematic market selection competence (SMS) - This refers to the ability to systematically select foreign markets (He and Wei, 2011; Brouthers and Nakos, 2005). SMS is important, because the choice of location has a critical impact on a firm's performance. Location can affect its strategic competitiveness, cost of distribution, operation, management, transactions, and the ability to coordinate international business activities (López-Duarte et al., 2015; He and Wei, 2011). In addition, because entering foreign markets involves a substantial allocation of resources, a firm has to make a strategic decision on which market it wants to enter into and apply its limited resources accordingly. This suggests that a firm's ability to systematically select an export market based on objective criteria that are obtained through generation and dissemination of export market intelligence - and responding swiftly to them is paramount to its success in export (Brouthers and Nakos, 2005). In turn, this shows the importance of EMO for international market selection and international performance. That means EMO is a valuable resource for an organization that must be accompanied by international market selection for optimal performance (He and Wei, 2011). By employing a systematized approach to their market selection process, export market-oriented firms can overcome the disadvantage of being foreign. This can be achieved through learning and the establishment of a market-oriented culture and activity routines throughout the whole organization (He and Wei, 2011). 
Table 2.3: Summary of IBC identified from the reviewed literature

\begin{tabular}{|c|c|c|c|c|c|c|}
\hline \multirow{2}{*}{$\begin{array}{l}\text { Competence } \\
\text { domain }\end{array}$} & \multirow[b]{2}{*}{ IBC } & \multirow[b]{2}{*}{ Underlying dimensions examined } & \multirow{2}{*}{$\begin{array}{l}\text { Frequency } \\
\quad \text { of } \\
\text { presence }\end{array}$} & \multicolumn{3}{|c|}{$\begin{array}{c}\text { Impact on } \\
\text { EP }\end{array}$} \\
\hline & & & & + & 0 & - \\
\hline \multirow[t]{11}{*}{$\begin{array}{l}\text { Orientation- } \\
\text { based }\end{array}$} & $\begin{array}{l}\text { International } \\
\text { orientation (IO) }\end{array}$ & $\begin{array}{l}\text { One-dimensional construct composed of } \\
\text { management's attitudes, motivation, resource } \\
\text { allocation, and development of organizational } \\
\text { culture that motivates employees' behaviour } \\
\text { in the direction of international activities }\end{array}$ & 8 & 8 & & \\
\hline & $\begin{array}{l}\text { Export market } \\
\text { orientation (EMO) }\end{array}$ & $\begin{array}{l}\text { One-dimensional construct composed of } \\
\text { information-based measures such as } \\
\text { generation, dissemination, and } \\
\text { responsiveness to export intelligence }\end{array}$ & 18 & 18 & & \\
\hline & & $\begin{array}{l}\text { One-dimensional construct composed of } \\
\text { behaviour-based measures such as customer } \\
\text { orientation, competitor orientation, inter- } \\
\text { functional coordination }\end{array}$ & 8 & 8 & & \\
\hline & & Information search & 2 & 2 & & \\
\hline & $\begin{array}{l}\text { International } \\
\text { entrepreneurial } \\
\text { orientation (IEO) }\end{array}$ & $\begin{array}{l}\text { One-dimensional construct composed of } \\
\text { innovativeness, proactiveness, and risk-taking } \\
\text { Individual effects of IEO's components }\end{array}$ & 14 & 14 & & \\
\hline & & innovativeness & 6 & 6 & & \\
\hline & & proactiveness & 3 & 2 & 1 & \\
\hline & & risk-taking & 4 & 2 & & 2 \\
\hline & & competitive aggressiveness & 1 & 1 & & \\
\hline & & communication & 1 & & & 1 \\
\hline & $\begin{array}{l}\text { Organizational } \\
\text { Learning orientation }\end{array}$ & $\begin{array}{l}\text { One-dimensional construct composed of } \\
\text { commitment to learn, shared vision, and open } \\
\text { mindedness }\end{array}$ & 5 & 5 & & \\
\hline \multirow[t]{2}{*}{$\begin{array}{l}\text { Marketing/sales- } \\
\text { based }\end{array}$} & $\begin{array}{l}\text { Marketing and sales } \\
\text { competence }\end{array}$ & $\begin{array}{l}\text { Export market planning, control and } \\
\text { evaluation of export marketing activities, } \\
\text { skills to segment and target individual export } \\
\text { markets, ability to use marketing mix tools }\end{array}$ & 13 & 13 & & \\
\hline & $\begin{array}{l}\text { Systematic market } \\
\text { selection } \\
\text { competence }\end{array}$ & $\begin{array}{l}\text { Ability to select export market based on } \\
\text { objective criteria }\end{array}$ & 2 & 2 & & \\
\hline \multirow[t]{2}{*}{$\begin{array}{l}\text { Networking- } \\
\text { based }\end{array}$} & $\begin{array}{l}\text { Networking } \\
\text { competence }\end{array}$ & $\begin{array}{l}\text { Ability to plan and conduct networking } \\
\text { activities strategically with key foreign } \\
\text { partners }\end{array}$ & 3 & 2 & 1 & \\
\hline & $\begin{array}{l}\text { Relationship } \\
\text { competence }\end{array}$ & $\begin{array}{l}\text { Exporter-distributor cooperation, relational } \\
\text { intensity, communication quality, long-term } \\
\text { relationship orientation, information sharing, } \\
\text { and importer involvement }\end{array}$ & 3 & 3 & & \\
\hline
\end{tabular}

Note: $(+)$ indicates a significant positive relationship; (0) indicates non-significant relationship; (-) indicates a significant negative relationship. 


\section{Networking-based IBCs}

Networking competence - This competence reflects a firm's ability to strategically plan and conduct networking activities with key foreign collaborators (Tang 2011). The external network relationships of organizations are used as a strategic asset that ultimately allows the firm to build a sustainable competitive advantage (Hadida et al., 2015; Yli-Renko et al., 2001). Firms benefit from network relationships in that they overcome their resource-based constraints through accessing a variety of resources held by other actors (Niesten and Jolink, 2015; Tang, 2011; Birru, 2011). Furthermore, network relationships serve as learning platforms through which entrepreneurial firms acquire knowledge about markets and operations (Perri and Peruffo, 2014; Oviatt and McDougall, 2005). Specifically, NC facilitates the acquisition of experiential knowledge about international markets, which in turn influences a firm's EP (Haahti et al., 2005). Mort and Weerawardena (2006) also explain that NC enables identification and exploitation of market opportunities and facilitates a firm's innovativeness.

Relationship competence - describes a firm's ability to manage, utilize, and invest in exchange relationships (Ritter and Gemünden, 2003). With regards specifically to export, studies have conceptualized RC as an intangible asset that reflects a series of interactions between exporter and importer (Lages et al., 2009). Lages and colleagues argue that forming and maintaining successful relationships with foreign distributors is critical to superior performance. They stressed that by managing customer relationships - and being more responsive to customer needs - exporting firms that possess $\mathrm{RC}$ increase their ability to generate tangible benefits, such as effective customer acquisition and retention.

Lages et al (2009) employed a one-dimensional construct made up of the relationship's communication quality and its long-term orientation, the sharing of information between firm and customers, and importer involvement. On the other hand, Ling-yee and Ogunmokun (2001) conceptualized RC as a two-dimensional construct comprised of exporter-distributor cooperation and exporter-distributor relational intensity. Nevertheless, both studies found a positive and significant link between firms' abilities to form and maintain relationships with their foreign distributors on the one hand and their EP on the other. 
Table 2.4: Summary of names/terms used in the reviewed studies

\begin{tabular}{ll}
\hline EMO & Export market orientation (Acikdilli, 2015; Hoang, 2015; Navarro-García et al., 2014; Singh \\
and Mahmood, 2013; Miocevic and Crnjak-Karanovic, 2011; Cadogan et al., 2009; Murray et \\
al., 2007) \\
Market orientation (Shavazi et al., 2015; Zhang and Zhu, 2015; Gerschewski et al., 2015; \\
Julian et al., 2014; Sørensen and Madsen, 2012; Murray et al., 2011; He and Wei, 2011; \\
Racela et al., 2007) \\
International market orientation (Knight and Kim, 2009) \\
Export market information use (Toften, 2005) \\
International entrepreneurial orientation (Gerschewski et al., 2015; Kuivalainen et al., 2007; \\
Knight and Cavusgil, 2004) \\
Export entrepreneurial orientation (Ibeh and Young, 2001) \\
International entrepreneurial proclivity (Zhou, 2007) \\
International entrepreneurship (O'Cass and Weerawardena, 2009) \\
Entrepreneurial orientation (Shavazi et al., 2015; Fernández-Mesa and Alegre 2015; \\
Brouthers et al., 2015; Rodriguez et al. 2013; Lisboa et al., 2011; Javalgi and Todd, 2011; \\
Okpara 2009; Hartsfield et al., 2008; Mavrogiannis et al., 2008; Kropp et al., 2006) \\
Exporting posture (Balabanis et al., 2003) \\
Entrepreneurship (Dimitratos et al., 2004) \\
Marketing and sales competencies (Kabagambe et al., 2012; Blesa and Ripollès, 2008) \\
International marketing orientation (Knight and Cavusgil, 2004) \\
International marketing skills (Knight and Kim, 2009) \\
Marketing capabilities (Acikdilli 2015; Nalcaci and Yagci 2014; Navarro-García et al., 2014; \\
Al-Aali et al., 2013; Zou et al., 2003) \\
Export marketing mix (Mavrogiannis et al. 2008) \\
International orientation (Knight and Kim, 2009; Zhou et al., 2007) \\
Global mind-set (Miocevic and Crnjak-Karanovic, 2011) \\
Management commitment (Javalgi and Todd, 2011) \\
International Commitment (Blesa and Ripollès, 2008; Baldauf et al., 2000) \\
Proactive/conservative export orientation (Francis and Collins-Dodd, 2000) \\
M\&SC
\end{tabular}

\subsubsection{Mediating factors}

The study findings elaborated on above suggest that the effect of a firm's IBC often affects EP through other variables, like: marketing capabilities (Navarro-García et al., 2014; Murray et al., 2011; Prasad et al., 2001); global mind-set (Miocevic and Crnjak-Karanovic, 2011); international market selection (He and Wei, 2011); generic strategies (Hoang, 2015; Hartsfield et al., 2008; Knight and Cavusgil, 2004; Julien and Ramangalahy 2003; Calantone and Knight, 2000); foreign market knowledge (Zhou, 2007; Mort and Weerawardena, 2006; Haahti et al., 2005); and home-based social networks (Zhou et al., 2007). These factors were 
detected widely in the relationships between EMO, IEO, IO, and NC and EP. Nonetheless, out of 58 studies reviewed, only 24 included mediating factors in their examination.

\subsubsection{Context factors}

The studies reviewed indicate that the process through which possession of IBC can influence EP and the positive relationship between the two do not hold homogeneously for all contexts. Rather, there are always likely to be contextual factors that determine in what way IBC affects EP (Zhang and Zhu, 2015; Navarro-García et al., 2014; Lisboa et al., 2011; Murray et al., 2011; Kuivalainen et al., 2007). Numerous contextual factors were identified in our review, they can be categorized into environmental, organizational, and personal factors. The environmental factors include market turbulence, technological turbulence; competitive intensity; and export market attractiveness (Gerschewski et al., 2015; Zhang and Zhu, 2015; Murray et al., 2011; Javalgi and Todd, 2011; Cadogan et al., 2009). The organizational context factors are firm size, firm age, coordination mechanisms, competitive advantages, experience in export, and motives for - and commitment to - internationalization (Al-Aali et al. 2013; Cadogan et al., 2009; O'Cass and Weerawardena 2009; Ling-yee and Ogunmokun 2001; Prasad et al. 2001). Personal factors commonly involve the founder/manager's prior international experience and level of education (Yi et al. 2013; Kaleka 2012). Contextual factors were found to act either as an antecedent for the development of IBC (Brouthers et al., 2015; Navarro-García et al., 2014; Mavrogiannis et al., 2008; Mort and Weerawardena, 2006; Ibeh and Young, 2001) or a moderator that influences the form and/or strength of the effect of a given IBC on facets of EP (e.g. Gerschewski et al., 2015; Zhang and Zhu 2015; Murray et al., 2011; Javalgi and Todd, 2011; Rose and Shoham, 2002). Indeed, some studies also considered context factors as control variables (Murray et al., 2011; Tang, 2011; Lisboa et al., 2011; Zhou, 2007). Only 20 out of 58 studies reviewed took into account effects of contextual factors in the IBC-EP relationship.

\subsection{Discussion and conclusions}

In light of the importance of IBC for explaining observed differences in international performance - and EP in particular - we have set out to provide a comprehensive and evaluative literature review documenting findings on IBCs that are essential for export and the process through which, and conditions under which, they influence a firm's EP. The 
diagram shown in Figure 2.1 highlights the specific constructs and relationships that emerged from the content analysis of the reviewed literature.

Our review revealed that the majority of studies on the IBC-EP link are based on the datasets of advanced and emerging economies and that there are few studies in the context of developing ones. Nevertheless, the last decade has seen an exponential growth in the number of IBC studies. This suggests that scientific interest into aspects of IBC and corresponding performance outcomes is a growth area from a research standpoint. The fact that most concern and critical exigency was expressed by those researching China is probably due to the country's booming economy and its heavy reliance on export. Regarding firm size, many of the studies reviewed concern SMEs, born-global entrepreneurial firms, and new ventures. This underscores the particular importance of IBC for firms lacking the tangible resources to build up advanced technologies to produce superior products for highly competitive international markets (Brouthers et al., 2015; Boso et al., 2012; Sørensen and Madsen, 2012; Kuivalainen et al., 2010; Knight and Kim, 2009). This focus on SMEs may also be attributed to the fact that there are simply more of such firms around - thus leading to larger sample sizes - with sizeable contributions to their country's economy in general and export in particular (Sousa et al., 2008). We nevertheless believe that this empirical focus on SMEs is problematic, as it seems odd to disentangle the performance effects of IBC across firms of different sizes (Keupp and Gassmann, 2009).

Our review revealed that survey methods where predominant in data collection. This can be attributed to the difficulties in physically reaching firms scattered across a broad geographical range. The dearth of data stemming from personal contact is further exacerbated in the case of cross-cultural studies, where firms were located in different countries (Sousa et al., 2008). Furthermore, the majority of studies relied heavily on the individual responsible for international marketing activities (e.g. export manager or CEO) as a major source for obtaining data and only a few studies collected data from more than one representative of the same firm. This might be because the information sought is so unique to the export function that there is only one person, or a small number of people, with access to the appropriate data. This is particularly true for small businesses, where only a small group or even a single individual deals with export-marketing issues (Sousa et al., 2008). As suggested by Sousa et al. (2008), procedural and statistical remedies should be used to ensure the quality of data in a situation where multi-source or multiple informant data are not available. In our review, we 
observed that researchers have made efforts to explore the validity and reliability of their data. However, we suggest that future research may need to move away from data based on questionnaires, which is provided by those with a stake in the outcomes, to researcher-based data (Singh and Mahmood, 2013).

A business firm selling some or all of its products abroad was the unit of analysis employed by the majority of the studies reviewed. The rationale behind the use of the firm as the unit of analysis is that firm-specific advantages are derived not only from developing and marketing a particular product but also from the firm's total learning process (Sousa et al., 2008). Most importantly, such a clear preference for an export firm-level unit of analysis might be partly because more than half of the reviewed studies targeted SMEs. Firm-level studies are deemed appropriate for SMEs because they often only have a single product line (Cavusgil and Zou, 1994).

These studies show a high tendency of using self-reported perceptual benchmarks for EP. This is in many ways consistent with previous reviews by Sousa et al. (2008), and Zou and Stan (1998). This growing use of perceptual benchmarks of EP might be due to: a) difficulties in accessing readily available and valid archival data, largely because owner/managers are generally reluctant to release confidential company information to outsiders (Singh and Mahmood, 2013; Morgan et al., 2004); b) the majority of the exporters investigated in the reviewed studies are SMEs, some of which may not have adequate export accounting mechanisms for reporting purposes; c) difficulty in establishing fixed reference points across firms, since financial success for one firm may constitute failure for another (Zhang and Zhu, 2015; Lages and Lages, 2004); d) previous studies have shown correlation between subjective and objective performance measures (Ren et al., 2009); and e) recommendations by previous studies for using more perceptual measures of export success or success in achieving organizational goals (Cavusgil and Zou, 1994). The majority of the studies used both financial as well as strategic dimensions of EP assessment, accompanied by satisfaction with overall EP. This highlights that EP is a multifaceted concept and that the use of single-item benchmarks is insufficient for reliable assessment (Leonidou et al., 2002).

Looking at the theoretical foundations used by the reviewed studies, $41 \%$ do not have a clearly specified theoretical foundation or framework on the basis of which they tackle their respective research question. Among the studies that did have such a foundation, the most recent ones were anchored mostly in the RBV paradigm to explain IBC as an important 
internal firm-specific resource that leads to success in export, and few on other theoretical perspectives. This increasing utilization of the RBV in recent studies might suggest a renaissance of this theoretical framework as a valuable lens through which to view international business phenomena.

From the studies reviewed, several patterns emerged concerning the sets of IBC that have been found to have association with a firm's EP. First, a large number of studies have explored the importance of EMO and IEO on EP, while quite a significant number of studies have also explored the impact of IO and M\&S competence on a firm's EP. The potential effects of OLO, SMS, NC, and RC are issues that - despite their importance - seem to be given little attention in international business and export literature. The growing importance of EMO and IEO in literature can be explained by the fact that the behaviours of consumers and competitors in different export markets are diverse and dynamic and that the export environment is frequently in a state of flux (Zhang and Zhu, 2015; Murray et al., 2011; He and Wei, 2011; Miocevic and Crnjak-Karanovic, 2011; Racela et al., 2007). Market orientation and entrepreneurial orientation provide an integrated perspective for determining EP by assessing the ability of an organization to predict, react, and capitalize on such dynamic business environments (Shavazi et al., 2015; Sørensen and Madsen, 2012; Boso et al., 2012; Murray et al., 2011; Cadogan et al., 2009). Studies have found that international entrepreneurial firms oriented towards the export market are better able to recognize and respond to global changes and opportunities in today's competitive environment (Shavazi et al., 2015; Mainela et al., 2014; Boso et al., 2012; Cadogan et al., 2003).

Second, although studies report positive relationships between different IBCs and EP, there is lack of consensus regarding the exact role of these IBCs and the process and conditions through which they influence EP. While some studies investigated direct linear relationships between IBCs and aspects of EP, others have included mediating and contextual factors in their evaluation. Mediating factors denote variables that aim to show the influence of aspects of IBC on facets of export performance. In other words, this means that a firm's possession of a given IBC affects its EP through leveraging other capabilities the firm has in the export market (Acikdilli ,2015; Murray et al., 2011; Lisboa et al., 2011; Hartsfield et al., 2008; Blesa and Ripollès, 2008; Zhou et al., 2007). The studies we reviewed investigated marketing capabilities, a global mind-set, international market selection, generic business strategies, 
foreign market knowledge, and home-based social networks as important mediators in the IBC-EP relationship.

Marketing capabilities (Navarro-García et al., 2014; Murray et al., 2011; Prasad et al., 2001), global mind-set (Miocevic and Crnjak-Karanovic, 2011), and international market selection (He and Wei, 2011) mediate the EMO-EP relationship. It has been argued that generating and disseminating market intelligence about export customers and competitors' activities and responding swiftly to said intelligence - enables firms to develop marketing capabilities in the export market. This in turn affects a firm's competitive advantage, which ultimately affects EP (Navarro-García et al., 2014; Murray et al., 2011). Miocevic and CrnjakKaranovic (2011) argue that firms generate and disseminate export market intelligence in order to cope with the complexity and dynamics of foreign business environments. Their global mind-set, as a cognitive mechanism, enhances their capabilities in the processing and utilisation of market intelligence. On the other hand, He and Wei (2011) state that EMO enables firms to deal with differences and potential conflicts, bear the risks associated with operating in foreign markets, reduce their concerns about uncertainty, and offers them an advantage in making informed decisions. This indeed suggests that firms who successfully combine EMO with international market selection perform better in export than those without such a fit (He and Wei, 2011).

Generic business strategy mediates both the EMO-EP and IEO-EP (Hoang, 2015; Knight and Cavusgil, 2004) relationships. Possessing market and entrepreneurial orientation support raises firms' awareness of key strategic initiatives that enable international success. Specifically, these sets of competencies foster a corporate culture that permits the development of focus strategies and the effective adaptation of said strategies to different international markets (Hoang, 2015; Hartsfield et al., 2008; Knight and Cavusgil, 2004). This is generally consistent with the contention that market-oriented entrepreneurial firms are more likely to be innovative and use their entrepreneurial mind-set and idiosyncratic capabilities to set their company and products apart from the competition (Porter, 1980).

Zhou et al. (2007) report the mediating role of social networks between firms' IO and EP. They argue that, since international orientation alone may not necessarily bring about sufficient knowledge for internationalizing firms to take risks and rapidly capture market opportunities, firms rely on readily available interpersonal ties and social interactions. They further emphasize that the information benefits thereof - such as knowledge of foreign market 
opportunities, advice and experiential learning, and referral trust and solidarity - eventually lead to improved performance outcomes. This view is consistent with the assertion by Mort and Weerawardena (2006) and Haahti et al. (2005), that the firms' networks influence EP through feeding their knowledge base with information on export markets. By the same token, firms' foreign market knowledge can also emerge from its entrepreneurial orientation (Zhou, 2007).

Overall, the results suggest the potential role of mediating factors in the IBC-EP relationship. However, the fact that 34 out of 58 studies disregard the role of these factors is a matter for concern in the empirical study of the IBC-EP relationship. Furthermore, the fact that particular IBCs or IBC dimensions were considered mediating factors suggests that the boundaries between the concepts are not clear. This demonstrates the need for researchers to develop clear conceptual domains to investigate the IBC-EP relationship.

As for the contextual factors determining how IBC affects EP, our review identified several factors that can be categorized into factors on the environmental, organizational, and personal level (Gerschewski et al., 2015; Shepherd and Rudd, 2014; Murray et al., 2011; Cadogan et al., 2009). These factors may serve as antecedents of IBC or may influence the relationship between IBC and EP. In the former case, the results reveal that context factors act as an impetus for the development of certain IBC; mostly connected to EMO, IEO, and M\&S competence (Navarro-García et al., 2014; Mavrogiannis et al., 2008; Mort and Weerawardena, 2006; Ibeh and Young, 2001). For instance, Zhou and colleagues argue that participation in home-based and foreign-based social networks enables internationally oriented firms to develop alternative IBC domains necessary for their internationalization process (Zhou et al., 2007). Different aspects of a firm's IBC can also emerge from personal level factors such as the founder/manager's prior international experience (Mavrogiannis et al., 2008; Ibeh and Young 2001). This can be explained by the fact that prior international experiences provide founders and managers with foreign market knowledge, skills, and attitudes that they can subsequently use to interpret their firm's environment and make key decisions towards internationalization (Mavrogiannis et al., 2008). In the latter case, studies report that some context factors systematically modify the form and/or strength of the influence of a given set of IBCs on facets of EP (Gerschewski et al., 2015; Zhang and Zhu, 2015; Murray et al., 2011; Javalgi and Todd, 2011; Rose and Shoham, 2002). In this context, industry, institutional distance, export channel, alliance use, environmental dynamism, firm 
size, coordination mechanisms, competitive advantages, and experiences in export were most often cited and used mainly to moderate the relationship between EMO and EP as well as IEO and EP. Some of these factors interact with EMO and IEO to affect the mediating factors, others interact with the mediators so that the value of the indirect effect of EMO and IEO on EP changes depending on the value of the moderator (e.g. Prasad et al., 2001). Some studies also utilised context factors - such as size, age and international experience of the firm - as control variables (e.g. Murray et al., 2011; Tang, 2011; Lisboa et al., 2011; Zhou, 2007). Consistent with most of the evidence in literature, this can be explained by the fact that relatively larger firms seem to have more resources and capabilities to amass foreign market knowledge, and such knowledge tends to grow richer as international experience increases (Christoffersen, 2013; Zhou, 2007; Zahra et al., 2000). Firm size can also influence performance through economies of scale and scope and bargaining power leverage (Balabanis and Katsikea, 2003). Other factors that came under scrutiny include environmental dynamism, ownership situation, industry type, and degree of internationalization (He and Wei, 2011; Kaleka, 2012; Zhou et al., 2007).

Overall, the results suggest that contextual variables are factors that researchers should include in order to realistically evaluate the IBC-EP relationship. Nevertheless, the fact that more than two-thirds of the reviewed studies failed to incorporate context factors in their model is a regrettable limitation in the current literature. Such a deterministic approach may lead to an over-generalization of the benefits of firms' IBC (Murray et al., 2011). We therefore suggest researchers start to assess whether or not context factors are present in the relationship (Lisboa et al., 2011). In our view, doing so will help researchers move away from the use of simplistic and naive conceptualization schemes and methodological procedures to more vigorous conceptual and measurement frameworks.

Two types of variation were also noted in the studies reviewed. First, there was a lot of variation in the use of terms and concepts. Although the basic nature of the constructs are not changed, there is a high tendency of using different names for the same IBC or the same name for different sets of IBCs. In addition, some authors used terms of their own choosing without referring to the context of the study, i.e. exporting or internationalization. Secondly, there was much variation in how dimensions of certain sets of IBC were integrated into the overall EMO and IEO constructs. Concerning IEO, the most common variations were for researchers to use either all three components - innovativeness, proactiveness, and risk-taking 
(e.g. Shavazi et al., 2015; Brouthers et al., 2015; Hartsfield et al., 2008) - use only one or two of them (e.g. Fernández-Mesa and Alegre 2015; Yi et al. 2013; Knight and Kim, 2009), or even inserting new dimensions like competitive aggressiveness (Kuivalainen et al., 2007) and communications (Kropp et al., 2006). The most prominent variation with regard to EMO is related to the choice between Kohli and Jaworski's (1990) three information-based benchmarks or Narver and Slater's (1990) three behaviour-based benchmarks. An important observation here is that - despite Narver and Slater's argument that their conceptualization of market orientation is consistent with Kohli and Jaworski's conceptualization because behavioural components comprehend the activities of market information acquisition and dissemination and the coordinated creation of customer values - most studies measured EMO using Kohli and Jaworski's (1990) information-based construct. This indicates the critical role of information of which the value is maximized when it is shared among virtually all functions in an organization and acted on swiftly in a coordinated manner (Acikdilli 2015; Kabagambe et al., 2012; Lages et al., 2009; Brouthers and Nakos, 2005). Nonetheless, this lack of agreement makes it very difficult to compare findings from the different studies and hinders theory development in the EP literature.

\subsection{Future research directions}

Our review provides evidence for the importance of a set of competencies firms need to develop in order to effectively enhance EP. Yet, discussion on such competencies in the literature is in its infancy. This section discusses three areas in which some shortcomings or gaps were observed that warrant closer attention in future research.

The context-specific nature of IBC - Beyond the general assertion that competence can help explain observed differences in performance, competence theory posits that competence is embedded in specific contexts and suggest that the required set of competencies for effective performance dynamically depends on the situation (Mulder, 2014; Le Deist and Winterton, 2005; Eraut, 1994). Therefore the potential uses, and thus the strategic value of a set of IBCs, to a large degree depend on each company's specific situation, the context in which it operates, and the effects of domestic and international environmental factors. In particular, Peng et al. (2008) argue that the institutional environment of a country significantly shapes firms' allocation of resources and their performance in international markets. In line with this view, Murray et al. (2007) found that different EMO components affect EP differently in the 
case of Chinese firms as opposed to non-Chinese ones. This suggests that in order to realistically evaluate the IBC-EP relationship, it is important for future studies to start with the exploration of sets of IBC that are thought to be vital for export within the context of where the study was conducted, instead of trying to investigate the impact of single or small sets of IBC of choice on facets of EP.

Interaction effects of different IBCs - In line with the Dynamic Capabilities View (DCV) of the firm, different sets of firm resources and competencies are likely to interact and complement each other to influence the firm's performance (Winter, 2003). This means that when different - but complementary - competencies are bundled together, they are likely to interact during the value creation process and enhance one another's performance impact (Sørensen and Madsen, 2012; Baker and Sinkula, 2009). Conversely, our review revealed that studies are characterized by fragmentation and diversity in that they mainly concentrate on the role of one particular IBC and its linear relationships with performance outcomes. While a limited number of studies explored two or more IBCs simultaneously (e.g. Gerschewski et al., 2015; Knight and Kim, 2009), they still focused on the differential effects of each and have largely ignored their interactions. Thus, opportunities abound to address this gap by predicting EP from both single and combined IBCs.

Learning context that underlies the development of IBC - The DCV suggests that competence is not a fixed structure, but a set of dynamic capabilities that can be improved through learning efforts and experiences (Clarke et al., 2013; Prahalad and Hamel, 1990). Teece et al. (1997) maintain that - in a dynamic environment - a firm's competitive advantage will rest on its internal processes and routines, which enable the firm to renew and change its organizational competence and enable it to respond effectively to changing business environments. However, most studies reviewed remained silent on the fundamental question of how companies develop the IBC that allows them to compete and gain an enduring competitive advantage in export markets. In particular, studies paid little attention to the role of firms' learning-oriented values in the relationship between their IBCs and EP. Therefore, we suggest that future work should advance the application of the dynamic capability framework to this field to capture the underlying learning processes through which firms develop IBC. 


\title{
CHAPTER 3
}

\section{INTERNATIONAL BUSINESS COMPETENCE NEEDS OF THE ETHIOPIAN EXPORT SECTOR: EXPERTS' VIEW}

\begin{abstract}
Literature describes numerous forms of International Business Competence (IBC) that underpin a firm's Export Performance (EP). In view that the importance of each set of IBCs depends on the specific situation in which it is utilized, we evaluated the literature-based IBC framework in a specific context of Ethiopia by interviewing experts. Experts confirmed the importance of the literature-based IBC framework; proposed to add three more competencies that did not show up in the literature; and identified international orientation, export market orientation, and international entrepreneurial orientation as most important IBCs for Ethiopian firms that are operating in a complex regulatory system and often suffer from resource constraints, little international experience, lack of marketing knowledge and information, and heavily dependent on the export of primary commodities. While providing a framework for investigating the relationship between IBC and export performance in Ethiopia and comparable countries, the study also provides important insights for managers of exporting firms in the said countries concerning focus areas for the improvement of their EP.
\end{abstract}

This chapter is based on Birru, W.T., Runhaar, P. Lans, T., Rae, D., and Mulder, M. (under review). International business competence needs of the Ethiopian export sector: experts' view. 


\subsection{Introduction}

A firm's success in international markets depends to a large extent on the level of competence it injects into its international marketing activities (Kabagambe et al., 2012; Munyoki, 2012; Knight and Kim, 2009; Wu et al., 2007). More specifically, International Business Competence (IBC) - referring to an "intangible, overarching firm resource that engenders superior international performance" (Knight and Kim, 2009: 255) - appears to be an important determinant of Export Performance (EP) (Lisboa et al., 2011; Cadogan et al., 2002). IBC is a multidimensional concept that reflects the extent to which a firm adopts a bundle of international competencies - covering multiple areas - to effectively carry out international business activities in foreign markets (Knight and Kim, 2009). And it has been argued in the literature that firms need to prepare for export ventures by developing appropriate sets of IBCs necessary for their internationalization process (Lisboa et al., 2011; Knight and Kim, 2009; Knight and Cavusgil, 2004).

Numerous forms of IBC underpinning a firm's EP have been identified in literature (Birru et al., submitted; Knight and Kim, 2009; Wu et al., 2007). Beyond the general assertion that IBC can help explain observed differences in firms' EP, a growing volume of studies also indicate that the potential use - and thus the strategic value of each set of IBCs - to a large degree depends on the specific context in which each company operates and the effects of domestic and international contextual factors on it (Lisboa et al., 2011; Knight and Kim, 2009). Because the majority of previous studies were based on the datasets of advanced economies - which have well-functioning institutional environments for business transactions - it is not clear whether the IBC associated with EP that are seen in advanced economies are also a source of competitive advantages for exporters within the context of developing economies (Birru et al., submitted; Boso et al., 2012). Furthermore, previous studies have mainly concentrated on examining different sets of IBCs in isolation (e.g., Murray et al., 2011; Okpara, 2009); therefore, they offer little information about the various combinations of IBCs that firms can pursue in order to boost their EP. In view of these, the objectives of this study are to: (a) examine whether the IBCs that were derived from the literature are also deemed to be important for export performance by Ethiopian experts, thereby supporting and validating the theoretical results; (b) identify other important competencies as they are perceived in practice; (c) to identify those forms of IBC that are considered most important for export performance in the Ethiopian context; (d) explore how and in what ways IBCs, 
which are chosen as being most important deemed to relate to export performance; and (e) identify other factors that may help or hinder firms to achieve higher export performance. The research questions guiding the conduct of this study are, therefore 1) To what extent do Ethiopian experts recognize IBCs, which were extracted from the literature, as an important factor which influences export performance? 2) Which other competence domains experts think are important for enhancing export performance? 3) Which IBCs are considered to be most important for export performance in the Ethiopian context, according to experts' perceptions? 4) How do experts characterize the process through which IBCs, which are chosen as being most important, influence export performance? And 5) what other factors help or hinder firms to achieve higher export performance?

This study contributes to both research and practice. From a research standpoint, better understanding of the sets of competencies and associated factors that are considered to be vital for export in a specific context is of great importance in order for realistically evaluate how such competencies relate to EP (Knight and Kim, 2009). In this light, this study provides an integrative framework useful for examining how IBC relates to EP and associated factors in the Ethiopian context and elsewhere with similar settings and contextual characteristics. From a practical perspective, previous studies have shown that exporting firms operating in developing countries do not dare internationalize due to a perceived lack of competence (Ibeh, 2003). Furthermore, those that do engage in exporting activities often perform poorly; in part because of a failure to identify, prioritize, and develop the required competencies for sustained export within their context (Kabagambe et al., 2012; Boso et al., 2012). Therefore, results from this study can provide important insights for managers of exporting firms in developing countries concerning focus areas for the improvement of their EP.

\subsection{Theoretical framework}

Organizational competence is understood in multiple ways, depending on the perspective from which it is viewed. In line with the Resource-Based View (RBV) of the firm - which sees organizations as a bundle of valuable, rare, hard to reproduce, and irreplaceable resources and capabilities (Barney, 1991) - organizational competence represents an intangible resource that comprises integrated knowledge and intensive performanceenhancing capabilities (Autio et al., 2000; Teece et al., 1997; Prahalad and Hamel, 1990). The term 'integrated' here refers to clusters of knowledge, skills, and attitudes necessary for task 
performance and problem solving (Mulder, 2014; Laghzaoui, 2011; Le Deist and Winterton, 2005). A recent extension of the RBV - the Dynamic Capabilities View (DCV) - argues that organizational competencies are not fixed structures but dynamic capabilities that can be improved through learning efforts and experiences (Helfat and Peteraf, 2003; Eisenhardt and Martin 2000; Prahalad and Hamel, 1990; Teece et al., 1997). Furthermore, the DCV takes into account how organizations' competencies interact to create competitive advantages for the firm (Baker and Sinkula, 2009; Winter, 2003). In accordance with these descriptions of organizational competence, IBC represents an intangible firm-specific resource out of which the firm's competitive advantage in foreign markets emerges (Kuivalainen et al., 2010; Knight and Kim, 2009; Wu et al., 2007). IBC comprises multiple competence domains that collectively guide the owning internationalizing firms on how it should use its resources and interact with environmental forces and transform resources into successful EP (Knight and Kim, 2009).

A major claim made by current competence theory (Mulder, 2014), is that the meaning of competence is embedded in specific contexts. Consequently, the integrated set of competencies that is a prerequisite for effective performance, dynamically emerges from the context in which it is applied (Mulder, 2014; Le Deist and Winterton, 2005; Eraut, 1994). Context is here defined as: "situational opportunities and constraints that affect the occurrence and meaning of organizational behaviour as well as functional relationships between variables" (Johns, 2006: 386).

Organizational and environmental context factors that deemed to be important determinants of the types and levels of competencies that firms need for their exporting activities are identified in the literature (Boso et al., 2012; Murray et al., 2011; Peng et al., 2008; Zhou et al., 2007). Organizational context refers to factors that are internal to an organization. Some of the factors often mentioned in international business literature as determinants of firms' selection and allocation of resources and capabilities include: size and experience in export; owners/managers' prior international experience; and their attitudes towards internationalization (Zhou et al., 2007; Reuber and Fischer, 1997). A firm's ability to develop the competence vital to its export activities is a function of its size and its experience in export (Zahra et al., 2000). Recent studies argue that the relatively larger firms seem to possess more resources and capabilities for amassing foreign market knowledge and said knowledge tends to grow richer as export experience grows (Murray et al., 2011; Lisboa et 
al., 2011). Regarding owners/managers' prior international experience and their attitudes towards internationalization, it has been argued that internationally experienced owners/managers have a better understanding of the export market and know what it takes to engage in export activities (Zahra and George, 2002; Autio et al., 2000; Reuber and Fischer, 1997). Most importantly, their experiences help firms in accumulating the additional foreign intelligence that: helps to reduce the uncertainty in operating abroad; increases their likelihood of successfully entering other foreign markets; increases their commitment to export (Autio et al., 2000). This is particularly useful for SMEs, where the owner/manager is usually the one who decides to start or expand international activities and determines the scope of the organizational commitment to international expansion (Burpitt and Rondinelli, 2000). Zhou et al. (2005a) show that top-managers' attitudes toward change foster market and technology orientations, while top management support significantly facilitates customer and technology orientations (Jeong et al., 2006).

The environmental context reflects the turbulence of international environments and institutional environments. The turbulence of international environments may include market dynamics, competitive intensity, technological change, and cultural diversity (Murray et al., 2011; Javalgi and Todd, 2011; Cadogan et al., 2009). It has been argued that resources and capabilities are differentially valuable across these environments (Sirmon et al., 2007; Priem and Butler, 2001). For instance, a less dynamic environment is likely to lead firms towards embracing more risk-taking and a prospective orientation (Lukas et al., 2001). Whereas dynamic market environments positively reinforce market orientation and technological dynamism facilitates a technology orientation (Jeong et al., 2006).

The institutional environments refer to regulatory, normative and cultural arrangements that engender, enforce, and limit economic and social activities (Scott, 1995). Institutions regulate economic activity by establishing the playing field for production (Scott, 2008; Dunning and Lundan, 2008). Institutional environment - both domestic and foreign - can significantly shape a firm's selection and allocation of resources and capabilities, as well as seriously affect its performance in international markets (Peng et al., 2008). For instance, Li, Sun, and Liu (2006) show that institutional factors, like government interference, have a detrimental impact on a firm's incentive to be market-oriented. Furthermore, different components of market orientation may have divergent effects on EP for firms in different institutional contexts (Zhou et al., 2007). Similarly, the development of entrepreneurial competence 
towards internationalization is dependent on the institutional context in which the firm operates (Wang et al., 2012); while a country's export policy and the support it provides may have impact on a firm's motivation to engage in export and the amount of information it will gather (Shamsuddoha et al., 2009; Czinkota and Ronkainen, 2007). In the same fashion, the diversity of the foreign markets in which firms operate determines the strengths of the market orientation competence (Ellis, 2007). When a firm exports to a country that has a different culture, and/or is on a different level of economic development, it may face increased uncertainty about important factors - such as local business practices - creating a need for additional market information. In contrast, when a firm exports to a country similar to its own - in terms of culture and economic development - it requires less market information and should be able to obtain any information needed without much obstacle. Also, a firm competing in an industry characterized by customer demands that differ from country to country - needs to collect and process an increased amount of information to adapt the firm's product to local consumer needs. In contrast, a firm competing in an industry characterized by uniform customer demands across the globe would require less information, because the firm can sell a standardized product to all markets.

Overall, it has been argued that a firm's perception of the contextual factors determines the choice of resources and capabilities - as well as the ability to use them - to enhance performance (He and Wei, 2011; Murray et al., 2007). In this study, these context factors serve as lenses for exploring major situations surrounding the contemporary exporting firms in Ethiopian and identifying which specific form of IBC firms need.

\subsection{Methodology}

\subsubsection{Material}

Through a comprehensive literature review of extant studies in the fields of international business, international marketing, and international entrepreneurship, Birru et al. (submitted) developed an IBC framework consisting of eight different but related forms of IBC (see Table 3.1). This study uses this framework as a starting point for: the empirical exploration of the Ethiopian export sector; identifying the types of IBC firms need for successful EP; and developing a concise IBC framework for use in Ethiopia and comparable countries. 
Table 3.1: IBC extracted from the literature (Birru et al. (submitted))

IBC

Definition

Orientation-based IBCs

International orientation

(IO)

Top management's favourable attitude towards, and its willingness to deploy necessary resources to, internationalization efforts (Knight and Kim, 2009)

Export market orientation

A firm's ability to understand its foreign market customers, competitors, and (EMO) environment and then act on that understanding (Murray et al., 2007; Racela, Chaikittisilpa, and Thoumrungroje, 2007; Knight and Cavusgil, 2004)

International entrepreneurial orientation A firm's ability associated with the potential creation of value, which manifest (IEOC) themselves as innovativeness, pro-activeness, and risk-taking (Murray et al., 2011; Javalgi and Todd, 2011)

Organizational learning orientation (OLO)

Organization-wide attitude towards creating and using knowledge about international markets to enhance competitive advantage, which manifests itself as a commitment to learn, shared vision, and open mindedness (Lages et al., 2009).

\section{Marketing/sales-based IBCs}

Marketing and sales competence

(M\&SC)

Systematic market selection competence (SMS)

Network-based IBC

Networking competence

Relationship competence
A firm's ability to create value for foreign customers through effective segmentation and targeting, and through integrated international marketing activities by planning, controlling, and evaluating how marketing tools are organized to differentiate offerings from those of competitors (Knight and Kim, 2009; Lages et al., 2009)

A firm's ability to select export markets based on objective criteria that involve evaluating worldwide export opportunities, identifying and evaluating foreign markets and selecting the best market for export activities in light of a company's needs and capabilities (He and Wei, 2011; Brouthers and Nakos, 2005)

A firm's ability to strategically plan and conduct networking activities with key domestic and foreign partners (Tang, 2011)

A firm's ability to interact with parties involved in an export venture relationship, namely: the degree of importer involvement, quality of communication within the relationship; long-term relationship orientation; and information sharing between the firm and its customers (Lages et al., 2009).

\subsubsection{Participants}

The participants in this study were 24 (15 male and 9 female) experts, who were selected on the basis of their experience in international business activities within an Ethiopian organization or business area (see Table 3.2). The sampling of these experts proceeded until the 'saturation' point was achieved, i.e., the point where the chance of getting new 
information becomes minimal (Eisenhardt, 1989). To ensure representativeness, experts were selected from various groups, such as academia $(n=5)$, export companies $(n=5)$, the Ethiopian competitiveness facility ${ }^{1}(n=3)$, the chamber of commerce and sectorial associations $(n=5)$, consultants $(n=4)$, and aid organizations that promote export in Ethiopia $(n=2)$. Most of the participants $(87.5 \%)$ had achieved the educational level of a master's degree or higher, many of them specializing in business administration, marketing, economics, and international trade. On average they had 11 years of work experience, ranging between five and twentyfive years.

\subsubsection{Procedure}

Data collection consisted of two steps. Firstly, we used a standardized semi-structured interview format. Prior to the start of the interview, the experts were given a very general introduction about the concept of competence in general and IBC in particular. They were then asked to read the list of IBCs derived from literature and their theoretical description. The interview consisted of questions that focused on: (a) a reflection on said IBCs in order to ascertain their support of - or discontent with - the value and usefulness of these IBCs, and other competencies they might think important for enhancing EP within their own context; (b) the context of the Ethiopian export sector and IBCs they consider the most important for firms' EP; (c) how they characterize the relationship between the identified IBCs and export performance. Probing questions were used to expand discussion and to explore key issues which emerged in the interview in-depth. Overall, the interviews lasted a maximum of 45 minutes. All interviews were conducted face-to-face by the first author in order to minimize any potential bias. Audio recordings of the interviews were made while, at the same time, notes where taken as a fail-safe measure.

In the second stage, the IBCs that the experts added to the list were reviewed - to eliminate duplicates - and then combined with those extracted from the literature. The resulting list of 11 competencies was sent back to the participating experts in order to investigate whether

\footnotetext{
${ }^{1}$ The Ethiopian competitiveness facility is a grant program of the Ethiopian government, aimed at improving the competitiveness of the private sector. It is particularly aimed at developing the foreign and domestic sales capability of Ethiopian firms through increasing their competitiveness and the strengthening of market support institutions and market information systems. It is a project operated by the Government of Ethiopia (GoE)'s Ministry of Industry (MOI) and financed by the Department for International Development (DFID-UK)'s Private Enterprise Programme Ethiopia (PEPE).
} 
they were consistent in their opinion regarding the IBCs they chose as being most important for the Ethiopian exporting firms.

Table 3.2: Experts' profile as of June $2014(N=24)$

\begin{tabular}{|c|c|c|c|c|c|}
\hline Experts $^{\mathrm{a}}$ & Gender & Age & Educational background & Current occupation & $\begin{array}{l}\text { Work } \\
\text { Experience }\end{array}$ \\
\hline $\mathbf{A}$ & Male & 33 & MBA & $\begin{array}{l}\text { International sales manager at a textile } \\
\text { company }\end{array}$ & 5 years \\
\hline B & Male & 38 & MBA in international business & $\begin{array}{l}\text { Lecturer at a university and freelancer at } \\
\text { a consulting firm }\end{array}$ & 11 years \\
\hline $\mathbf{C}$ & Male & 35 & MBA & $\begin{array}{l}\text { Lecturer at a university and freelancer at } \\
\text { an export firm }\end{array}$ & 7 years \\
\hline D & Male & 36 & MA in marketing & $\begin{array}{l}\text { Sales manager at a leather shoe } \\
\text { manufacturing company }\end{array}$ & 9 Years \\
\hline $\mathbf{E}$ & Female & 39 & MBA & Owner-manager of a consulting firm & 7 years \\
\hline $\mathbf{F}$ & Male & 51 & $\mathrm{PhD}$ in marketing & Assistant professor at a university & 17 years \\
\hline G & Female & 37 & MA in marketing & $\begin{array}{l}\text { Owner-manager of a marketing services } \\
\text { company }\end{array}$ & 9 years \\
\hline $\mathbf{H}$ & Male & 31 & $\begin{array}{l}\text { MA in economics with } \\
\text { specialization in international } \\
\text { trade }\end{array}$ & Consultant & 6 years \\
\hline I & Male & 38 & $\begin{array}{l}\text { MA in marketing with } \\
\text { specialization in product design }\end{array}$ & $\begin{array}{l}\text { International sales officer at a textile } \\
\text { company }\end{array}$ & 8.5 Years \\
\hline $\mathbf{J}$ & Female & 34 & MA in marketing & $\begin{array}{l}\text { Commercial manager at a textile } \\
\text { company }\end{array}$ & 7 years \\
\hline $\mathbf{K}$ & Female & 34 & MBA in international business & $\begin{array}{l}\text { Marketing specialist at an aid } \\
\text { organization }\end{array}$ & 7 years \\
\hline $\mathbf{L}$ & Male & 36 & MA in marketing & Trade manager at a brewery & 9 years \\
\hline $\mathbf{M}$ & Male & 43 & MBA and doctoral candidate & $\begin{array}{l}\text { Assist. Prof. at a university and } \\
\text { freelancer for the Ethiopian commodity } \\
\text { exchange }\end{array}$ & 10 years \\
\hline $\mathbf{N}$ & Male & 52 & MBA in marketing & $\begin{array}{l}\text { Management specialist with the } \\
\text { Ethiopian competitiveness facility }\end{array}$ & 25 years \\
\hline $\mathbf{O}$ & Male & 45 & $\begin{array}{l}\text { BSc. In engineering and } \\
\text { bachelor of commerce }\end{array}$ & $\begin{array}{l}\text { Production specialist with the Ethiopian } \\
\text { competitiveness facility }\end{array}$ & 22 years \\
\hline $\mathbf{P}$ & Male & 56 & $\mathrm{BA}$ in economics & $\begin{array}{l}\text { Head of the Ethiopian competitiveness } \\
\text { facility }\end{array}$ & 32 years \\
\hline $\mathbf{Q}$ & Female & 39 & BA in political science & $\begin{array}{l}\text { Business support manager- } \\
\text { chamber of commerce }\end{array}$ & 12 years \\
\hline $\mathbf{R}$ & Male & 46 & MBA & $\begin{array}{l}\text { Business plan and entrepreneurship } \\
\text { support coordinator - chamber of } \\
\text { commerce }\end{array}$ & 12 years \\
\hline $\mathbf{S}$ & Male & 48 & $\begin{array}{l}\text { Doctor of business } \\
\text { administration }\end{array}$ & $\begin{array}{l}\text { Business advisor - chamber of } \\
\text { commerce }\end{array}$ & 14 years \\
\hline $\mathbf{T}$ & Female & 29 & $\begin{array}{l}\text { MA in economics with } \\
\text { specialization in international } \\
\text { trade }\end{array}$ & Researcher- chamber of commerce & 5 years \\
\hline $\mathbf{U}$ & Female & 34 & MBA in international business & $\begin{array}{l}\text { Head of business development service - } \\
\text { chamber of commerce }\end{array}$ & 8 years \\
\hline $\mathbf{V}$ & Male & 31 & MA in economics & Business advisor at aid organization & 7 years \\
\hline $\mathbf{W}$ & Female & 39 & MBA in international business & Consultant & 9 years \\
\hline $\mathbf{X}$ & Male & 28 & MBA & $\begin{array}{l}\text { Lecturer at a university and freelancer at } \\
\text { export firm }\end{array}$ & 6 years \\
\hline
\end{tabular}

\footnotetext{
${ }^{a}$ For privacy reason experts' names are substituted by alphabets
} 


\subsubsection{Analysis}

As the interview consisted of a limited number of questions, the interview transcripts were analysed manually, utilizing a combination of qualitative and quantitative analysis techniques. The overall prioritization of IBCs were analysed quantitatively by summing all the individual scores awarded by experts to each competence.

\subsection{Results}

This section presents the results, organized along the lines of the main sections of the list of interview-questions and the themes that emerged: (a) recognizing and expanding the IBC framework; (b) the context of the Ethiopian export sector and prioritizing IBC within the Ethiopian context; and (c) respondents' opinions regarding how the identified IBCs relate to EP and contextual factors. The findings are supported by verbatim as well as translated interview fragments.

\subsubsection{Recognizing and expanding the IBC framework}

All experts acknowledged the importance of the IBC framework found in literature for firms' export performance. They accentuated the particular importance of these competencies for firms lacking substantial tangible resources.

"Success in export performance can be achieved not only by investing in physical and human capital, or new technologies, but also by developing appropriate sets of these competencies" (Expert J)

"With the business environment becoming more complex and dynamic, and the global competition around the world continuing to intensify, these competencies are necessary for any organization to be able to compete in international markets" (Expert K)

"Exporting is a dynamic process and companies need to identify and use those competencies that lead to successful performance. This is particularly important for firms with limited tangible resources that are inclined to pursue foreign markets" (Expert T)

In addition to confirming the usefulness of the IBC framework found in literature, experts complemented it with 3 additional competencies that couldn't be derived from previous 
studies. In the following, we present these newly added competencies in terms of how they are conceptualized and how they are perceived to influence EP.

Cross-cultural business competence $(C B C)$ - A majority of the experts $(\mathrm{N}=13)$ accentuated the importance of cross-cultural business competence (CBC) for competing effectively in the export market. They argued that culture constitutes the broadest influence on most dimensions of human behaviour and that - consequently - an export firm's ability to think and ponder on cultural differences, manage their experiences appropriately, and build an efficient and suitable communication with partners in a cross-cultural environment are important factors for exporting successfully. They stressed that CBC facilitates: the identification of international business opportunities; the understanding of customer needs; the design of products so as to meet customer demands; the handling of conflicts that might arise within a business relationship.

"It is obvious that the way societies make economic decisions depends on cultural values. Thus, to compete effectively in the world marketplace, firms need to be open-minded and actively seek to understand cultural norms and expectations of others, and leverage this gained knowledge to interact, communicate and work effectively outside one's environment" (Expert C)

"Possession of cross-cultural business competence helps firms in two ways: first, it helps to create and maintain good relationships with foreign partners, and secondly, it helps in understanding consumer preferences and offering products that fit with the needs and wants of the customers" (Expert B)

Ethical competence $(E C)$ - Some experts $(\mathrm{N}=7)$ felt the complexity of international trade showed itself clearly in the wildly varying ethical standards at work in the different export destinations. They suggest that firms need to develop the ability to handle ethical issues and maintain effective organizational structures and routines to address ethical dilemmas. They viewed ethical competence as actions performed - and attitudes held - by a business and its employees that are considered professionally and morally responsible. According to the experts, some of the most critical ethical issues surrounding export include: commitment to customer satisfaction; good corporate citizenship; responsible environmental, financial and community stewardship. Where it comes to communicating with foreign customers, the experts mentioned a firm's ability to clearly, honestly, and accurately represent its products 
and its terms and conditions and to deliver its products as represented. All seven experts agreed that firms with a strong ethical identity tend to be better able to maintain a trusted and sustainable relationship with foreign partners, which in turn positively influences the firm's financial results. By contrast, firms that adopt short term wealth creation strategies and goals, whether ethical or unethical, lose customers and consequently risk their sales performance.

“... firm's ability to use a suitable problem-solving and decision-making method when facing a moral problem and its ability to build, maintain, and use suitable processes, tool, and mechanisms in handling relevant moral issues is an important capability for firms to succeed in international markets" (Expert W)

“...trust-based relationship with foreign customers is a way to success. Important to that is doing business in an ethical manner. To the contrary, when ethical practices are not observed or are broken, many export customers show their dissatisfaction by no longer buying the company's products or by not working with the company again, which in turn leads to lower export sales" (Expert $O$ )

Communication and Negotiation $(C \& N)$ - Three experts underscored that export business dealings involve communications and negotiations, and they emphasized the importance of a firm's ability to discuss and reach a mutually satisfactory agreement with their foreign customers to attain export success. According to these experts, C\&N may include: knowing the best time to communicate sensitive information; having a good understanding of your audience and knowing the best way to extend information to it; having the ability to clearly and politely state one's own position; having good listening skills. They said that firms equipped with this competence are better able to build those positive and productive working relationships with foreign partners that will ultimately lead to EP success.

"As export business dealings involve multiple communications and negotiations, developing the competence to discuss and reach a mutually satisfactory agreement with foreign customers are an important tool for firms' success in export. In my view, this is one of the prevailing limitations of Ethiopian exporters" (Expert $N$ ) 


\subsubsection{Context of Ethiopian export sector and prioritization of IBC}

\subsubsection{Context of Ethiopian export sector}

The synthesis of the interview transcripts identified organizational and environmental contexts of the Ethiopian exporting firms that are deemed to determine the types and levels of IBCs they need for EP improvement.

Organization-related contexts - The experts mentioned three organization-related contexts. First and foremost, a significant majority $(\mathrm{N}=19)$ spoke about the differences between export firms in developing and developed economies; especially regarding the level of tangible resources. They emphasized that most export companies in developing countries are small to medium-sized enterprises (SMEs), which are often faced with many challenges and are often deprived of the resources typically required for a firm to expand abroad. The experts highlighted that, due to their tangible asset limitation, Ethiopian exporters cannot compete with these larger competitors on price but they can create an advantage based on acquisition and use of competencies that help them overcome their resource limitations when entering foreign markets.

"Exporting is a dynamic and highly competitive process, thus, companies need to identify and use those competencies that lead to successful performance. This is particularly important for firms from developing countries, like Ethiopia, where substantial differences exist between domestic and export markets and firms have fewer investments to compete with larger firms from developed economies" (Expert T)

Secondly, 15 of the experts mentioned the nature of the country's export business activities, which most of them described as traditional and in essence based on trial and error. They suggested that firms need to periodically review the likely effect of changes in the export environment and search for the knowledge necessary to understand the forces that influence their customers' needs and preferences and then act on that understanding. They further indicated that increasingly diverse and demanding customers, intensifying market competition, and globalization have significantly enhanced the importance of taking bold action - such as innovation - to the success of firms entering into new foreign markets. 
“...firms operate in exporting markets in a rapidly changing environment that demands of them to follow and adapt to changes in their environment, by leaving aside ongoing traditional practices" (Expert M)

Thirdly, 13 of the experts spoke about the concentration phenomenon - basically, a concentration of commodities and markets - which they say is the major contributor to the instability in export revenues of many developing countries. The experts indicated that because of a heavy concentration of exports in only a few commodities and a small number of markets, Ethiopian exporters are adversely affected by market price volatility and continuously changing consumer preferences. Consequently, they pointed out that these firms need competencies that enable them to broaden their export base and emerge as multi-product and multi-destination exporters.

"Due to concentration in few commodities and markets, Ethiopian exporting firms are highly vulnerable to the effect of fluctuation in prices and customer preferences. In my view, the sets of competencies they need are those that help them broaden their export base through diversification of their products and their markets" (Expert $P$ )

Environmental factors that have explicitly or implicitly been emphasized by all interviewed experts are market turbulence and competitive intensity. Experts stressed that the success of Ethiopian firms in export markets is under constant threat from the ever changing preferences of consumers and the constantly intensifying competition. Consequently, their survival lies in their ability to understand and respond to customers' needs. In particular, since most of Ethiopian firms export products the demand for which depends on seasonal requirements (e.g. leather and leather products, textiles, products of agro-processing), organization-wide behaviours and activities for acquiring and disseminating information concerning export markets and consequently taking timely action upon it are inarguably very important for creating competitive advantages. Furthermore, Ethiopian firms sell their export products to local distributors in the importing countries. These have multiple suppliers that provide them with the same or competitive products and they obviously prefer suppliers that respond satisfactorily to their needs, like: a coordinated set of products; problems being solved quickly; and swift improvement of products and processes where required. Ethiopian export can benefit from adopting export market-oriented strategies, because they guide a firm's processes for: acquiring information, developing a shared understanding of the information acquired, and acting swiftly to market demands in a coordinated manner. 
Also 13 experts spoke about the institutional underpinnings of the home country and those of the targeted foreign markets providing a context of competition among firms. They stressed that the Ethiopian government sees private sector firms as the main driving force behind development dynamics and the country's export goals. However, local institutional constraints constitute major challenges for such an endeavour. These include, among others: cumbersome, bureaucratic and lengthy procedures for export licensing; lack of access to credit and foreign exchange; lack of a reliable and uninterrupted power supply; corruption; long overdue bottlenecks in the logistics sector. Furthermore, the performance of Ethiopian exporters is also influenced by the institutional environments in the foreign markets targeted. In order to overcome these institutional constraints, Ethiopian exporters need to be entrepreneurial to sustain themselves under the various prevailing national and international conditions. This can be achieved through generating information concerning trends in their export markets in order to try and find institutional loopholes and exploit them.

\subsubsection{Prioritizing IBC in the Ethiopian context}

The experts unanimously agreed that while a firm might possess enough of each of the presented IBCs, the contexts of the contemporary Ethiopian export sector discussed above will require said firm to draw on some of these competencies more than others. A large majority of them spoke about the importance of being internationally oriented $(\mathrm{N}=20)$; being sensitive to customers and markets facilitated through organization-wide generation, dissemination, and responsiveness to export market intelligence $(\mathrm{N}=19)$; and being entrepreneurial in their pursuit of international markets $(\mathrm{N}=16)$. This is shown in Table 3.3 which shows the overall ranking of IBCs in terms of level of importance.

Table 3.3: Overall ranking of IBC according to level of importance for Ethiopian export sector $(N=22)$

\footnotetext{
1. International orientation (32)

2. Export market orientation (57)

3. International entrepreneurial orientation (65)

4. Organizational learning orientation (113)

5. Cross-cultural business competence (128)

6. Ethical competence (151)

7. Networking competence (160)

8. Systematic market selection competence (165)

9. Marketing and sales competence (191)

10. Relationship competence (202)
}

Note: The scores between parentheses are sum scores based on the individual rankings of 22 experts using values of 1 most important through 11 least important. Hence, a low score indicates the most important IBC 


\subsubsection{Interrelatedness between, and learnability of the identified IBCs}

All the experts were of the opinion that although different forms of IBC can drive individual export success, their joint implementation may bring firms even more positive outcomes. In particular, they noted that IO, EMO, and IEO are complementary capabilities that should be pursued simultaneously for a synergistic outcome. 11 experts stressed that the benefits of possessing market orientation behaviours is higher when paired with entrepreneurial characteristics. Likewise, the complementarity between IO and IEO, or all the three IBC identified, were stressed by nine and six experts respectively. In line with the latter, they underlined that those firms that have a high intention and motivation to go abroad, that sense and seize on market opportunities, that gather information regarding export market trends, and that always offer appropriate and finely targeted products tend to be in a better position.

"I believe that co-existence of EMO and IEO complement each other and together contribute to the creation of competitive advantage" (Expert $K$ )

"A firm with the right motivation for exporting its products, that tends to look for different opportunities in export markets and entrepreneurially responds to the changing environment performs better in export" (Expert $N$ )

"I believe that organizations with internationally and entrepreneurially oriented top management that can deal sensitively and effectively with customers, competitors and the overall market environments will have higher competitive advantage as compared to those who don't"' (Expert C)

The experts also spoke about the learnability of the identified IBCs. They stressed the value of experience in helping firms compete across borders to leverage their competence in order to enhance their EP. In addition, experts explicitly stated that the performance impact of an export firm's strategic resources - such as IO, EMO, and IEO - are enhanced by said firm's propensity for gathering, accumulating, and utilizing export market-related information.

“...experienced firms possess higher levels of these competencies than newcomers; yet such differences vary with firms' propensity to gather, accumulate, and use knowledge regarding their export activities" (Expert $B$ ) 


\subsection{Conclusions and discussion}

\subsubsection{Conclusions}

This study's results show that Ethiopian experts confirmed the importance to EP improvement of the IBC framework found in literature, and then went on to add three more competencies to the list that did not show up in the literature: Cross-cultural Business Competence (CBC), Ethical Competence (EC), and Communication and Negotiation Competence $(\mathrm{C} \& N)$. The experts agreed with the notion that different types of context influence which IBCs are most important for EP. International Orientation (IO), International Entrepreneurial Orientation (IEO), and Export Market Orientation (EMO) were identified as the most important IBCs for the Ethiopian exporting firms. This sector is characterized by consisting mostly of SMEs featuring: limited resources and little international experience; heavy reliance on only a few export commodities and markets; a conservative approach to internationalization; a complex regulatory system; and less advanced supportive business institutions and structures. It has also been emphasized that IO, IEO, and EMO are complementary capabilities that interact during the value creation process and enhance each other's performance impact. Experts have also expressed the opinion that the key combination of IBCs that firms need for successful EP can change over time, because of evolving contexts and the fact that firms learn from their experiences.

\subsubsection{Discussion}

The export market offers exciting opportunities for firms from developing countries in terms of growth potential. However, it should be noted that such firms must compete with international companies that far outstrip them in capacity and experience. As they cannot compete with said competitors on price, they can create an advantage based on acquisition and the use of competencies vital to their internationalization. IO, IEO, and EMO are viewed as the most valuable resources for Ethiopian exporting firms to possess in order to overcome contextual constraints and beat the competition in fast-changing export markets.

The experts indicate that many Ethiopian export firms have strategies focused on domestic market exploitation instead of going abroad. Indeed, exporting is not really an option for some companies as they mainly serve local markets and employ business models that are difficult to scale up to the export market. Others may have the potential for international 
expansion but might not act on it or act only when pushed by the government to do so. To achieve successful EP, it is important for such firms to develop a vision and a proactive organizational culture in order to attain the particular resources needed for achieving company goals in foreign markets. A firm's IO influences the boundaries of its international opportunities in the way it configures its operations, the way it selects the scale and scope of its operations, and the way it assembles and allocates its various tangible and intangible resources in international markets; consequently adding to a firm's performance advantage (Knight and Kim, 2009; Zahra et al., 2005). Empirical evidence from literature also shows that the most successful international SMEs are those that have left behind their domestic orientation and adopted a global mind-set (Knight and Kim, 2009; Nummela et al., 2004).

The experts say that because the behaviours of consumers and competitors in different export markets are diverse and dynamic, the export environment is frequently in a state of flux. They therefore emphasize that the success of Ethiopian firms in export markets depends on their ability to consistently identify and respond to customers' current needs and demands and learn to anticipate their future ones. This confirms the assertion that an export marketoriented strategy is increasingly important to reduce a firm's vulnerability to turbulent conditions (He and Wei, 2011).

The experts point out that Ethiopian firms commonly adopt conservative strategies where it comes to their export activities. They therefore suggest that, in order to obtain greater returns, firms need to expand internationally by: rejecting ongoing practices, rejuvenating themselves, and distinguishing themselves in the highly turbulent export markets. Doing so will ensure that firms are better able to adjust their operations in a dynamic and competitive export market environment and perform better (Boso et al., 2012). More importantly, they will be better able to match customer needs to the resources or technologies available to them for exploiting uncertain opportunities. This is in line with the assertion by Boso et al. (2012) and Baker and Sinkula (2009) that those firms that regard entering export markets as critical to their company's growth, profitability, and success should be able to explore new and creative ideas that may lead to marketplace changes; especially when doing so proactively - and ahead of the competition - in anticipation of future demand.

The Ethiopian experts also support the notion that the competencies firms need to effectively respond to their dynamic export business environment are not fixed structures but dynamic capabilities that can be improved through learning effort and experience. They suggest that 
the level of importance of each competence changes over time, as the environment changes and firms learn from their experiences. Furthermore, the experts subscribe to the view that the specific combination of competencies a firm possesses are likely to interact with and complement each other when influencing a firm's performance. This means that the impact of a firm's intention and motivation to go abroad - and the allocation of resources towards export market performance - is strengthened by a surge in a firm's ability in gathering information on export market trends and the offering of finely targeted and appropriate products. The marketing knowledge obtained through market-oriented activities can also shape a firm's ability to sense international market opportunities and seize on them. This, in other words, means that high levels of export market orientation offset the risks taken by international entrepreneurial-oriented exporters in an environment where they have a better knowledge of markets and the likely response of customers and competitors to market offerings (Boso et al., 2012; Sørensen and Madsen, 2012). Firms that adopt an export strategy that involves combinations of internationally-oriented, entrepreneurially-oriented, and market-oriented tactics are more likely to achieve successful EP. Conversely, firms that invest a lot in one of these competencies - but under-invest in the others - will be less able to realize the full potential of their investments, and as a result EP success is less likely.

Based on the results of these expert interviews, we are now able to develop a much clearer IBC framework for use in Ethiopia and countries comparable to it (Figure 3.1). The framework shows how IO, EMO, and IEO are interrelated and interact with contextual factors to influence EP. This framework will form the basis for designing effective tools to utilize in future research. 


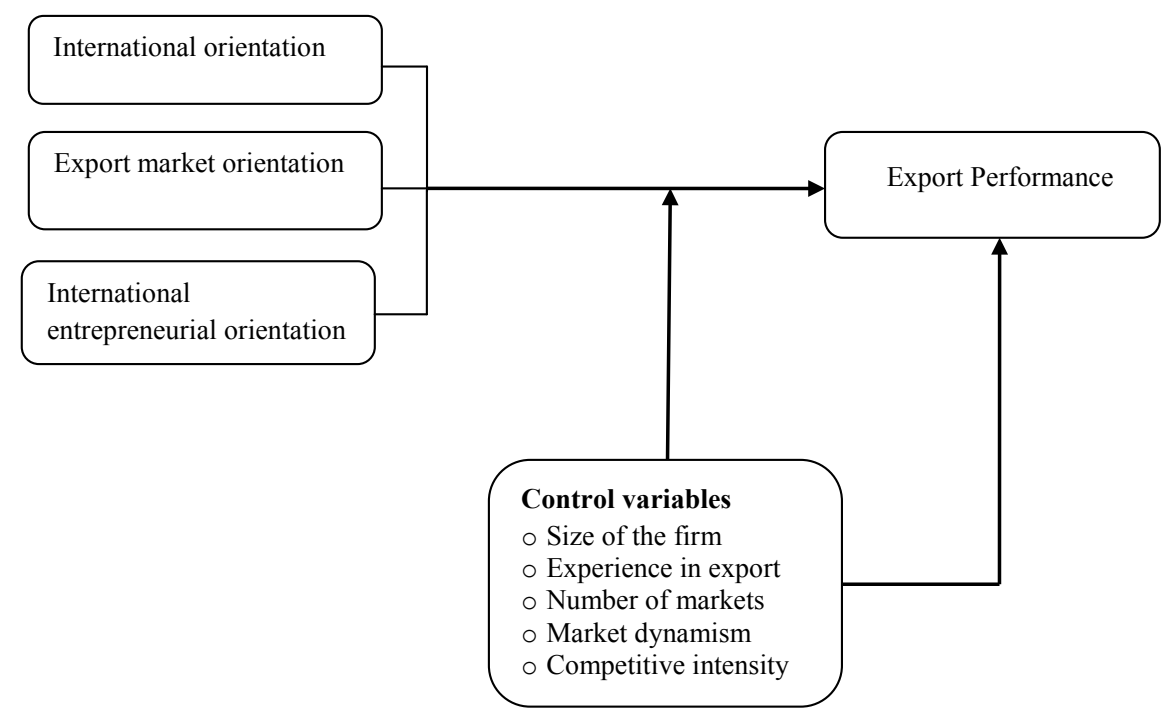

Figure 3.1: IBC framework for use in Ethiopia

\subsection{Implications for practice and directions for future research}

The results of this study have two practical implications for companies in Ethiopia and comparable countries: (a) firms need to identify, prioritize, and develop complementary sets of IBCs that are relevant for internationalization within their context; and (b) firms need to develop organizational systems and values that encourage learning.

We suggest this study should be followed by a large scale survey study, which could shed more light on the relationship between the three sets of IBC and EP in the context of developing countries (Boso et al., 2012) mentioned above. Also, we suggest that further work should focus on advancing the application of the dynamic capability framework to this field in order to get an idea of the extent to which organizational learning oriented values help enhance the performance impact of these IBCs (Heugens, 2006). 


\title{
CHAPTER 4
}

\section{EXPLAINING ORGANIZATIONAL EXPORT PERFORMANCE BY SINGLE AND COMBINED INTERNATIONAL BUSINESS COMPETENCIES}

\begin{abstract}
This study explores relationships between export performance and international business competencies (international orientation, export market orientation and international entrepreneurial orientation), and interactions between the competencies. Data from on-site structured interviews with 159 owners and managers of exporting firms from different economic sectors show direct relationships between the competencies and export performance. However, analyses of the effects of interactions between the competencies and export performance show mixed results. The findings suggest developing the identified competencies to increase export performance, but if this would be exclusively based on the direct relationships between the competencies and export performance, results may be suboptimal.
\end{abstract}

This chapter is based on Birru, W.T., Runhaar' P., Zaalberg, R., Lans, T., and Mulder, M. (Revised and resubmitted). Explaining organizational export performance by single and combined international business competencies. 


\subsection{Introduction}

A recurrent issue in international business research is the investigation of factors that can help explain observed differences in international performance and, more specifically, in Export Performance (EP) (Knight and Kim, 2009; Sousa et al., 2008). Recent studies point to international business competence (IBC) as important predictors of firm's successful EP (Gerschewski et al., 2015; Covin and Miller, 2014). According to Knight and Kim (2009), IBC refers to overarching intangible firm resources from which firms' competitive advantages emerge in international markets. According to this definition, IBC encompasses key firm characteristics or factors expected to collectively enhance EP (Shavazi et al., 2015; Hutzschenreuter et al., 2015). This suggests that for effective EP, firms need to identify, prioritize and develop appropriate sets of IBC necessary for their internationalization activities (Knight and Kim, 2009).

Numerous forms of IBC underpinning a firm's EP have been identified in literature (Knight and Kim, 2009). Recent empirical studies underscore the importance of three specific IBCs, namely international orientation (IO) (Moen et al., 2015; Sørensen and Madsen, 2012) export market orientation (EMO) (Shavazi et al., 2015), and international entrepreneurial orientation (IEO) (Deligianni et al. 2015; Gerschewski et al., 2015). Sørensen and Madsen (2012) claim that possession of such competencies guide a firm's strategic actions towards exporting and subsequently to successful performance in international markets. These competencies are said to be particularly important for firms lacking tangible resources to build up advanced technologies, to produce superior products for highly competitive international markets often times small and medium-sized enterprises (SMEs) (Felzensztein, et al. 2015; Kuivalainen et al., 2010; Knight and Kim, 2009) as well as those firms exporting from developing countries (Boso et al., 2012). Due to their limitation in tangible resources, such firms cannot compete with larger competitors for price, but use IO, EMO, and IEO as their most competitively valuable resources (Knight and Kim, 2009). In line with this, an exploratory study conducted in Ethiopia revealed that Ethiopian exporting firms lack substantial physical, financial, and human resources; consequently, such firms have much to gain by nurturing intangible resources comprising IO, EMO, and IEO (Birru et al. under review). For instance, one Ethiopian firm expressed this as follows: 
"Since we have limited physical and financial resources, we highly depend on our entrepreneurial and market-oriented capabilities to stay competitive in the export market".

The research questions guiding the conduct of this study are: 1) To what extent are IO, EMO, and IEO related to export performance of the companies in Ethiopia?? 2) To what extent and in what ways do these IBCs interact in realizing export performance? The study contributes in two ways to the existing firms' internationalization literature. First, notwithstanding that previous studies generally confirm the positive impact of IO, EMO, and IEO on firms' EP, such studies are characterized by fragmentation and diversity in that they mainly concentrate on the role of one particular competence and its direct relationships with performance outcomes (Shavazi et al., 2015; Murray et al., 2011; Knight and Kim, 2009). While a limited number of studies explored two or more of these competencies simultaneously, they still focused on the differential effects of each and have largely ignored their interactions (Knight and Kim, 2009). In line with competence-based strategic management theory (Sanchez and Heene, 2004), competencies are interdependent and likely to interact to influence the firm's performance. This was expressed by one Ethiopian firm as "IO, EMO, and IEO are complementary capabilities that we should pursue simultaneously for a synergistic outcome" Consequently, identifying and specifying interaction effects pertaining to relations between different IBCs and EP provide more detailed predictions about the relationships, going beyond the simplistic argument (Sørensen and Madsen, 2012). By investigating both the individual and interactive effects of IO, EMO, and IEO on firms' EP, we attempt to address this gap in the literature.

Secondly, despite the particular importance of export for firms operating within developing economies (Ibeh, 2003), extant research on IBCs and associated factors are based on Western and advanced economies' datasets. These are places where there are economically developed markets, good local business conditions, and greater resource availability. On the other hand, there is less research investigating the increasing role of these competencies in the developing economies contexts that are characterized by mostly SMEs, poor local business conditions, resource scarcity, and little international experience (Alvi, 2012; Boso et al., 2012). Consequently, it remains to be determined whether the findings that apply to developed economies, also applies to exporting firms in developing economies, given the prevailing differences in contextual variables important for IBC identification, definition, development 
and assessment between advanced and developing economies (Boso et al., 2012). By focusing on export manufacturing firms in a developing country context, Ethiopia, our study seeks to extend knowledge about a category of firms that deserve more research attention.

From a practical perspective, the contribution of the study is straightforward. Firms' survival and expansion is strongly dependent on a better understanding of the determinants that influence their export performance (Sousa et al., 2008). Thus, the results of this study will serve to guide business practitioners concerning conditions under which they should invest in the development of strategic resources such as IO, EMO, and IEO. Furthermore, it will also serve policy-makers in developing national export promotion programs.

\subsection{Theoretical background and research hypotheses}

The Resource-Based View (RBV) of the firm addresses the central issue of how superior performance can be attained relative to other firms in the same market. It suggests that a competitive advantage derives from the firm's control of resources, which are valuable, rare, imperfectly inimitable and irreplaceable (Barney, 1991). The RBV recognizes both tangible and intangible resources that firms possess and permits them to create and apply valueenhancing strategies (Day, 1994). Tangible resources are those that have a physical substance, for example, an investment in facilities; while intangible resources are a firm's complex bundles of knowledge, skills, and attitudes that enable the firm to coordinate activities and make the best use of its assets (Day, 1994; Barney, 1991).

Internationalizing firms may possess specific resources that are instrumental to the conception and implementation of activities in international markets. Although these firms lack substantial tangible resources, they likely have to leverage a collection of more fundamental intangible resources that facilitate their international success by enabling them produce value-added offerings for given markets (Lampel et al., 2014; Baker and Nelson, 2005). The resources consist largely of international business competencies that are embedded in the firm's structure, processes, and interpersonal and intergroup relationships (Knight and Kim, 2009; Prahalad and Hamel, 1990). As firms' strategic resources, IBCs provide the owning internationalizing firms with substantial competitive advantages by facilitating foreign market entry and operations and eventual successful performance in international markets (Kuivalainen et al., 2010; Knight and Kim, 2009). 
While the RBV helps explain the contribution of various resources and capabilities to the firms' performance, it doesn't provide a full conceptual model which includes contextual embeddedness of firms. Embeddedness theory (Granovetter, 1985) suggests that economic actions of individuals and firms do not happen independent of the social and institutional environments. Consistent with this perspective, a major claim made by current competence theory (Mulder, 2014; Le Deist and Winterton, 2005) is that the meaning of competence is embedded in specific contexts. These theoretical underpinnings seem to suggest on the one hand that the integrated set of a firm's resources and capabilities that are prerequisite for effective performance dynamically emerges from the context in which it is applied (Mulder, 2014), and on the other hand that social and institutional environments affect how such resources and capabilities influence a firm's performance (Okhmatovskiy, 2010; Dacin et al., 1999). These views were relentlessly upheld by international business studies that assert that social and institutional environments can significantly shape a firm's selection and allocation of its strategic resources and capabilities, as well as seriously affect its performance in international markets (Peng et al., 2008). For instance, Li et al., 2006) show that institutional factors, like government interference, have a detrimental impact on a firm's incentive to be market-oriented. On the other hand, Zhou et al. (2007) pointed out that different components of market orientation have divergent effects on EP for firms in different social and institutional contexts. Wang et al. (2012) also identified that the development of entrepreneurial-oriented competencies towards internationalization is dependent on the institutional context in which the firm operates. In the same manner, a country's export policy and the support it provides may have impact on a firm's motivation to engage in export and the amount of information it will gather (Shamsuddoha et al., 2009; Czinkota and Ronkainen, 2007). These generally suggest that the potential use - and thus the strategic value of each set of IBC - to a large degree depends on the specific context in which each company operates and the effects of domestic and international contextual factors on it (Lisboa et al., 2011; Knight and Kim, 2009).

Below, we explore the logic underpinning IBCs such as IO, EMO, and IEO as firm-specific strategic resources and hypothesize their direct positive impact on EP.

International Orientation (IO) refers to top management's favourable attitude toward and willingness to deploy necessary resources to internationalization efforts (Cadogan et al., 2005; Knight and Cavusgil, 2004). It chiefly concerns the degree to which managers see the 
world as their market place as well as their motivation to deal with international customers and partners. Consequently, top management employs a clear commitment of resources and develops an organizational culture that motivates employees' behaviour in the direction of international activities (Sørensen and Madsen, 2012; Knight and Cavusgil, 2004). Furthermore, as a fundamental corporate posture, IO determines the boundaries of the firm's international opportunities, the way the firm configures its operations, selects the scale and scope of its operations, and assembles and allocates its various tangible and intangible resources in international markets; and consequently adds to the firm's performance advantage (Knight and Kim, 2009; Zahra et al., 2005). We, accordingly, hypothesize that:

Hypothesis 1: IO has a positive relationship with a) financial export performance b) strategic export performance

The behaviours of consumers and competitors in different export markets are diverse and dynamic (Leonidou et al., 2002) and export environment is frequently in flux (McDougall et al., 2003). This calls for exporting firms to adopt a market-oriented strategy in their export activities (Cadogan et al., 2009). Export Market Orientation (EMO) represents firms' competence to recognize and respond to changes in export customers' needs and preferences, and to export competitors' strategies (Shavazi et al., 2015; Murray et al., 2011). This competence is usually manifested as an operative export marketing capability of the firm, which facilitates generating and disseminating export market information and swift coordinated action (Lages et al., 2009). This means that export market-oriented firms possess capabilities necessary to gather and evaluate information in a systematic manner, about current and future needs and wants of customers, the plans and capabilities of competitors as well as the changing nature of the business environment (He and Wei, 2011). Consequently, firms with more developed EMO offer well-tailored products whose value is perceived by buyers to exceed the expected value of alternative offerings; thus, consistently they achieve higher market place performance (He and Wei, 2011; Cadogan et al., 2009). We, accordingly, hypothesize that:

Hypothesis 2: EMO has a positive relationship with a) financial export performance b) strategic export performance

International Entrepreneurial Orientation (IEO) refers to the entrepreneurial ability of an organization operating across national borders that are reflected in its overall innovativeness, 
pro-activeness and risk-taking in the pursuit of international markets (Swoboda and Olejnik, 2016; Javalgi and Todd, 2011; Knight and Cavusgil, 2004). Innovativeness reflects an organization's tendency to enter into experimentation, support new ideas and depart from established practices. It embraces generating new products, processes, and organizational systems that set the company apart from its rivals as it expands its international operations ( $\mathrm{Li}$ et al., 2010). Proactiveness describes the characteristics of entrepreneurial actions to anticipate future opportunities in the international markets, both in terms of products and technologies and in terms of markets and consumer demand (Li, Wei, and Liu, 2010; Baker and Sinkula, 2009). Risk-taking deals with tendencies in taking bold action, such as entering new foreign markets (Baker and Sinkula, 2009). It has generally been argued that organizations acting in risk-taking, innovative and proactive manner are better able to adjust their operations in dynamic competitive environments (Covin and Slevin 1989). In accordance with this view, entrepreneurially-oriented exporters possess important strategic capabilities that enable them to differentiate themselves from export competitors by taking calculated risks to proactively introduce new and innovative products and enter new markets (Shavazi et al., 2015; McDougall et al., 2003). Furthermore, organizations which have this competence tend to explore new and creative ideas that may lead to changes in the marketplace, and do so proactively ahead of the competition in anticipation of future demand. In a nutshell, IEO represents important firm-specific resources that positively affects the performance of organizations in export by promoting the renewal of existing practices and the pursuit of new export opportunities (Gerschewski et al., 2015; Javalgi and Todd, 2011). Therefore, we hypothesize that:

Hypothesis 3: IEO has a positive relationship with a) financial export performance b) strategic export performance

Competence-based strategic management theory (Sanchez and Heene 2004) posits that competencies possessed by the firm are interrelated and used in an integrated manner. In line with this theory, the RBV and its recent extension, so called 'Dynamic Capabilities View', of the firm have also recently made significant headway in explaining interdependence of organizational resources and capabilities. Extant research in this area accentuates that in a dynamic market environment, firm's resources are interrelated and depend on each other to create and sustain a competitive advantage to the firm (King et al., 2008; Tanriverdi and Venkatraman, 2005). Furthermore, studies pointed out that the relationship between different 
resources of the firm could have additive, substitutive, or synergistic effects on its performance (Delery, 1998). An additive effect exists when if using different resources together, they generate greater effects on an outcome than if they were used alone, but the effects of using them together are not more than the sum of their individual effects. A substitutive effect exists when using different resources together does not have a greater impact compared to their individual effects. Lastly, a synergistic effect exists if different resources work together interdependently, such that the effectiveness of one resource depends on the other. In this study, we argue that firms' strategic resources such as IO, EMO, and IEO are complementary competencies that, when bundled together, enhance one another's performance impact (Sørensen and Madsen, 2012; Baker and Sinkula, 2009). Hence, in addition to their individual contribution, we postulate three synergistic effects of these competencies on firms' export market performance.

$I O$ and EMO are factors involved in a firm's motivation to internationalize and its export market-oriented activities. They are interlinked and in combination provide a company with better EP (Miocevic and Crnjak-Karanovic, 2011). Specifically, the performance enhancing effect of being highly internationally-oriented is strengthened by intensive knowledge about international markets as well as capabilities to react and make decisions based on such knowledge (Sørensen and Madsen, 2012). Since market orientation is crucial for creation and utilization of market-based knowledge assets and capabilities (Slater et al., 2012), higher levels of a firm's ability to generate and disseminate export market information and develop marketing adaptable strategies enhance the impact of internationally-oriented behaviours and activities on export market performance. We hypothesize that:

Hypothesis 4: The positive relationship between IO and a) financial export performance b) strategic export performance is strengthened for higher values of EMO

$E M O$ and IEO are both important to satisfy expressed and latent customer needs, pursue market expansions as they are identified, and capitalize on emerging opportunities (Boso et al., 2012). Mainly, marketing knowledge and information obtained through market-oriented activities support the entrepreneurial behaviour of the firm, and together, leads to higher marketplace performance (Cadogan et al., 2009). A high degree of EMO would mean that entrepreneurial-oriented exporters would take risks in an environment with better knowledge 
of markets and the likely response of customers and competitors to market offerings (Boso et al., 2012; Baker and Sinkula, 2009). Consequently, we hypothesize that:

Hypothesis 5: The positive relationship between IEO and a) financial export performance b) strategic export performance is strengthened for higher values of EMO

Having an IEO in a multitude of diverse international markets supports a firm's international intent allowing it to be more capable and willing to pursue international opportunities (Knight and Cavusgil, 2004). A high level of entrepreneurs'/managers' motivations to internationalize their firms' operations also determines the strategic choices that the firm makes regarding its international entrepreneurial activities (Zahra et al., 2005). We then hypothesize that:

Hypothesis 6: The positive relationship between IO and a) financial export performance b) strategic export performance is strengthened for higher values of IEO

H6

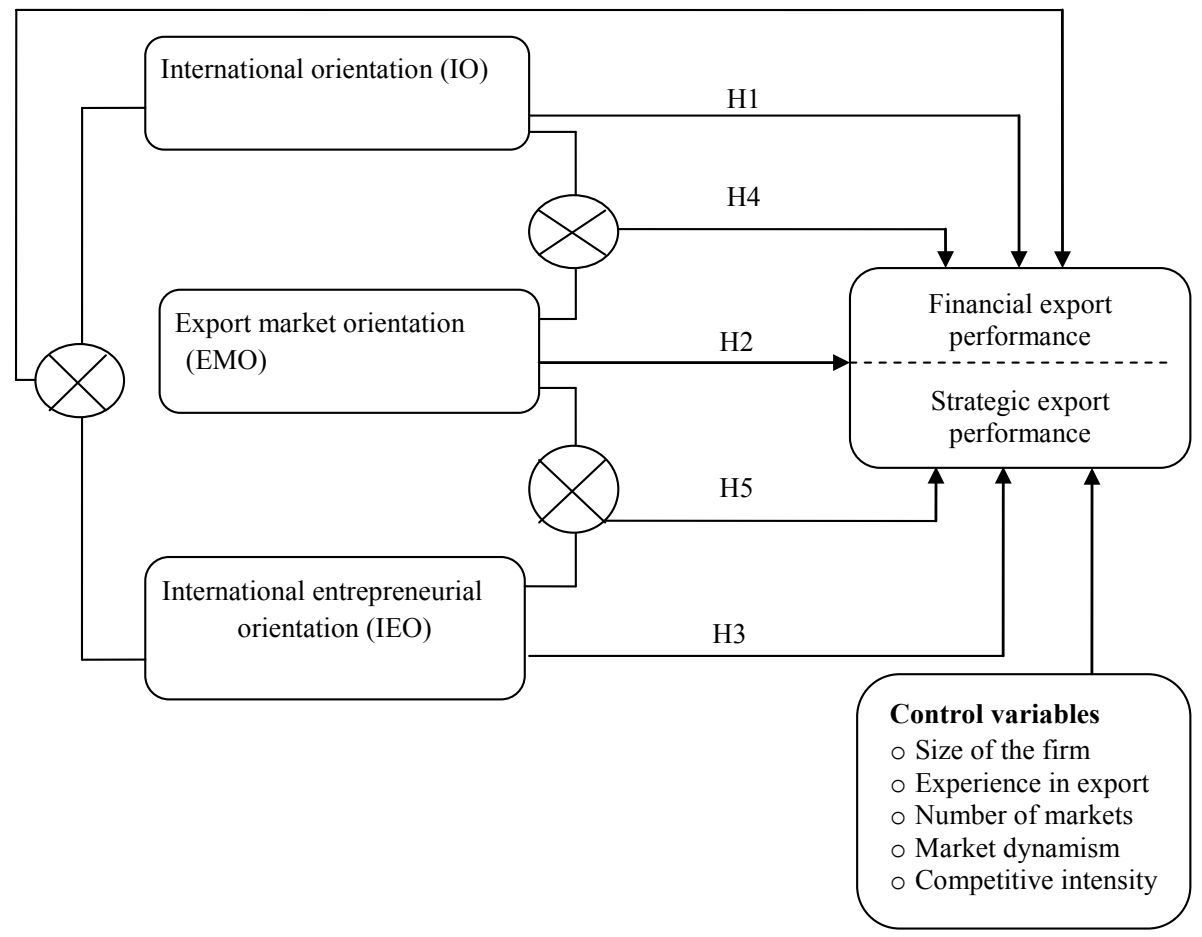

Figure 4.1. Conceptualized model (Note: crosses in the circles show interaction between competencies) 


\subsection{Methodology}

\subsubsection{Sample}

A list of exporters was generated using an export directory provided by the Ethiopian Chamber of Commerce and Sectoral Association. We used a multi-industry sample (textile and garment; leather and leather products; and agro processing) to increase observed variance and to strengthen the generalizability of the results, thereby improving the external validity of the research (Morgan et al., 2004). Service firms and those engaged in primary industries were excluded due to their idiosyncratic characteristics in terms of international expansion, regulatory requirements, and performance characteristics (Zou and Cavusgil, 2002). In addition, multinational corporations were excluded from the sample because their export is generally done via their overseas affiliates. Subsequently, we found 218 eligible firms for this study. We contacted each firm by telephone to explain the purpose of the study, requested their participation; and identified key informants who had knowledge of, and access to, the type of data needed for the study. Fifty-nine firms were dropped from our contact list for several reasons. Either they were unwilling to participate, key individuals who could provide the required information were not available, or the firm was no longer dealing in the exporting business.

The average size of the participating firms was about 127 employees. Among the sampled firms, 37.7 percent had below 50 employees, 29.6 percent had 50-100 employees, and 32.7 percent had above 100 employees. Whether the firm is characterized as "small", "medium" or "large" is not straightforward and depends on the industry in which it competes. However, it is reasonable to argue that in an Ethiopian context, some of the firms in the sample, particularly those that exceed 100 employees, are considered large firms. The weight of the sample skews toward SMEs, as this category constitutes 67.3 percent of the total sample.

\subsubsection{Data collection}

The survey was conducted via face-to-face interviews with owners and senior managers, who were either in charge of exporting, or other types of international business activities for their respective firms. Given the relatively small population sizes of the study, this data collection method was opted to increase the response rate, mainly because many previous studies have recognized low response rate as one of the major problems of mail surveys (Singh and 
Mahmood, 2013). In order to minimize any potential common method variance, we ensured that the order of questions asked was mixed, and reverse-coded items were included. On top of this, we assured participants they remained anonymous, that there was no right or wrong answers, and that they were requested to answer as honestly as possible (Chang et al., 2010).

\subsubsection{Instrument development}

The instrument development consisted of three steps.

First, we developed the questionnaire by sourcing relevant scales in the literature. With the exception of firm size and experience in export, we measured all the constructs in this study using multi-item scales (see appendix). In addition, in view that firm-specific advantages are derived from the firm's total learning process (Sousa et al., 2008), the business firm was used as the unit of analysis for all construct measures.

More in detail, concerning our dependent variables, export performance (EP) was measured by means of four items that measure financial benchmarks such as export sales, export growth, export market share, and export profit, and six items that measure the extent to which a firm's strategic objectives of exporting are achieved (Cavusgil and Zou, 1994). Regarding our independent variables, the scale of IO (which consisted of six items to measure top management's attitudes and resource allocations with regard to international activities) was adopted from Knight and Kim (2009) and Knight and Cavusgil (2004). For measuring EMO 14 items were used, which were adopted from Murray et al. (2011) and Racela et al. (2007). These items were used on three different dimensions, namely the gathering of export market intelligence, dissemination, and responsiveness. Drawing on Lumpkin and Dess (1996), IEO was operationalized to comprise export innovativeness, export pro-activeness, and export risk-taking behaviours. It was measured by 13 items in total, and based on Zhou (2007) and Knight and Cavusgil (2004). In addition, four control variables, two organization specific variables (such as size and export experience of the firm), and two environmental variables (such as export market dynamism and competitive intensity), were included (Lisboa et al., 2011; Zhou, 2007). Firm size, measured by the natural logarithm of the number of full-time employees, was used to control for the potential effect of differences in economy of scale (Hultman et al., 2011). Export experience was measured by the natural logarithm of the number of years which lapsed since the first exporting activity was conducted. This, to control for extra resources and capabilities that firms that have been exporting for a longer 
time might possess; and the number of markets in which the firm has regular exporting activities (Lisboa et al., 2011; Hultman et al., 2011). Market dynamism (measured by seven items) measures the rate of change of the composition and preferences of customers (Kaleka, 2011). Competitive intensity was measured by five items, which indicate the degree of competition, that is reflected in the number of competitors and the frequency and intensity of using certain marketing techniques (Kaleka, 2011).

Second, the items were refined by expert appraisal. Two academicians with extensive knowledge of questionnaire construction and research in international marketing, as well as three export managers with practical knowledge on international business activities in Ethiopia, served as expert judges and scrutinized the initial questionnaire and measures. Their suggestions led to exclusion of seven items (see appendix) because of inappropriateness in the Ethiopian context or considered as repetitions. This approach resulted in an increased of content validity of the research instrument. Then, the revised questionnaire was tested among twelve exporting firms in order to assure the items were clear and interpreted in the way they were intended. The pilot study did not indicate a need for change of the research instrument.

Third, the scores on the items were entered into an exploratory factor analysis (EFA) using principal axis factoring with oblique rotation (direct oblimin), as we anticipated a high intercorrelation between factors (Hair et al. 1998). A separate EFA was conducted on the dependent variables, independent variables, and control variables.

The EFA of the dependent variables showed that all finance-related items loaded on a different factor than the strategy-related items, indicating two empirically separate constructs. Both constructs of the dependent variables explained 72.6 percent of the total variance and received a Cronbach's Alpha reliability of 0.92 and 0.93, respectively.

The initial EFA on the independent variables resulted in the elimination of five items from each of EMO and IEO either because of low communalities, cross-loadings on multiple factors, or failure to meet the minimum standard of having a factor loading of $>.60$, which was set to determine the minimum number of items that adequately assess the constructs (see appendix).

The final EFA (see Table 4.1) resulted in a three-factor solution (Eigenvalue $>1$ ) with clean loadings for the items on their respective constructs. These three factors explained 64.4 percent of the total variance. Four items (of the original six) loaded on IO (Cronbach's alpha 
$=0.89$ ), eight items (of the original fourteen) loaded on EMO (Cronbach's alpha $=0.93$ ), and seven items (of the original thirteen) loaded on IEO (Cronbach's alpha $=0.95$ ).

The EFA on the control variables resulted in a two-factor solution (see Table 4.1) whereby all items which were related to market dynamics loaded clearly on factor one, and those items related to competitive intensity on factor two. These two constructs explained 57.0 percent of the total variance and received a Cronbach's Alpha reliability of 0.88 and 0.77 , respectively.

For an overview of the original questionnaire, including all the (dropped) items, see appendix.

Table 4.1: Factor loadings of items and reliability of constructs as measured $\left({ }^{a}{ }^{-}\right.$reverse-coded item)

\begin{tabular}{|c|c|c|c|}
\hline Constructs & Reliability & Items & $\begin{array}{c}\text { Factor } \\
\text { loading }\end{array}$ \\
\hline
\end{tabular}

Financial export
performance
$\begin{aligned} & 1=\text { strongly disagree, } \\ & 7=\text { strongly agree })\end{aligned}$
performance $(1=$ strongly disagree, $7=$ strongly agree)

\section{Dependent variables}

We are satisfied with the export turnover achieved through our export activities.

We are satisfied with the export growth achieved in recent years. We are satisfied with the export profit achieved through our export activities.

We are satisfied with the export market share achieved through our export activities.

Our firm is better able to build brand awareness by exporting. Exporting has enhanced the relative position of the firm in our home market by making it more competitive.

Exporting has helped our firm in gaining access to new technology.

Exporting has helped our firm in improving response to competitive pressure.

Exporting has contributed to the overall quality of the firm's management.

Exporting has helped our firm in reducing market dependency.

0.601

\section{Independent variables}

International orientation $\alpha=0.89$ ( $1=$ strongly disagree, $7=$ strongly agree)

\footnotetext{
Export market $\quad \alpha=0.93$ orientation (1=strongly disagree, $7=$ strongly agree)
}

The prevailing organizational culture at our firm (management's collective value system) is conducive to active exploration of new export opportunities. Management develops human and other resources for achieving our goals in international markets.

Top management tends to see the world, instead of just the Ethiopia, as our firm's marketplace.

Management continuously communicates its mission to succeed in international markets to firm employees.

We generate a lot of information in order to understand the forces that influence our overseas customers' need and preferences In this company, we generate a lot of information concerning trends in our export markets. 
International

entrepreneurial

orientation

( 1 =strongly disagree

$7=$ strongly agree)
We periodically review the likely effect of changes in our export environment.

If a major competitor were to launch an intensive campaign targeted at our foreign customers, we would implement a response immediately.

Information that can influence the way we serve our export customers takes forever to reach export personnel. ${ }^{\text {a }}$

We rapidly respond to competitive actions that threaten us in our export markets.

Too much information concerning our export competitors is discarded before it reaches decision makers. ${ }^{\text {a }}$

When we find out that our export customers are unhappy with the quality of our product, we take corrective action immediately.

abroad.

Our top management actively seeks contact with suppliers or clients in international markets.

When confronted with decisions about exporting or other international operations, our top management is always tolerant to potential risks.

Our top management values risk-taking opportunities abroad. In the design and manufacture of our product, we employ some of the most skilled specialists in the industry.

Our top management continuously searches for new export markets.

Over the past 3 years, our firm has marketed very many products in foreign markets.

\section{Control variables}

Export market $\quad \alpha=0.88$ dynamism

Our export customers tend to look for new products all the time. We are witnessing changes in the type of products/services demanded by our export customers.

New export customers tend to have product-related needs that are different from those of our existing export customers.

Our export customers' product preferences change quite rapidly.

Competitive intensity

$\alpha=0.77$

$(1=$ not at all; $7=$ to an

Competition in our export market is cutthroat.

Anything that one competitor can offer in our export market, others can match readily.

One hears of a new competitive move in our export markets

almost every day.

Price competition is a hallmark of our export market.

There are many "promotion wars" in our export market.

\subsubsection{Analysis}

We tested our conceptual framework for each dependent variable separately using hierarchical Moderated Multiple Regression (MMR) using SPSS version 22. Mean score of the items representing each construct was used in the regression analysis. Overall, we estimated a total of six main and interaction effects, reflecting the prediction of financial and strategic export performance from the three competencies and their interplay. 


\subsection{Results}

Table 4.2 shows the means, standard deviations, and correlations of all the used variables. Relatively strong correlations were observed among explanatory variables. To alleviate concerns about multicollinearity in our regression analyses, we mean centered relevant variables before creating their interaction terms (Aiken and West, 1991). For each coefficient across all the models presented, the highest variance inflation factors (VIF) was 2.695. To address the common method bias concern associated with the survey research method, we conducted Harman's one-factor test (Chang et al., 2010). We run an un-rotated EFA of all items selected for the model by constraining the number of factors to one. The single factor solution explained 40.32 percent of the variance in the data. An unconstrained, obliquely rotated EFA resulted in a seven-factor solution explaining 69.1 percent of the data variance. With all items loaded substantially and significantly onto their theoretical constructs, the first factor explained only 19.5 percent of the variance. The results generally indicate that neither multi-collinearity nor common method variance were pervasive issues.

Table 4.2: Correlation Matrix and Descriptive Statistics

\begin{tabular}{|c|c|c|c|c|c|c|c|c|c|c|c|c|}
\hline & Mean & SD & 1 & 2 & 3 & 4 & 5 & 6 & 7 & 8 & 9 & 10 \\
\hline 1. Firm size (log of employees) & 4.39 & 0.87 & 1 & & & & & & & & & \\
\hline 2. Log of number of years & 1.82 & 0.57 & -.089 & 1 & & & & & & & & \\
\hline 3. Number of markets & 3.84 & 1.84 & .045 & $.388^{* *}$ & 1 & & & & & & & \\
\hline 4. Export market dynamism & 4.53 & 1.05 & .051 & -.043 & .022 & 1 & & & & & & \\
\hline 5. Competitive intensity & 5.15 & 0.91 & .053 & -.101 & -.021 & $.291 * *$ & 1 & & & & & \\
\hline 6. International orientation & 3.97 & 1.14 & .103 & $.398^{* *}$ & $.370^{* *}$ & .000 & -.005 & 1 & & & & \\
\hline 7. Export market orientation & 4.41 & 1.11 & .121 & $.509^{* *}$ & $.310^{* *}$ & -.066 & -.038 & $.531 * *$ & 1 & & & \\
\hline 8. International entrepreneurial & 4.11 & 1.21 & $.219^{* *}$ & $.485^{* *}$ & $.385^{* *}$ & $-.181^{*}$ & -.077 & $.536^{* *}$ & $.672 * *$ & 1 & & \\
\hline 9. Financial export performance & 3.46 & 1.29 & -.019 & $.518^{* *}$ & $.285^{* *}$ & -.024 & -.048 & $.297 * *$ & $.473 * *$ & $.460 * *$ & 1 & \\
\hline 10. Strategic export performance & 4.48 & 1.29 & $.181^{*}$ & $.475^{* *}$ & $.435^{* *}$ & -.094 & -.008 & $.576^{* *}$ & $.698 * *$ & $.761 * *$ & $.464 * *$ & 1 \\
\hline
\end{tabular}

Note: ${ }^{*} p<0.05, * * p<0.01$ (two-tailed)

Table 4.3. summarizes the results of the regression analyses. Model 1 investigated the influence of the control variables on our dependent variables, financial and strategic EP. The regressions were significant $(\mathrm{p}<.001)$ for both EP dimensions. While firm size was positively related to strategic EP $(\beta=0.205, \mathrm{p}<.01)$, the number of years the firm had been in the export business was positively related to both financial and strategic EP $(\beta=0.483, p$ $<.001$ and $\beta=0.386, p<.001$, respectively). The number of markets in which the firm had regular exporting activities had a positive relationship with strategic $\mathrm{EP}(\beta=0.280, \mathrm{p}<.001)$. 
Export market dynamism and competitive intensity were not significantly related to both financial and strategic EP.

Model 2 investigated the direct effects of single competencies. The increase in explained variance for financial EP was 7.8 percent $(p<.001)$ and 32.4 percent $(p<.001)$ for strategic EP when competencies were added to the model. Five out of six regression parameters are in the expected direction and statistically significant. Our first hypothesis (H1), in which we expected a positive relationship between IO and EP, could be partially supported. That is, IO was positively related to strategic EP $(\beta=0.136, p<.05)$, however unrelated to financial EP. The estimated coefficients for EMO on financial EP and strategic EP were both positive and significant $(\beta=0.196, p<.001$ and $\beta=0.278, p<.001$ respectively), thereby fully corroborating our second hypothesis (H2). Similarly, fully supporting our third hypothesis (H3), which claimed direct effects of IEO on export market performance, IEO was found to be positively associated with financial EP as well as strategic EP $(\beta=0.224, p<.001$ and $\beta$ $=0.436, \mathrm{p}<.001$, respectively).

Table 4.3: Regression Estimates for Export Market Performance (N=159)

\begin{tabular}{|c|c|c|c|c|c|c|}
\hline \multirow[b]{2}{*}{ Variables } & \multicolumn{3}{|c|}{ Financial Export Performance } & \multicolumn{3}{|c|}{ Strategic Export Performance } \\
\hline & Model 1 & Model 2 & Model 3 & Model 1 & Model 2 & Model 3 \\
\hline \multicolumn{7}{|l|}{ Control variables } \\
\hline Firm size (log of employees) & 0.018 & -0.063 & -0.157 & $0.205^{* *}$ & 0.033 & 0.023 \\
\hline Number of years & $0.483 * * *$ & $0.316^{* * *}$ & $0.307^{* * *}$ & $0.386^{* * *}$ & 0.028 & 0.059 \\
\hline Number of markets & 0.096 & 0.038 & 0.062 & $0.280^{* * *}$ & $0.120^{*}$ & $0.128 *$ \\
\hline Export market dynamism & 0.045 & 0.098 & 0.051 & -0.111 & -0.012 & -0.027 \\
\hline Competitive intensity & -0.011 & -0.016 & -0.054 & 0.58 & 0.044 & 0.041 \\
\hline \multicolumn{7}{|l|}{ Direct effects } \\
\hline International orientation & & -0.060 & -0.101 & & $0.136^{*}$ & $0.136^{*}$ \\
\hline Export market orientation & & $0.196 *$ & $0.286^{* *}$ & & $0.278 * * *$ & $0.287 * * *$ \\
\hline $\begin{array}{l}\text { International entrepreneurial } \\
\text { orientation }\end{array}$ & & $0.224^{*}$ & $0.242 *$ & & $0.436^{* * *}$ & $0.402 * * *$ \\
\hline \multicolumn{7}{|l|}{ Interaction effects } \\
\hline $\begin{array}{l}\text { International orientation } * \text { Export } \\
\text { market orientation }\end{array}$ & & & $-0.242 * *$ & & & $-0.150 *$ \\
\hline $\begin{array}{l}\text { International entrepreneurial } \\
\text { orientation * Export market } \\
\text { orientation }\end{array}$ & & & $0.275^{* *}$ & & & 0.009 \\
\hline International orientation * & & & $0.310^{* *}$ & & & 0.122 \\
\hline $\begin{array}{l}\text { International entrepreneurial } \\
\text { orientation }\end{array}$ & & & & & & \\
\hline $\mathrm{R}^{2}$ & 0.279 & 0.356 & 0.491 & 0.352 & 0.676 & 0.687 \\
\hline Adjusted $\mathrm{R}^{2}$ & 0.255 & 0.322 & 0.453 & 0.331 & 0.659 & 0.664 \\
\hline $\mathrm{R}^{2}$ change & & $0.078 * *$ & $0.13 .5 * *$ & & $0.324 * * *$ & 0.011 \\
\hline F-value & $11.817 * * *$ & $10.381 * * *$ & $12 . .915^{* * *}$ & $16.634 * * *$ & $39.209 * * *$ & $29.349 * * *$ \\
\hline
\end{tabular}


Two-way interaction terms were added to Model 3 in order to test hypotheses 4, 5, and 6 . Only the model for financial EP was significant $(\mathrm{p}<.001)$ with an increase of explained variance by 13.5 percent. This suggests that the addition of interaction terms make a significant contribution to the explained variance for financial EP only. A three-way interaction among the competencies has also been tested as an additional model 4 . However, this interaction did not suggest a significant change in explained variance for both financial and strategic EP and was therefore not included in this study. For a more specific test of our hypotheses, we conducted simple slope analyses of significant interactions as proposed by Aiken and West (1991).

Hypothesis 4 expected a stronger, positive relationship between IO and export market performance for higher values of EMO. The regression analysis revealed a significant negative interaction effect between the two variables on both financial and strategic EP $(\beta=-$ $0.242, \mathrm{p}<.05$ and $\beta=-0.150, \mathrm{p}<.05$, respectively). Simple slope test (Fig. 2) disclosed that IO negatively relates to financial EP under the condition of high values of EMO $(b=-0.081$, $\mathrm{p}<.05$ ) and does not relate in case of low values. Conversely, a simple slope test (Fig. 3) revealed that IO does not relate to strategic EP for high values of EMO, whilst positively relates for low values $(b=0.065, p<.05)$. The results are contrary to our hypothesis; hence, neither the null nor the alternative hypothesis (H4) is supported.

Hypothesis 5 anticipated that the relationship between IEO and export market performance becomes stronger with higher values of EMO. The regression analysis revealed that the interaction effect between the two variables was positively related to financial EP ( $\beta=0.275$, $\mathrm{p}<.001$ ) and not related to strategic EP. Simple slope test (Fig. 4) disclosed that IEO positively relates to financial EP for high values of EMO $(b=0.062, p<.01)$ and does not relate for low values. Hypothesis 5 is therefore partially supported.

Hypothesis 6 predicted a stronger, positive relationship between IO and export market performance for higher values of IEO. The regression analysis revealed that the interaction between the two variables was positively related to financial EP $(\beta=0.275, p<.001)$ but not related to strategic EP. Simple slope test (Fig. 5) shown that IO marginally positively associates to financial EP for higher values of IEO $(b=0.061, p<.10)$ and negatively relates for lower values of IEO $(b=-0.095, p<.01)$. Hypothesis 6 is therefore partially supported. 

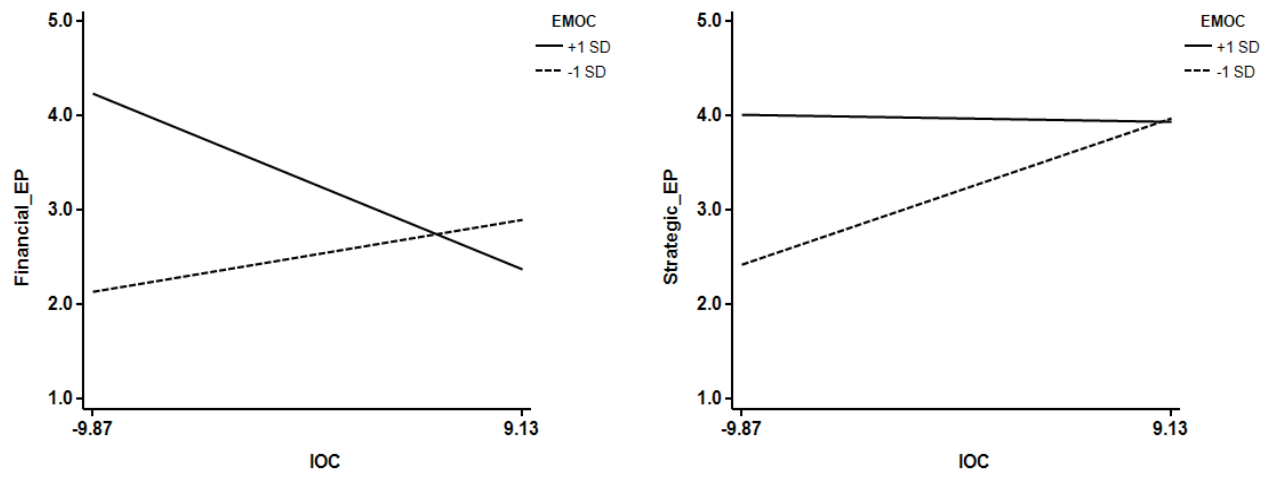

Figure 4.2: Interaction Effect of EMO and IO on Financial EP

Figure 4.3: Interaction Effect of EMO and $I O$ on

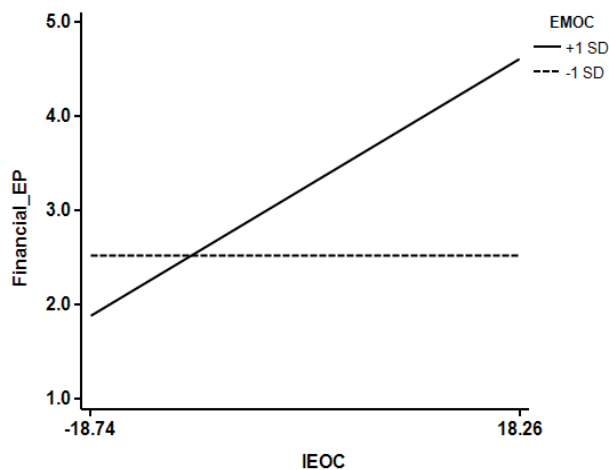

Figure 4.4: Interaction Effect of IEO and EMO on Financial EP

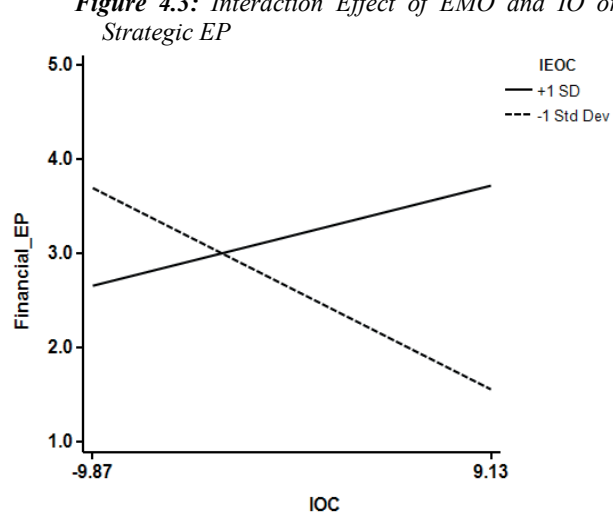

Figure 4.5: Interaction Effect of IO and IEO on Financial EP

\subsection{Discussion}

Knight and Kim (2009) direct our attention to assessing the impact of various forms of IBCs that explain observed differences in export market performance among firms. Sørensen and Madsen (2012) point to the importance of investigating the interactive effects of these strategic capabilities to better understand their relation with performance. Boso et al. (2012) accentuated the importance of assessing the performance impact of such competencies in developing economies datasets in view that contextual variables important for IBC identification, definition, development and utilization differ between advanced and developing economies, and that findings in developed economies may not hold in exporting firms in developing economies. In response to these calls, we examined in this study both the 
direct and interactive effects of three IBCs, namely IO, EMO, and IEO on both financial and strategic related EP in a developing economy dataset, Ethiopia.

The results indicate that the direct effects of IO, EMO and IEO on financial and strategic EP - with the exception of IO's non-significant effect on financial EP - were in line with our expectations. This means that possession of EMO and IEO has a direct relationship with higher financial and strategic EP, while possession of IO is related only with strategic EP. These results, in many ways, are consistent with previous studies. The discrepancy in the relationship between IO and financial EP, however, conveys important message. That is, despite earlier research efforts' assertion that firms' IO is generally positively related to export market success (Sørensen and Madsen, 2012, Knight and Kim, 2009), our result highlights that IO can have differential effects on financial and strategic EP when such relationship is examined separately for each dimension.

By contrast, a different story emerged regarding the interactive effects of our focal IBCs. Firstly, as opposed to our hypothesis, we found that the effect of IO on both financial and strategic EP is opposite, depending on the levels of EMO. Earlier studies argued that the full effect of being highly internationally oriented would require intensive knowledge about international markets as well as capabilities to react and make decisions based on such knowledge. This, suggesting the existence of synergistic interaction effect between the two competencies leading to higher EP. In our study, we found this not to be the case. As shown in Figure 4.2 and Figure 4.3, our results generally suggest that firms with higher values of EMO achieve higher export market performance when their IO is lower, whilst vice versa for firms with lower EMO denoting a substitutive relationship between the two competencies (cf. Jiang et al., 2012; Voss et al., 2010). A plausible explanation for this result might be that firms in developing countries have less advanced supportive business institutions and structures and rely to a larger extent on their own market information intelligence in order to overcome the liability of foreignness. On the other hand, such firms' export operations are very much constrained by limited resources (Birru et al., under review). Consequently, they cannot invest in both international-oriented and export market-oriented activities at the same time. For instance, a resource constrained firm cannot commit its resources for the development of organizational culture that motivates employees' behaviours in the direction of international activities, whilst at the same time investing highly on generating, disseminating, and responding to export market intelligence. Doing so would deplete their 
already limited resources, ultimately resulting in reduced success in EP. For example, one Ethiopian firm explained the situation as follows:

"....because of our limited resources, we are not able to invest equally on international-oriented and export market-oriented activities. Often times, costs on generating, disseminating, and responding to export market intelligence depletes our limited resource that would be better invested on other international activities....."

It could also be the case that despite their vision and resource allocations with regard to international activities, most of such firms still serve mainly local markets (Birru et al. under review); a lot of emphasis on export market-oriented activities does not add as much value as their associated costs. An Ethiopian firm explained this situation as follows:

"Indeed, currently we have got strategies mostly focused on serving domestic markets than the export market. However, we devote quite a lot of our resources on gathering export market information and competitors' strategy upon which we will base our future export market expansion activities...."

Secondly, concerning the interactive effect of IEO and EMO, we anticipated that greater levels of EMO act to make the IEO's impact on export market performance substantial in view that export market-oriented activities make firms wiser in their international entrepreneurial decisions making. As shown in Figure 4.4, the combination of high values of IEO and high values of EMO is positively associated with higher financial EP, whilst it was vice versa for firms with lower levels of EMO. This means that developing export marketorientated capabilities strengthen the international entrepreneurial orientation-financial EP relationship. This, in other words, means that when a firm's international entrepreneurialorientated activities and market-oriented activities are aligned (Boso et al., 2012); the firm more likely acts on opportunities that the export market-oriented activities provide it, and consequently achieves a higher financial EP.

Finally, as we expected, we found a synergistic interactive effect of IEO and IO on financial $\mathrm{EP}$, in which IO was found to have a non-significant effect individually, but combined with IEO, a significant positive effect (Andersson et al., 2014). Figure 4.5 shows that an additional investment on development of international entrepreneurial-oriented capabilities resulted in higher financial EP for firms with higher values of IEO and vice versa for those firms with lower values, indicating that IEO appeared to strengthen the effects of IO. In accordance with 
our hypothesis, this suggests that an export strategy that involves increased internationaloriented activities accompanied by increased international entrepreneurial-oriented capabilities seems to be more effective for manufacturing exporting firms in Ethiopia.

We have also found mixed results concerning the effects of control variables. First, we found that firm size has a negative effect on financial EP suggesting that a relatively firms with lower asset base tend to perform better than their larger counterparts. Secondly, we found number of years the firm has been in export is positively related to financial performance, while the number of markets in which the firm has regular export activities affects its strategic export performance. In sum, this seems to suggest that firms gaining experience and have successfully established themselves in several foreign markets over time are able to perform better (Zhou, 2007). Finally, in contrast to the results shown by earlier studies (e.g., Kaleka, 2012; Lisboa et al., 2011), the control variable EMD was not significant. This might be due to the fact that Ethiopian firms usually export through distributors rather than establish their own sales subsidiaries, and consequently, they believe that preference change of the final users doesn't directly affect their performance. Finally, the negative impact of competitive intensity can be explained by the fact that in highly competitive export market environment, firms cannot fully capitalize on the transparent predictability of their own behaviours by taking risks to proactively act on opportunities to achieve competitive advantage and enhance their performance.

\subsection{Conclusions, limitations and future research}

This study has sought to contribute to the knowledge base of the relationships among IBC and export performance. Consistent with previous studies, our results generally support the notion that IBCs (international orientation, export market orientation, and international entrepreneurial orientation) are instrumental for export market success of firms. However, we found mixed results concerning their interactive effects. The nature of the relationship between international orientation and export market performance changes as a function of export market orientation and international entrepreneurial orientation. Specifically, there is a trade-off between investing scarce time, energy and resources on developing becoming a highly internationally-oriented firm or on retrieving and managing export market information. On the other hand, internationally entrepreneurially-oriented activity of the firm has synergistic relationship with both competencies. 
Our results provide an interesting insight into the limitations of the dominant proposition, which states that having higher levels of intention and motivation to export, accompanied by higher levels of market-oriented activities and a firm's abilities to sense and seize on market opportunities, are undisputed valuable strategic resources for success in export. At least for resource-constrained firms exporting from developing countries, our study suggests to develop the identified competencies to increase export performance, but if this would be exclusively based on the direct relationships between the competencies and export performance, results may be suboptimal. The results complement Jaworski, Kohli, and Sahay's (2000) and Sigglekow's (2002) suggestions that highly successful firms are those that achieve a balance between their strategic resources. This has important implications for research that attempts to simply report the individual impact of these IBCs. This study shows that ignoring the interactive effects provides an incomplete and simplistic picture of determinants of EP, on the one hand, and an over-generalization of their benefits on the other hand.

Due to challenges of getting data from multiple countries, this study was limited to Ethiopia, a developing East African country going through political, economic, social and technological transitions. Nonetheless, the findings have important practical implications for exporting firms operating from other developing countries. Despite variations, there exist similarities among a large number of developing countries in terms of variables important for export performance (Alvi, 2012; Tesfom and Lutz, 2006). First, most developing countries have complex regulatory system and underdeveloped institutions and structures supporting international operations (Global Entrepreneurship Monitor, 2014; Boso et al., 2012; Bianchi, 2010; Okhmatovskiy, 2010). Secondly, as opposed to their counterparts in developed economies, exporting firms operating from developing countries are mostly small to mediumsized enterprises that have: a myriad of resource constraints (Boso et al., 2012; Tesfom and Lutz, 2006), little international experience (Gries and Naude, 2010), lack of marketing knowledge and information (Tesfom and Lutz, 2006), and are heavily dependent on the export of primary commodities (World Bank Group, 2014). Third, exporting firms from developing countries often face significant tariff and non-tariff barriers applied to their manufactured exports (Korneliussen and Blasius, 2008). Taking these similarities into account, we argue that the results of this study can provide managers, policy-makers, and export promotion support organizations in the developing countries concerning focus areas for the improvement of export performance. 
Notwithstanding their importance, however, the results should be treated with caution due to the cross-sectional nature of the data used in this study. Longitudinal data can offer further insights into the links among IBCs and export performance, thus, future researchers might consider design issues on this front. The collection of financial performance data from secondary informants, or the use of secondary data, would help to further alleviate concerns regarding potential biases arising from common method variance. Hence, future research might look into the feasibility of generating information using alternative data sources. Examining the potentially moderating role of external factors (e.g., market dynamism and competitive intensity) in the IBC-export performance relationship would also be another promising future research direction. 


\title{
CHAPTER 5
}

\section{EXPLAINING EXPORT PERFORMANCE: AN EXAMINATION OF THE ROLES OF INTERNATIONAL BUSINESS COMPETENCIES AND ORGANIZATIONAL LEARNING ORIENTATION}

\begin{abstract}
The study explores the extent to which organizational learning orientation strengthens the effect of the various interactions between international business competencies (international orientation, export market orientation, and international entrepreneurial orientation) on export performance. Data from on-site structured interviews with 159 owners and managers of exporting firms from different economic sectors show that organizational learning orientation strengthens the relationship between international orientation and export performance for firms with lower level of export market orientation as well as higher levels of international entrepreneurial orientation. The findings suggest that international business competencies influence each other's' effects on the one hand and establishing and maintaining higher level of organizational learning-oriented values strengthen the performance effects of such interaction on the other hand.
\end{abstract}

This chapter is based on Birru, W.T., Runhaar' P., Zaalberg, R., Lans, T., and Mulder, M. (Working paper). Explaining export performance: an examination of the roles of international business competencies and organizational learning orientation. 


\subsection{Introduction}

In the international business literature, we find the firm's international business competencies (IBCs) as an important determinant of successful export performance (EP) (Gerschewski et al., 2015; Covin and Miller, 2014; Knight and Kim, 2009). IBC refers to a firm's intangible, overarching resource that engenders superior international performance (Knight and Kim, 2009). It denotes a multidimensional concept that reflects the extent to which a firm adopts a bundle of international competencies - covering multiple areas - to effectively carry out international business activities in foreign markets (Shavazi et al., 2015; Hutzschenreuter et al. 2015; Lisboa et al., 2011; Knight and Kim, 2009).

Despite the robust evidence for the positive relationships between different forms of IBC and $\mathrm{EP}$, the role of organizational learning orientation (OLO) has not been given much attention in that relationship (Souchon, et al., 2012; Boso et al., 2012; Murray et al., 2011). OLO refers to a set of organizational values that influence the firm's propensity to generate and use new knowledge (Rhee et al, 2009; Sinkula et al., 1997). Organizational learning literature suggests that a firm's learning-oriented values prevent rigidity in the organization and determine the level of manifestation of its competencies and their impact on performance (Hakala and Kohtamäki, 2011; Sinkula et al., 1997). An organization possessing different sets of competence still requires OLO to achieve higher performance (Huang and Wang 2011). This, in other words, means that the performance impact of a firm's competencies is contingent on the level of its learning-oriented values (Huang and Wang 2011; Newbert et al., 2008).

The purpose of this study is, therefore, to provide new insights into the link between three forms of IBCs - international orientation (IO), export market orientation (EMO), and international entrepreneurial orientation (IEO) on the one hand and EP on the other hand by examining whether OLO acts to strengthen the relationship. Particularly, in line with competence-based strategic management theory that stipulates that competencies possessed by the firm are interrelated and used in an integrated manner to create competitive advantages for the firm (Sanchez and Heene, 2004), we explore whether the various interaction effects of these IBCs on EP are dependent on the level of the firm's learning-oriented values. The research questions guiding the conduct of this study is, therefore, 'to what extent does an organizational learning orientation strengthen the effect of the various interactions between international orientation, export market orientation, and international entrepreneurial orientation on export performance?' 
We investigate the proposed relationship based on data collected from Ethiopian manufacturing exporting firms. Studying such relationships among firms in developing countries like Ethiopia will have important contribution to the export marketing research agenda for two reasons. First, datasets of previous studies are typically from developed countries, where institutions of business transaction and commercial adjudication are well developed (Birru et al. under review; Boso et al., 2012). On the other hand, there is less research investigating the increasing role of these competencies in the developing economies contexts that are characterized by mostly SMEs, poor local business conditions, and resource scarcity (Boso et al., 2012). Secondly, contextual embeddedness matters in interpreting how competencies play out in influencing a firm's performance. The socio-economic literature posits that economic actions of individuals and firms do not happen independent of the social and institutional environment (Okhmatovskiy, 2010; Dacin et al., 1999; Granovetter, 1985). Consistent with this view, competence theory stipulates that the meaning of competence is embedded in specific contexts (Mulder, 2014; Le Deist and Winterton, 2005; Eraut 1994). This suggests that the potential use - and thus the strategic value of each set of IBCs - to a large degree depends on the specific context in which each company operates and the effects of domestic and international contextual factors on it (Lisboa et al., 2011; Knight and Kim, 2009). Consequently, given the prevailing differences in contextual variables important for IBC identification, definition, development and assessment between advanced and developing economies (Boso et al., 2012), it remains to be determined whether the research undertaken in western economies is relevant to developing countries (Boso et al., 2012; Kabagambe et al., 2012). This study, therefore, seeks to help redress this balance by providing evidence from Ethiopia, a developing economy going through political, economic, social and technological transitions.

\subsection{Theoretical background and research hypothesis}

\subsubsection{Conceptualizing IBCs}

The conceptualization of IBC is in line with basic thinking on the Resource-Based View (RBV) of the firm (Barney, 1991) and Dynamic Capability View (DCV) of the firm (Teece et al., 1997). The RBV of the firm posits that superior performance rests on resources and capabilities that are valuable, rare, hard to reproduce, and irreplaceable (Barney, 1991). A firm's resources consist of all assets, both tangible and intangible, that it possesses and permit 
it to create and apply value-enhancing strategies (Day, 1994). In line with this view, IBCs represent intangible firm-specific strategic resource that comprises integrated knowledgeintensive performance-enhancing capabilities (Autio et al., 2000; Teece et al., 1997; Prahalad and Hamel, 1990). The term 'integrated' here refers to clusters of knowledge, skills, and attitudes necessary for task performance and problem solving (Mulder, 2014; Le Deist and Winterton, 2005). IBCs guide the owning internationalizing firms on how it should use its resources and interact with environmental forces and transform resources into successful EP (Sørensen and Madsen, 2012; Boso et al., 2012; Murry et al., 2011; Knight and Kim, 2009).

Within the resource-based view, however, we lack a clear conceptual model that includes explanation on the dynamic character of organizational competence. The Dynamic capabilities view enhanced the RBV by addressing the evolutionary nature of a firm's resources and capabilities (Helfat et al., 2003; Teece et al., 1997). This view takes seriously the dynamics of both organizations' external environment and their internal process for building and leveraging competencies that enable them to respond effectively to their changing environments (Eisenhardt and Martin, 2000). This, in turn, suggests that firm competencies are dynamic capabilities that can be improved through firm's learning efforts and experiences (Eisenhardt and Martin, 2000; Prahalad and Hamel, 1990).

A firm's IBC can be characterized along several domains (Knight and Kim, 2009). Three orientation-based IBCs such as IO, EMO, and IEO are the focus of much recent research as most important intangible resources that guide the firm's strategic actions towards exporting and subsequently to successful performance in international markets (e.g., Gerschewski et al., 2015; Shavazi et al., 2015; Moen et al., 2015; Boso et al., 2012). These competencies are said to be particularly important for firms lacking tangible resources to build up advanced technologies, to produce superior products for highly competitive international markets often times small and medium-sized enterprises (SMEs) (Felzensztein, et al. 2015; Kuivalainen et al. 2010; Knight and Kim, 2009) as well as those firms exporting from developing countries (Boso et al., 2012). Given that such firms tend to lack substantial physical, financial, and human resources they cannot compete with larger competitors for price, but see IO, EMO, and IEO as their most competitively valuable resources (Knight and Kim, 2009).

International orientation refers to top management's favourable attitude toward, and willingness to deploy necessary resources to internationalization efforts (Knight and 
Cavusgil, 2004). It particularly concerns the degree to which managers see the world as their market place as well as their motivation to deal with international customers and partners; and consequently, top management has a clear commitment of resources and develops an organizational culture that motivates employees' behaviour in the direction of international activities (Sørensen and Madsen, 2012; Knight and Cavusgil, 2004). Export market orientation denotes a firm's mind-set that emphasizes the development of customer value through the organization's marketing practices (Shavazi et al., 2015; Murry et al., 2011). In line with Kohli and Jaworski's (1990) definition of market orientation, EMO is conceptualized by many international business scholars as a firm's ability associated with organization-wide generation of export market intelligence pertaining to current and future customer needs, dissemination of intelligence across departments, and organization-wide responsiveness to it (Acikdilli 2015; Hoang 2015; Racela et al., 2007). International entrepreneurial orientation refers to a firm's ability associated with the potential creation of value, which manifest themselves as innovativeness, pro-activeness, and risk-taking (Gerschewski et al., 2015; Lisboa et al., 2011; Murray et al., 2011; Javalgi and Todd, 2011). Innovativeness means an organization is willing to pursue new ideas and concept in process, products, or services development. Proactiveness describes the characteristics of forwardlooking and responsive of the firm in the industrial environment it involves in. Risk-taking means an organization pursues an entrepreneurial opportunity without regarding the resources it may have or may not have.

Competence-based strategic management theory's stipulates that competencies possessed by the firm are interrelated and used in an integrated manner (Sanchez and Heene, 2004). Moreover, empirical research drawing on the RBV and DCV has also suggested that firm's resources are interrelated and depend on each other to create and sustain a competitive advantage to the firm (King et al., 2008; Tanriverdi and Venkatraman, 2005). Accordingly, it has been argued that firms' strategic resources such as IO, EMO, and IEO are complementary competencies that, when bundled together, enhance one another's performance impact (Sørensen and Madsen, 2012; Baker and Sinkula, 2009).

\subsubsection{Conceptualizing organizational learning orientation}

Organizational learning orientation refers to a set of organizational values that defines the ability to create, disseminate, and utilize knowledge (Sinkula et al., 1997). These values 
include organization's commitment to learning, open-mindedness, and its convergence around a shared vision of the future (Sinkula et al., 1997; Baker and Sinkula, 1999; Lumpkin and Dess, 1996). Commitment to learning or the degree to which an organization values and promotes learning relates to the management's commitment to support a culture that fosters learning orientation as one of its main values (Sinkula et al., 1997). Committed organization considers learning as an important investment that is crucial for survival (Baker and Sinkula 1999). Open-mindedness is the willingness to critically evaluate the organization's operational routine and to accept new ideas (Sinkula et al., 1997). This is, essentially, linked to the questioning of long-held assumptions about the order of things and how events occur, and suggest carrying out a process of "unlearning", oriented to avoid rigidities in the organizational. Shared vision refers to an organization-wide focus on learning that includes the firm's interest in sharing the organization's view of objectives and priorities, as well as the commitment to them (Sinkula et al., 1997; Senge, 1990). This dimension is essential to guarantee learning to occur in the same direction and to motivate so that it really takes place.

\subsubsection{Research hypothesis}

Studies suggest that the performance effects of a firm's strategic resources like IO, IEO, and EMO are facilitated by the firms' propensity to gather, accumulate, and use knowledge (Boso et al., 2012; Baker and Sinkula, 2009; Wang, 2008). It has been argued that firms with higher learning-oriented values possess the ability to view the organization and the surrounding environment through a wider-angled lens and, consequently, are more likely able to successfully leverage and utilize their performance-enhancing strategic resources (Hakala and Kohtamäki, 2011; Baker and Sinkula, 1999). This means, OLO prevents rigidity in the organization; consequently, determining the level of manifestation of each of the firm's competencies and strengthen their performance impacts (Hakala and Kohtamäki, 2011; Rhee et al. 2009; Sinkula et al., 1997). In view of this and in line with the interrelatedness of a firm's competencies, the underlying assertion of this study is that the EP impact of the various interactions between IO, EMO, and IEO are contingent on an organization's learningorientated values. The specific hypotheses are presented below.

The role of $O L O$ in the interaction effect of $I O$ and EMO: it has been argued that the performance enhancing effect of being highly internationally-oriented and deployment of resources for international activities is strengthened by a firm's ability to gather, disseminate 
and react to export market information (Slater et al., 2012; Sørensen and Madsen, 2012). On the other hand, information derived through export market-oriented activities is novel, complex, diverse, and ambiguous, the interpretation and use of such information effectively requires a high level OLO (Baker and Sinkula, 1999; Day, 1994). It has been argued that the critical appraisal involved in OLO guarantees the quality, relevance and timely use of such information (Wang et al., 2009; Slater and Narver, 1995). More importantly, the firm's learning-oriented values facilitate its ability to challenge long-held assumptions about its fundamental operating philosophies; especially, assumptions about the market and how a firm should be organized to address it (Wang et al., 2009). This, in other words, suggest that a firm's commitment and deployment of resources for its internationalization accompanied by increased export market-oriented activities and a strong organizational learning-oriented values will lead to efficient tracking and responding to customer needs and offering appropriate and finely targeted products, resulting in successful EP. Accordingly, we hypothesize that:

Hypothesis 1: OLO strengthens the interaction effect of IO and EMO on EP. Specifically, IO has a strong positive relationship with a) financial EP b) strategic EP for firms with high levels of EMO under the condition of a high level of OLO.

The role of $O L O$ in the interaction effect of IEO and EMO: marketing knowledge and information obtained through export market-oriented activities support the international entrepreneurial behaviour of the firm (Cadogan et al., 2009). It has also been argued that a firm's export market orientation should be integrated with an organization's learning oriented values to successfully sensing and seizing on market opportunities (Slater and Narver 1995). Organization's learning-oriented values facilitate a firm's intelligence in collecting, sharing, and disseminating the entrepreneurial information effectively to become an entrepreneurial-driven organization (Wang et al. 2009). By increasing the flexibility, learning-oriented values enable the organization to quickly react against new market opportunities and threats, ultimately leading to successful market performance (Brockman and Morgan, 2003; Slater and Narver, 1995). Accordingly, we hypothesize that:

Hypothesis 2: OLO strengthens the interaction effect of IEO and EMO on EP. Specifically, IEO has a strong positive relationship with a) financial EP b) strategic EP for firms with high levels of EMO under the condition of a high level of OLO. 
The role of $O L O$ in the interaction effect of IO and IEO: a firm's learning-orientated values also appear to complement the interaction effect of IO and IEO on EP. The performance impact of a firm's commitment and deployment of resources for its internationalization efforts is strengthened by its ability to identify and pursue export market opportunities (Zahra et al., 2005). On the other hand, learning-orientated values enable the firm evaluate outside opportunities more favourably than do firms without such values (Chandra et al., 2009; Weerawardena et al., 2007). Consequently, firms oriented in this way combine greater commitment and deployment of resources and abilities to explore and pursue new business opportunities abroad, which ultimately lead to successful performance in export (Mort and Weerawardena, 2006; Knight and Cavusgil, 2004). We, then, hypothesize that:

Hypothesis 3: OLO strengthens the interaction effect of IO and IEO on EP. Specifically, IO has a strong positive relationship with a) financial EP b) strategic EP for firms with high levels of IEO under the condition of a high level of OLO.

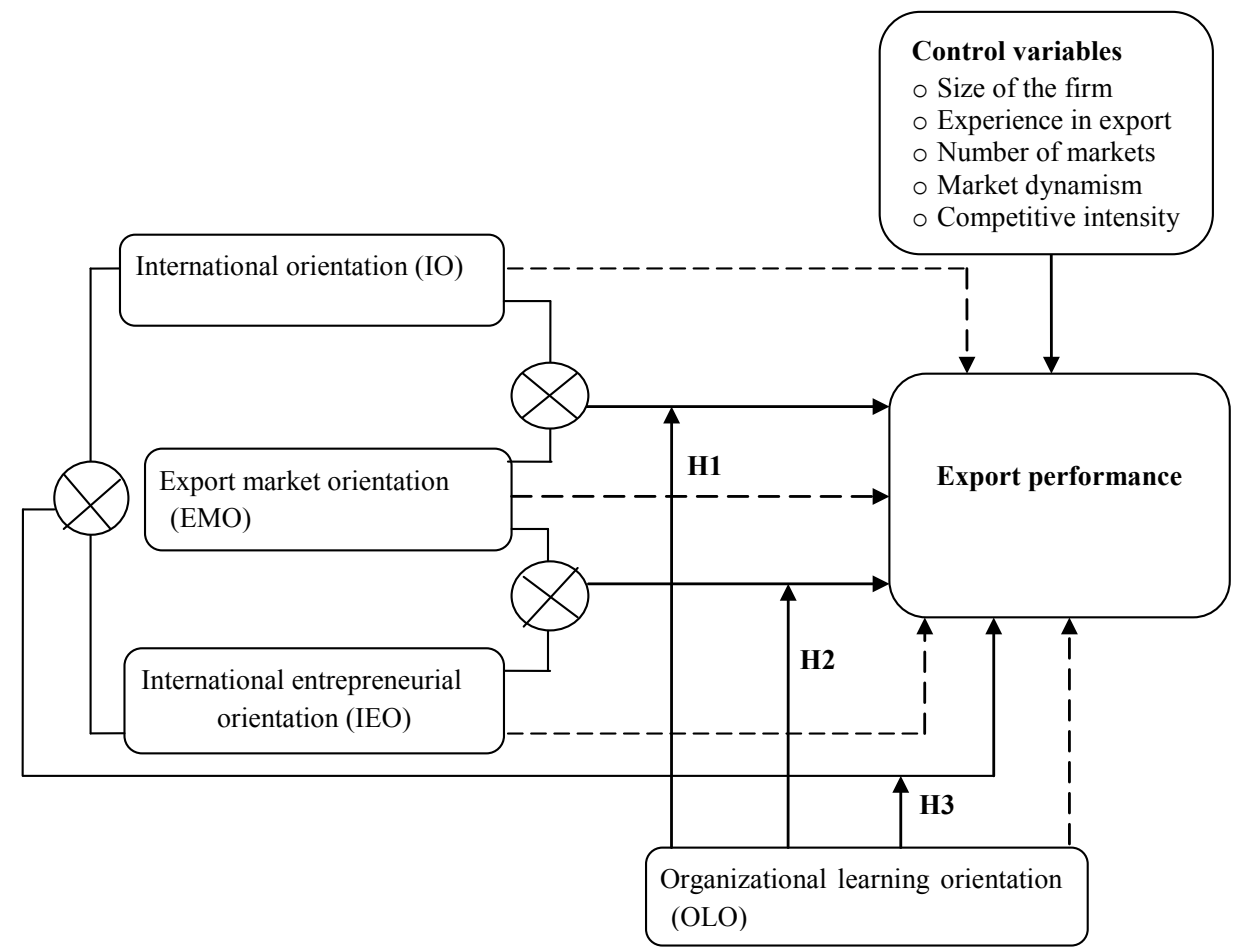

Figure 5.1: Conceptualized model (Note: a) solid lines show the focus of the study; b) crosses in the circles show interaction between competencies) 


\subsection{Methodology}

\subsubsection{Sample}

The analyses are based on data from on-site structured interviews with owners and managers of 159 exporting firms from different economic sectors in Ethiopia (textile and garment; leather and leather products; and agro-processing). The use of a multi-industry sample helps to increase observed variance and to strengthen the generalizability of the results, thereby improving the external validity of the research (Morgan et al., 2004). However, service firms and those engaged in primary industries were not included in the sample due to their idiosyncratic characteristics in terms of international expansion, regulatory requirements, and performance characteristics (Zou and Cavusgil, 2002). In addition, the sample did not include multinational corporations in view that their export is generally done via their overseas affiliates. Overall, of the 218 eligible firms found from a list of exporters generated using an export directory provided by the Ethiopian Chamber of Commerce and Sectoral Association, 59 firms were not included in this study because of either they were unwilling to participate, key individuals who could provide the required information were not available, or the firm was no longer dealing in the exporting business. The average size of the participating firms was about 127 employees. Among the sampled firms, 37.74 percent had below 50 employees, 29.56 percent had 50-100 employees, and 32.70 percent had above 100 employees.

\subsubsection{Data collection}

The survey was conducted via face-to-face interviews with owners and senior managers, who were either in charge of exporting or other types of international business activities for their respective firms. Given the relatively small population sizes of the study, this data collection method was opted to increase the response rate, mainly because many previous studies have recognized low response rate as one of the major problems of mail surveys (Singh and Mahmood, 2013). To minimize the effects of common method variance, the order of questions asked was mixed, and reverse-coded items were included, participants remained anonymous, and ensured that there was no right or wrong answers (Chang et al., 2010). 


\subsubsection{Instrument development}

With the exception of firm size and experience in export each of the variables used in this study was measured using multi-item scales (see appendix for original questionnaire). The instrument was developed in three phases.

First, items were developed based on existing scales from literature. The business firm was used as the unit of analysis for all construct measures, because firm-specific advantages are derived from the firm's total learning process (Sousa et al., 2008). To start with the dependent variables, export performance (EP) was assessed using 10 items. Four items measured financial benchmarks such as export sales, export growth, export market share, and export profit, and six items measured the extent to which a firm's strategic objectives of exporting were achieved (Cavusgil and Zou, 1994). Concerning the explanatory variables, international orientation (IO) was measured using six items adopted from Knight and Kim (2009). The indicators tap top management mind-set, attitude and resource allocations of the firm with regard to international activities. For EMO, we adapted Kohli and Jaworski's (1990) multiindicator measures assessing market-oriented behaviour that integrates the export market intelligence generation, dissemination and responsiveness components into a single and more comprehensive construct. Accordingly, EMO was measured using 14 items adopted from Murray et al. (2011) and Racela et al. (2007). The measures of IEO integrate the firm's innovativeness, proactiveness, and risk-taking into a single construct. It was measured by 13 items adopted from Zhou (2007) and Knight and Cavusgil (2004). Organizational learning orientation (OLO) was measured using 11 items that integrate the firm's commitment to learning, open-mindedness, and its convergence around a shared vision of the future. The items were adopted from Real et al. (2012) and Santos-Vijande et al. (2005). Lastly, four control variables (firm size, experience in export, market dynamism, and competitive intensity) were included to account for firm characteristics and environmental forces that may influence the hypothesized relationships. Firm size, measured by the natural logarithm of the number of full-time employees, was used to control for the potential effect of differences in economy of scale (Hultman et al., 2011). Export experience was measured by the natural logarithm of the number of years which lapsed since the first exporting activity was conducted. This, to control for extra resources and capabilities that firms that have been exporting for a longer time might possess; and the number of markets in which the firm has regular exporting activities (Lisboa et al., 2011; Hultman et al., 2011). Market dynamism 
(measured by seven items) measures the rate of change of the composition and preferences of customers (Kaleka, 2011). Competitive intensity was measured by five items, which indicate the degree of competition, that is reflected in the number of competitors and the frequency and intensity of using certain marketing techniques (Kaleka, 2011).

In the second phase, the items were refined to the study context through pilot reading of the questionnaire by experts, thereby increasing the content validity of the research instrument, followed by pretesting. Two academicians with extensive knowledge of questionnaire construction and research in international marketing, as well as three export managers with practical knowledge on international business activities in Ethiopia, served as expert judges and scrutinized the initial questionnaire and measures. Their suggestions led to exclusion of seven items (see appendix) because of inappropriateness in the Ethiopian context or considered as repetitions. This approach resulted in an increased of content validity of the research instrument. Then, the revised questionnaire was tested among twelve exporting firms in order to assure the items were clear and interpreted in the way they were intended. The pilot study did not indicate a need for change of the research instrument.

Thirdly, the items were further refined via exploratory factor analysis (EFA), using principal axis factoring with oblique rotation (direct oblimin). We used oblique rotation because we expected the emerging factors to be theoretically correlated (Hair et al. 1998). We conducted a separate EFA on three clusters of variables - dependent variables, independent variables, and control variables.

The EFA on the dependent variables resulted in a two-factor solution whereby all financerelated items loaded clearly on factor one and all strategy-related items loaded clearly on factor two. These two constructs of the dependent variables explained 72.56 percent of the total variance and received a Cronbach's Alpha reliability of 0.92 and 0.93 respectively.

The initial EFA of the independent variables resulted in the exclusion of 15 items (five items from each of EMO, IEO, and OLO) either because of low communalities, highly loading on different factors simultaneously, or failing to meet factor loading cut-off value (see appendix). As presented in Table 5.1, the final EFA of the independent variables resulted in a four-factor solution (Eigenvalue $>1$ ) with all items loading on their respective factors at 0.45 or better. According to Hair et al (1998) factor loadings exceeding 0.45 are acceptable for a sample size above 150. These four constructs of the independent variables explained 64.52 
percent of the total variance. Four items loaded on IO (Cronbach's alpha $=0.89)$, eight items loaded on EMO (Cronbach's alpha = 0.93), seven items loaded on IEO (Cronbach's alpha = 0.95), and six items loaded on OLO (Cronbach's Alpha $=0.90)$.

The EFA of the control variables (see table 5.1) showed that market dynamism items load on a different factor than the competitive intensity items, indicating two separate constructs. These two constructs explain 57.0 percent of the total variance and have Cronbach's Alpha reliability of 0.88 and 0.77 , respectively.

Table 5.1: Factor loadings of items and reliability of constructs as measured $\left({ }^{a}\right.$ reverse-coded item)

\begin{tabular}{|c|c|c|c|}
\hline Constructs & Reliability & Items & $\begin{array}{c}\text { Factor } \\
\text { loading }\end{array}$ \\
\hline $\begin{array}{l}\text { Financial export } \\
\text { performance } \\
(1=\text { strongly } \\
\text { disagree, } 7= \\
\text { strongly agree) }\end{array}$ & $\alpha=0.92$ & $\begin{array}{l}\text { Dependent variables } \\
\text { We are satisfied with the export turnover achieved through our } \\
\text { export activities. } \\
\text { We are satisfied with the export growth achieved in recent } \\
\text { years. } \\
\text { We are satisfied with the export profit achieved through our } \\
\text { export activities. } \\
\text { We are satisfied with the export market share achieved through } \\
\text { our export activities. }\end{array}$ & 0.870 \\
\hline $\begin{array}{l}\text { Strategic export } \\
\text { performance } \\
(1=\text { strongly } \\
\text { disagree, } 7= \\
\text { strongly agree })\end{array}$ & $\alpha=0.93$ & $\begin{array}{l}\text { Our firm is better able to build brand awareness by exporting. } \\
\text { Exporting has enhanced the relative position of the firm in our } \\
\text { home market by making it more competitive. } \\
\text { Exporting has helped our firm in gaining access to new } \\
\text { technology. } \\
\text { Exporting has helped our firm in improving response to } \\
\text { competitive pressure. } \\
\text { Exporting has contributed to the overall quality of the firm's } \\
\text { management. } \\
\text { Exporting has helped our firm in reducing market dependency. }\end{array}$ & $\begin{array}{l}0.812 \\
0.601\end{array}$ \\
\hline $\begin{array}{l}\text { International } \\
\text { orientation } \\
(1=\text { strongly } \\
\text { disagree, } 7= \\
\text { strongly agree })\end{array}$ & $\alpha=0.89$ & $\begin{array}{l}\text { Independent variables } \\
\text { The prevailing organizational culture at our firm (management's } \\
\text { collective value system) is conducive to active exploration of } \\
\text { new export opportunities. } \\
\text { Management develops human and other resources for achieving } \\
\text { our goals in international markets. } \\
\text { Top management tends to see the world, instead of just the } \\
\text { Ethiopia, as our firm's marketplace. } \\
\text { Management continuously communicates its mission to succeed } \\
\text { in international markets to firm employees. }\end{array}$ & $\begin{array}{l}0.778 \\
0.747 \\
0.622\end{array}$ \\
\hline $\begin{array}{l}\text { Export market } \\
\text { orientation } \\
(1=\text { strongly } \\
\text { disagree, } 7= \\
\text { strongly agree) }\end{array}$ & $\alpha=0.93$ & $\begin{array}{l}\text { We generate a lot of information in order to understand the } \\
\text { forces that influence our overseas customers' need and } \\
\text { preferences. } \\
\text { In this company, we generate a lot of information concerning } \\
\text { trends (e.g., regulation, technological developments, politics, } \\
\text { and economy) in our export markets. }\end{array}$ & -0.822 \\
\hline
\end{tabular}


International entrepreneurial orientation ( 1 = strongly disagree, $7=$ strongly agree)

Organizational learning orientation ( 1 = strongly disagree, $7=$ strongly agree ) $\alpha=0.95$

O

When confronted with decisions about exporting or other international operations, our top management is always tolerant to potential risks.

Our top management actively seeks contact with suppliers or clients in international markets.

In the design and manufacture of our product, we employ some of the most skilled specialists in the industry.

Our top management values risk-taking opportunities abroad

Our top management continuously searches for new export markets.

0.776

Over the past 3 years, our firm has marketed very many products in foreign markets.

0.660

$\alpha=0.90$

There is a total agreement on our organizational vision across all levels, functions and divisions.

The employees' contribution of original ideas is highly valued in this organization.

There is a commonality of purpose in my organization.

Personnel in this organization realize that the way they perceive the marketplace must be continually questioned.

Managers basically agree that our organization's ability to learn (modification of one's behaviour as a result of some experience or even before a certain event takes place) is one of the essential keys to the achievement of competitive advantage.

The basic values of our firm include learning as a key to improvement.

\section{Control variables}

Export market $\quad \alpha=0.88$

Our export customers tend to look for new products all the time. We are witnessing changes in the type of products/services demanded by our export customers.

New export customers tend to have product-related needs that are different from those of our existing export customers.

Our export customers' product preferences change quite rapidly.

Competitive

$$
\alpha=0.77
$$

Competition in our export market is cutthroat.

Anything that one competitor can offer in our export market, others can match readily.

One hears of a new competitive move in our export markets almost every day.

Price competition is a hallmark of our export market. $\quad 0.550$ There are many "promotion wars" in our export market. 


\subsubsection{Analysis}

To test the hypotheses, we conducted hierarchical Moderated Multiple Regression (MMR) using SPSS version 22, centering predictor variables around their grand mean in order to minimize the effect of multicollinearity (Aiken and West, 1991). Variance inflation factors (VIF) range from 1.02 to 3.0, well below the cut-off value of 10 recommended by Neter et al. (1985), meaning that the independent variables are not correlated with each other.

\subsection{Results}

Table 5.2 displays the descriptive statistics and correlation matrix for all variables. Table 5.3 and Table 5.4 display, respectively, the results of the hierarchical multiple regression analyses for financial and strategic EP. We concentrate on the three-way interactions (Model 6 in each table), which are central to this study.

Table 5.2: Correlation matrix and descriptive statistics

\begin{tabular}{|c|c|c|c|c|c|c|c|c|c|c|c|c|c|}
\hline & Mean & SD & 1 & 2 & 3 & 4 & 5 & 6 & 7 & 8 & 9 & 10 & 11 \\
\hline $\begin{array}{l}\text { 1. Firm size (log of } \\
\text { employees) }\end{array}$ & 4.39 & 0.87 & 1 & & & & & & & & & & \\
\hline 2. $\log$ of number of years & 1.82 & 0.57 & -.089 & 1 & & & & & & & & & \\
\hline 3. Number of markets & 3.84 & 1.84 & .045 & $.388^{* *}$ & 1 & & & & & & & & \\
\hline 4. Export market dynamism & 4.53 & 1.05 & .051 & -.043 & .022 & 1 & & & & & & & \\
\hline 5. Competitive intensity & 5.15 & 0.91 & .053 & -.101 & -.021 & $.291 * *$ & 1 & & & & & & \\
\hline 6. IO & 3.97 & 1.14 & .103 & $.398 * *$ & $.370 * *$ & .000 & -.005 & 1 & & & & & \\
\hline 7. EMO & 4.41 & 1.11 & .121 & $.509 * *$ & $.310 * *$ & -.066 & -.038 & $.531 * *$ & 1 & & & & \\
\hline 8. IEO & 4.11 & 1.21 & $.219^{* *}$ & $.485^{* *}$ & $.385 * *$ & $-.181 *$ & -.077 & $.536 * *$ & $.672 * *$ & 1 & & & \\
\hline 9. OLO & 3.97 & 1.08 & .080 & $.494 * *$ & $.317 * *$ & -076 & -.079 & $.519 * *$ & $.640 * *$ & $.699 * *$ & 1 & & \\
\hline 10. Financial EP & 3.46 & 1.29 & -.019 & $.518^{* *}$ & $.285^{* *}$ & -.024 & -.048 & $.297 * *$ & $.473 * *$ & $.460 * *$ & $.495 * *$ & 1 & \\
\hline 11. Strategic EP & 4.48 & 1.29 & $.181^{*}$ & $.475^{* *}$ & $.435 * *$ & -.094 & -.008 & $.576^{* *}$ & $.698 * *$ & $.761 * *$ & $.749 * *$ & $.464 * *$ & 1 \\
\hline
\end{tabular}

Note: ${ }^{*} p<0.05,{ }^{* *} p<0.01$ (two-tailed)

As shown in table 5.3, the three-way interaction model was significant for financial EP (p $<.05$ ) explaining an additional $3.3 \%$ of the variance, whilst Table 5.4 revealed that the model was not significant for strategic EP. This suggests that the addition of three-way interaction terms make a significant contribution to the explained variance for financial EP only. For a more specific test of our hypotheses, we conducted simple slope analyses of significant interactions (Figure 5.2-5.4) as proposed by Aiken and West (1991). 
Table 5.3: Regression estimates for financial EP $(N=159)$

\begin{tabular}{|c|c|c|c|c|c|c|}
\hline Variables & Model 1 & Model 2 & Model 3 & Model 4 & Model 5 & Model 6 \\
\hline \multicolumn{7}{|l|}{ Control variables } \\
\hline Firm size (log of employees) & 0.018 & -0.063 & $-0.157 * *$ & $-0.149 * *$ & $-0.125 *$ & $-0.125^{*}$ \\
\hline Number of years & $0.483^{* * * *}$ & $0.316^{* * * *}$ & $0.307 * * * *$ & $0.297 * * * *$ & $0.307^{* * * *}$ & $0.313 * * * *$ \\
\hline Number of markets & 0.096 & 0.038 & 0.062 & 0.063 & 0.057 & 0.078 \\
\hline Export market dynamism & 0.045 & 0.098 & 0.051 & 0.050 & 0.060 & 0.070 \\
\hline Competitive intensity & -0.011 & -0.016 & -0.054 & -0.049 & -0.049 & -0.051 \\
\hline \multicolumn{7}{|l|}{ Direct effects } \\
\hline IO & & -0.060 & -0.101 & -0.113 & -0.047 & -0.119 \\
\hline EMO & & $0.196 * *$ & $0.286 * * *$ & $0.261 * * *$ & $0.230 * *$ & $0.351 * * *$ \\
\hline IEO & & $0.224 * *$ & $0.242 * *$ & $0.201 *$ & 0.083 & 0.007 \\
\hline \multicolumn{7}{|l|}{ Two-way interaction effects } \\
\hline $\mathrm{IO} * \mathrm{EMO}$ & & & $-0.242 * * *$ & $-0.238 * * *$ & $-0.374 * * * *$ & $-0.403 * * * *$ \\
\hline IEO * EMO & & & $0.275 * * *$ & $0.273 * * *$ & $0.326^{* * *}$ & $0.249 *$ \\
\hline $\mathrm{IO} * \mathrm{IEO}$ & & & $0.310 * * *$ & $0.292 * * *$ & $0.219 * *$ & $0.390 * * *$ \\
\hline \multicolumn{7}{|l|}{ Learning orientation } \\
\hline$O L O$ & & & & 0.097 & $0.172 *$ & $0.180^{*}$ \\
\hline \multicolumn{7}{|c|}{ Interaction between competencies } \\
\hline $\mathrm{IO} * \mathrm{OLO}$ & & & & & $0.272 * *$ & $0.189^{*}$ \\
\hline $\mathrm{EMO} * \mathrm{OLO}$ & & & & & 0.041 & 0.137 \\
\hline $\mathrm{IEO} * \mathrm{OLO}$ & & & & & -0.150 & $-0.219 * *$ \\
\hline \multicolumn{7}{|l|}{ Three-way interaction effects } \\
\hline $\mathrm{IO} * \mathrm{EMO}^{*} \mathrm{OLO}$ & & & & & & $-0.269 * *$ \\
\hline IEO * EMO *OLO & & & & & & -0.160 \\
\hline $\mathrm{IO} * \mathrm{IEO} * \mathrm{OLO}$ & & & & & & $0.431 * * *$ \\
\hline $\mathrm{R}^{2}$ & 0.279 & 0.356 & 0.491 & 0.495 & 0.521 & 0.554 \\
\hline Adjusted $\mathrm{R}^{2}$ & 0.255 & 0.322 & 0.453 & 0.454 & 0.471 & 0.497 \\
\hline $\mathrm{R}^{2}$ change & & $0.078 * * *$ & $0.135^{* * * *}$ & 0.004 & $0.026^{*}$ & $0.033 * *$ \\
\hline F-value & $11.817 * * * *$ & $10.381^{* * * *}$ & $12.915 * * * *$ & $11.939^{* * * * *}$ & $10.374 * * * *$ & $9.657 * * * *$ \\
\hline
\end{tabular}

Note: $*=\mathrm{p}<.10 ; * *=\mathrm{p}<.05 ; * * *=\mathrm{p}<.01, * * * *=\mathrm{p}<.001$ (two-tailed)

Table 5.4: Regression estimates for strategic EP $(N=159)$

\begin{tabular}{|c|c|c|c|c|c|c|}
\hline Variables & Model 1 & Model 2 & Model 3 & Model 4 & Model 5 & Model 6 \\
\hline \multicolumn{7}{|l|}{ Control variables } \\
\hline Firm size (log of employees) & $0.205 * * *$ & 0.033 & 0.023 & 0.051 & 0.048 & 0.043 \\
\hline Number of years & $0.386 * * * *$ & 0.028 & 0.059 & 0.022 & 0.022 & 0.012 \\
\hline Number of markets & $0.280 * * * *$ & $0.120 * *$ & $0.128 * *$ & $0.131 * * *$ & $0.129 * * *$ & $0.134 * * *$ \\
\hline Export market dynamism & -0.111 & -0.012 & -0.027 & -0.031 & -0.028 & -0.006 \\
\hline Competitive intensity & 0.058 & 0.044 & 0.041 & 0.059 & 0.069 & 0.062 \\
\hline \multicolumn{7}{|l|}{ Direct effects } \\
\hline $\mathrm{IO}$ & & $0.136 * *$ & $0.136^{* *}$ & $0.093 *$ & $0.131 * *$ & 0.097 \\
\hline EMO & & $0.278 * * * *$ & $0.287 * * * *$ & $0.200 * * *$ & $0.166^{* *}$ & $0.251 * * *$ \\
\hline IEO & & $0.436 * * * *$ & $0.402 * * * *$ & $0.259 * * *$ & $0.211 * *$ & $0.224 * *$ \\
\hline \multicolumn{7}{|l|}{ Two way interaction effects } \\
\hline $\mathrm{IO} * \mathrm{EMO}$ & & & $-0.150 * *$ & $-0.133 * *$ & $-0.199 * * *$ & $-0.183 * *$ \\
\hline $\mathrm{IEO} * \mathrm{EMO}$ & & & 0.009 & 0.003 & 0.809 & 0.009 \\
\hline $\mathrm{IO} * \mathrm{IEO}$ & & & 0.122 & 0.059 & -0.694 & 0.020 \\
\hline \multicolumn{7}{|l|}{ Learning orientation } \\
\hline OLO & & & & $0.339 * * * *$ & $0.379 * * * *$ & $0.409 * * * *$ \\
\hline \multicolumn{7}{|c|}{ Interaction between competencies } \\
\hline \multicolumn{7}{|c|}{ and $O L O$} \\
\hline $\mathrm{IO} * \mathrm{OLO}$ & & & & & $0.227 * * *$ & $0.171 * *$ \\
\hline $\mathrm{EMO} * \mathrm{OLO}$ & & & & & -0.114 & -0.062 \\
\hline $\mathrm{IEO} * \mathrm{OLO}$ & & & & & 0.021 & -0.013 \\
\hline \multicolumn{7}{|l|}{ Three-way interaction effects } \\
\hline $\mathrm{IO} * \mathrm{EMO}^{*} \mathrm{OLO}$ & & & & & & -0.130 \\
\hline $\mathrm{IEO} * \mathrm{EMO} * \mathrm{OLO}$ & & & & & & -0.166 \\
\hline $\mathrm{IO} * \mathrm{IEO} * \mathrm{OLO}$ & & & & & & $0.186^{*}$ \\
\hline $\mathrm{R}^{2}$ & 0.352 & 0.676 & 0.687 & 0.734 & 0.753 & 0.763 \\
\hline Adjusted $\mathrm{R}^{2}$ & 0.331 & 0.659 & 0.664 & 0.712 & 0.727 & 0.733 \\
\hline $\mathrm{R}^{2}$ change & & $0.324 * * * *$ & 0.011 & $0.047 * * * *$ & $0.019 * *$ & 0.010 \\
\hline F-value & $16.634^{* * * *}$ & $39.209 * * * *$ & $29.349 * * * *$ & $33.568^{* * * *}$ & $29.071 * * * *$ & $25.057 * * * *$ \\
\hline
\end{tabular}

Note: ${ }^{*}=\mathrm{p}<.10 ; * *=\mathrm{p}<.05 ; * * *=\mathrm{p}<.01,{ }^{* * * *}=\mathrm{p}<.001$ (two-tailed) 
The regression analysis revealed a significant negative three-way interactive effects of IO, EMO, and OLO on financial EP $(\beta=-0.269, \mathrm{p}<.05)$. In Figure 5.2, slope 1 and slope 2 depict the relationship between IO and financial EP for high, whilst slope 3 and slope 4 show for low levels of EMO, at different levels of OLO. The figure disclosed that IO negatively relates to financial EP for high levels of EMO, irrespective of the levels of OLO. Under the condition of high levels of OLO, IO positively relates to financial EP for low levels of EMO and vice versa, otherwise. The results lend no support for our first hypothesis (H1) which proposed strong positive relationship between IO and EP for firms with high, as compared to firms with low levels of EMO, under the condition of high levels of OLO. Nevertheless, the results suggest the increasing importance of OLO for firms with low levels of EMO.

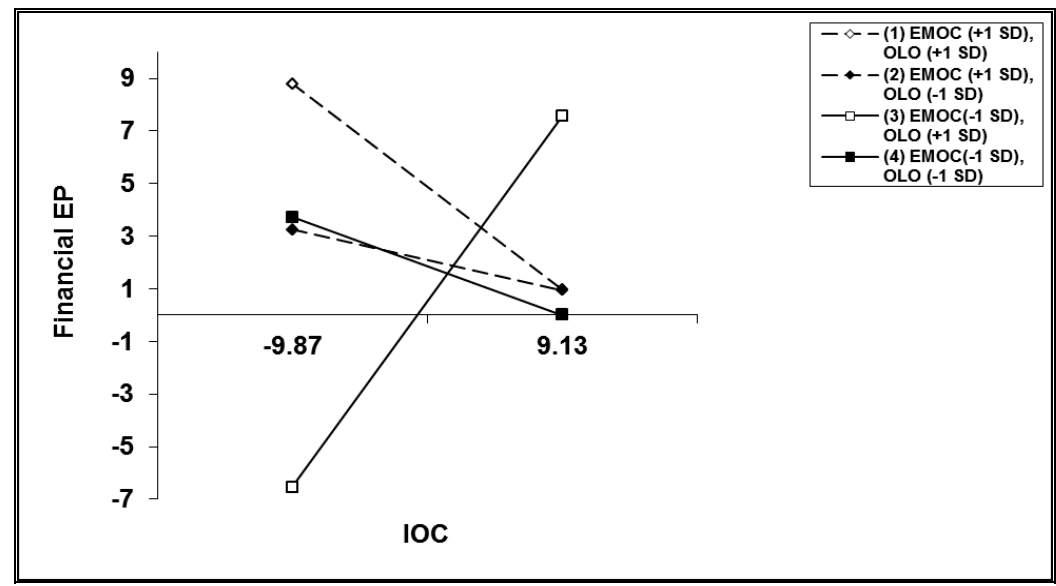

Figure 5.2: Three-way interactive effects of IO, EMO, and OLO on financial EP

Hypothesis 2 proposed a stronger, positive relationship between IEO and EP for higher, as compared to lower, values of EMO under the condition of high levels of OLO. The regression analysis however revealed that the three-way interactive effects of these variables on both financial and strategic EP are non-significant, lending no support for H2.

The three-way interactive effects of IO, IEO, and OLO on financial EP is significant ( $\beta=$ $0.431, \mathrm{p}<.01)$, and marginally significant on strategic $\operatorname{EP}(\beta=0.186, \mathrm{p}<.10)$. Figure 5.3 and Figure 5.4 show, respectively, the three-way interactive effects of these variables on financial and strategic EP. In each figure, slope 1 and slope 2 depict the relationship between IO and EP for high, whilst slope 3 and slope 4 show for low, levels of IEO at different levels of 
OLO. As revealed in the two figures, IO positively relates to both financial and strategic EP for high levels of IEO, under the condition of high levels of OLO, but vice versa when OLO is low. For low levels of IEO, IO negatively relates to financial EP irrespective of the levels of OLO, whereas it positively but less strongly relates to strategic EP under the condition of low, as compared to high levels of OLO. The results confirm our third hypothesis (H3) which proposed strong positive relationship between IO and EP for firms with high, as compared to low levels of IEO, under the condition of high levels of OLO.

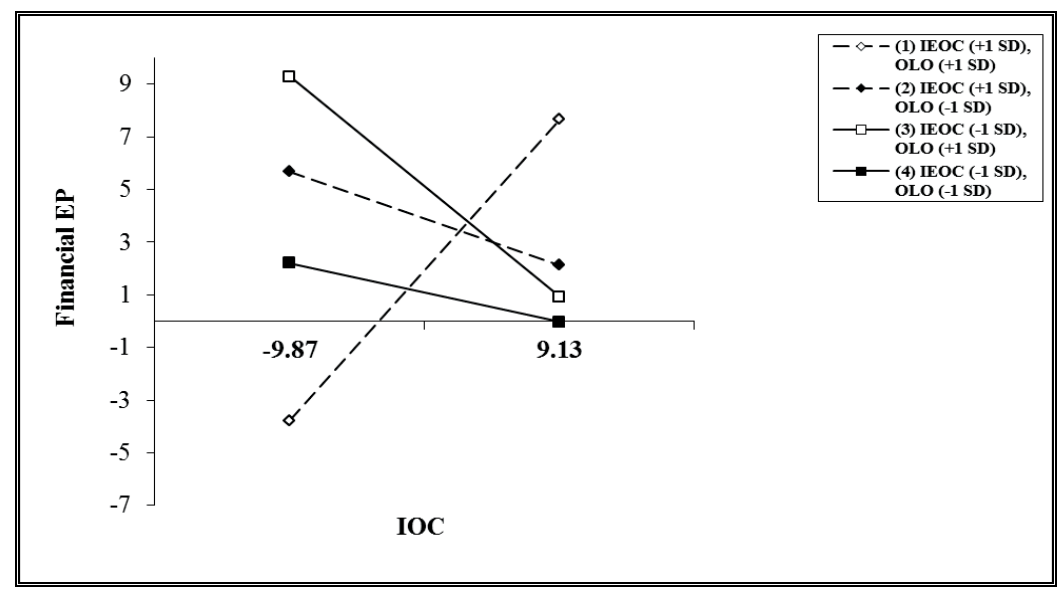

Figure 5.3: Three-way interactive effects of $I O, I E O$, and $O L O$ on financial EP

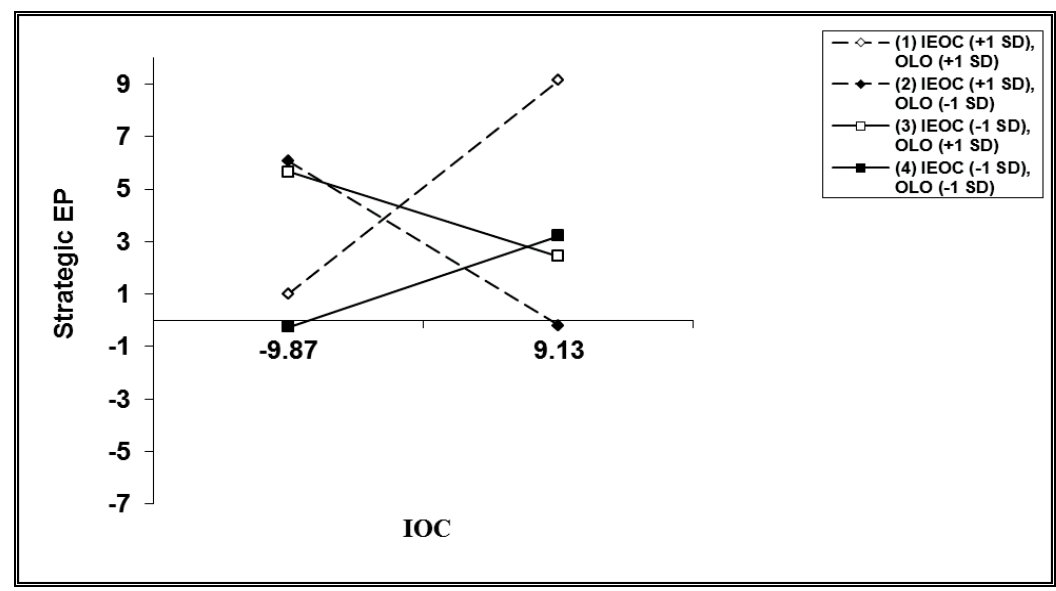

Figure 5.4: Three-way interactive effects of $I O, I E O$, and OLO on strategic EP 


\subsection{Discussion}

Literature indicates that the firms' competencies have only potential value and realizing this potential in enhancing performance requires alignment with other important internal and external environmental factors (Murry et al., 2011; Ketchen et al. 2007). In accordance with this view, this study has sought to provide insights into the degree to which IBCs and EP are associated under different conditions of organization's learning-oriented values. Specifically, the study explores the extent to which organization's learning-oriented values strengthen the different interactive effects of three international business competencies that are given significant attention in recent studies as most important intangible organizational resources for successful EP (Sørensen and Madsen, 2012; Boso et al., 2012) - international orientation (IO), export market orientation (EMO), and international entrepreneurial orientation (IEO).

Based on the existing literature, we hypothesized that management's favourable attitude toward, and willingness to deploy necessary resources to internationalization efforts (i.e., IO) is positively and strongly associated with EP for firms with high ability to generate, disseminate and respond to export market intelligence (i.e., EMO) under the condition of high levels of organizational learning-oriented values. Conversely, our study demonstrates a strong, positive association between IO and financial EP for firms with low levels of EMO under the condition of higher levels of OLO, and vice versa for firms with high levels of EMO. The results denote a substitutive relationship between IO and EMO, in which using the two IBCs together does not have a greater impact compared to their individual effects (cf. Jiang et al. 2012; Voss et al., 2010). One explanation is that EMO is a resource consuming activity; as such generating, disseminating, and responding to export market intelligence requires considerable resource commitments (Cadogan and Cui, 2004; Slater and Narver, 1994). On the other hand, SMEs particularly those in developing countries like Ethiopia have limited resources to invest highly in such activities (Birru et al., under review). For such firms, lot of emphasis on export market-oriented activities on one hand deplete their already limited resources that undoubtedly be better invested on other international activities (Cadogan and Cui, 2004), and on the other hand a high level of cost associated with employing market-oriented behaviours in exporting may outweigh the benefits accrued (Sørensen and Madsen, 2012; Cadogan et al., 2003). It should, however, be noted that this result by no means leads to the conclusion that higher level of EMO always results in lower financial EP. It rather highlights that organization's learning-oriented values seem key to help 
the firm perform higher in export even when it is less able to gather, disseminate and respond to export market intelligence. An interesting message that can be drawn from this result is that for resource constrained exporting firms, the critical appraisal and the ability to make sense of export market intelligence guarantees the firm's financial EP rather than the efforts made on gathering, disseminating and responding such intelligence.

As hypothesized, our study demonstrates a strong, positive association between a firm's IO and EP for firms with higher levels of IEO under the condition of higher levels of organizational learning-oriented values. On the other hand, the results have shown that firms that have higher levels of both IO and IEO, but possess lower levels of OLO seem to be less able to leverage the full potential of their international and entrepreneurial-oriented capabilities, and as a result export market success is less likely. This means that higher levels of organization's learning-oriented values strengthen the IO-EP relationship for firms with higher, as compared to lower, levels of IEO. In other words, these results affirm the view that learning-orientated firms are more able to evaluate outside opportunities more favourably than do firms without such values (Chandra et al., 2009).

This study didn't show a three-way interactive effect between IEO, EMO and OLO. It was anticipated that greater levels of EMO act to make the IEO's impact on EP substantial for firms with higher levels of organizational learning-oriented values. The unexpected lack of support for such relationship was a surprise because earlier research efforts asserted that firms' entrepreneurial-oriented and market-oriented capabilities are learning constructs, the performance impact of which can be enhanced by the firm's OLO (Boso et al., 2012; Cadogan et al., 2009). Although there exist a positive two-way interactive effect of IEO and EMO on financial EP (see Model 2 in Table 5.3), suggesting that when a firm's international entrepreneurial-orientated activities and market-oriented activities are aligned the firm more likely acts on opportunities that the export market-oriented activities provide it (Boso et al., 2012), that relationship is not dependent on the firm's learning oriented values.

\subsection{Conclusions, limitations and future research}

The current study argued that the export performance impact of the various interactions between a firm's international orientation, export market orientation, and international entrepreneurial orientation are dependent on its learning-oriented values. Our study shows that for Ethiopian based exporters, organizational learning orientation strengthens the 
relationship between international orientation and export performance for lower levels of export market orientation and higher levels of international entrepreneurial orientation. The key implications for theory from this research are: a) different sets of international business competence influence each other's performance effects and should always be examined in combination; and b) organizational learning-oriented values strengthen the performance effects of such interactions. These results also have clear and important practical implications that are relevant to exporters operating in Ethiopian and other developing economies with similar contextual characteristics. For such resource-constrained exporting firms, establishing and maintaining higher level of organizational learning-oriented values compensate their resource limitations for investing on gathering, disseminating and responding export market intelligence.

Notwithstanding the important contribution of this study, given that the study is limited to Ethiopia - a developing East African country, the relatively small sample size, and the crosssectional nature of the data used, it is important that the model is explored empirically in other developing economies in order to assess the stability and generalizability of the research findings. Furthermore, the collection of financial performance data from secondary informants, or the use of secondary data, would help to further alleviate concerns regarding potential biases arising from common method variance, which was caused by collecting both independent and dependent variables from the same respondent. Hence, future research should look into the feasibility of generating information using alternative data sources. 


\section{CHAPTER 6}

\section{GENERAL DISCUSSION AND CONCLUSION}

\subsection{Introduction}

The studies in this thesis pursued the main research objective to better understand the relationships between international business competencies and export performance in the developing country context. Although the topic has been discussed in the literature, datasets are typically from developed rather than developing countries (Boso et al., 2012; Kabagambe et al., 2012). In view that contextual embeddedness matters in interpreting how different competencies play out to influence performance (Mulder, 2014; Okhmatovskiy, 2010; Dacin et al., 1999), more study and data from the contexts of developing economies help broaden contribution to knowledge on the subject. The main research question in this thesis is 'What is the relationship between international business competencies and export performance in developing economies?' To answer this main question, we conducted: 1) a systematic literature review to identify IBCs and associated factors linked with export performance and develop a tentative framework for analysing the relationship between IBC and export performance; 2) an exploratory study consisting of experts' interviews to validate the literature-based IBC framework in the specific context of a developing country, Ethiopia, identifying IBCs most important for Ethiopian exporting firms, and developing IBC framework for use in Ethiopia; and 3) a quantitative survey of Ethiopian exporters to investigate the relationship between the identified IBCs and export performance as well as the role of organizational learning orientation in that relationship.

In this final chapter, we will first summarize the main findings and draw the main conclusions from our study and then discuss the strengths and limitations of our research. Afterwards we will outline the implications of the research in terms of suggestions for future research and practical implication.

\subsection{Main findings}

\subsubsection{Identification and validation of IBCs}

As the main research question already reveals, we studied in this thesis the relationship between IBCs and export performance in a developing country context. But the thesis begins 
with reviewing the extant studies, because despite empirical studies on IBCs that underpin a firm's export performance is growing, there appears to be no comprehensive framework for studying how IBC relates to export performance and contextual factors. A systematic literature review of 58 empirical studies associating different sets of IBC to export performance was therefore conducted to answer research questions, which are described in Chapter 2: 'What does IBC, which is essential for export performance, consist of? How does it influence export performance? And which context factors influence the IBC-export performance relationship? The synthesis of the review of IBC associated with export performance resulted in eight sets of competencies which, based on the substantive conceptual meanings of the underlying constructs examined in the studies, can be categorized into three inter-related domains (Orientation-based, Marketing and sales-based, and Networking-based competencies). The relationship between these IBCs and export performance was studied mostly in advanced economies, and linked with export performance of SMEs, born-global entrepreneurial firms, and new ventures, implying that these strategic resources are particularly importance for firms lacking tangible resources to build up advanced technologies to produce superior products for highly competitive export markets. There is, however, variation among studies in the use of terms and concepts representing a given IBC. Although the basic nature of the constructs are not changed, there is a high tendency of using different names for the same IBC or the same name for different sets of IBCs. Lack of consensus among studies was also observed regarding how a given set of IBC relates to export performance. While some studies investigated the direct linear relationships between IBCs and aspects of EP, others have included mediating and contextual factors in their evaluation. Particular IBCs or IBC dimensions were considered as mediating factors suggesting that the boundaries between the concepts are not clear. On the other hand, multiple contextual factors, which comprise environmental, organizational, and personallevel forces were examined either as antecedents for the development of IBC in the firm or moderators in the relationship between IBC and export performance. But the fact that most of the studies failed to incorporate context factors in their model is a regrettable limitation in the current literature. Also important observation of the reviewed studies was that a wide array of measures for export performance was used. Authors generally used both financial, strategic (non-financial) as well as satisfaction related measures of export performance (Zou \& Stan, 1998). This review study led to a comprehensive picture of IBC and associated factors linked 
to export performance, which was presented in Chapter 2, followed by practical implications and avenues for future research in the field.

As stated in Chapter 1 and also revealed in the literature review (Chapter 2), majorities of studies on the relationship between IBCs and export performance have been conducted in the context of Western and advanced economies. It has therefore become important to determine whether IBCs found to be associated with export performance in the developed economies context - where there are a well-functioning institutional environment of business transactions - are also the source of competitive advantages for exporting firms in an institutional context of developing economies contexts, which are known for lack of capacity to successfully meet demand for their products in foreign markets (Boso et al., 2012; Kabagambe et al., 2012). Accordingly, the research questions in the second study (described in Chapter 3) were: 'To what extent do Ethiopian experts recognize IBCs, which were extracted from the literature, as an important factors which influences export performance? Which other competence domains experts think are important for enhancing export performance? Which IBCs are considered to be most important for export performance in the Ethiopian context, according to experts' perceptions? How do experts characterize the relationship between IBCs, which are chosen as being most important, and export performance? What other factors help or hinder firms to achieve higher export performance?' Results of in-depth interviews with 24 Ethiopian experts confirmed the importance of the IBC framework found in the literature for export performance improvement, and also three more competencies that did not emerge from the literature (cross-cultural business competence; ethical competence; and communication and negotiation competence) were identified. More importantly, three orientation-based IBCs (international orientation, export market orientation, and international entrepreneurial orientation) were identified as most important for Ethiopian exporting firms. It was also emphasized that the key combination of IBCs that firms need for successful export performance can change over time, depending on the evolving contexts and the fact that firms learn from their experiences. On the other hand, market dynamism, competitive intensity, size and export experience of the firm were indicated as factors determining how and in what ways the identified IBCs relate to export performance of the firms. 


\subsubsection{Relationships between IBCs and export performance}

In the quantitative study, based on the literature review and also the exploratory study, explicit attention was paid to the investigation of the relationship between three IBCs, which were identified in Chapter 3 as most important for Ethiopian exporting firms and export performance of the firms as well as the role of organizational learning orientation in that relationship. As stated in Chapter 1 of this thesis, strategic management theory and the current studies that draw on RBV and DCV of the firm suggest that competencies are interdependent and likely to interact in influencing one another's performance impact. However, scientific evidence focusing on identifying and specifying interaction effects pertaining to relations between different IBC's and export performance was strikingly lacking. Research questions described in Chapter 4 were therefore: 'To what extent are international orientation, export market orientation, and international entrepreneurial orientation related to export performance?' To what extent and in what ways do these IBCs interact in realizing export performance? Also as described in Chapter 1, IBCs are learning construct; and consequently, the benefits of possessing higher level of different sets of IBC materialize if the firm has organizational systems and values that encourage learning. The organizational learning literature suggests that organizational learning-oriented values guide the firm's behaviour and processes of acquiring various information, developing shared understanding of information acquired, and generating new knowledge or organizational insights (Škerlavaj et al., 2010; Nguyen and Barrett, 2006). Notwithstanding this, thus far, little empirical work has been done to empirically examine the role of organizational learning orientation in the relationship between IBCs and export performance (Souchon et al., 2012). In particular, examination of the extent to which an organizational learning orientation strengthens the various interaction effects of different sets of firms' IBC seems to have been neglected in the exporting literature. Accordingly, a research question described in Chapter 5 was: 'To what extent does an organizational learning orientation strengthen the effect of the various interactions between international orientation, export market orientation, and international entrepreneurial orientation on export performance?'

To answer these research questions, we conducted hierarchical Moderated Multiple Regression (MMR) on the data collected from 159 owners and managers of exporting firms from different economic sectors in Ethiopia. Chapter 4 presented the results of the analysis of the direct and the interaction effects between international orientation, export market 
orientation, and international entrepreneurial orientation on export performance. Positive direct relationships between each of the competencies and export performance were found. On the other hand, the effects of the interactions between the competencies and export performance showed mixed results. First, as opposed to our expectation (we expected synergistic interaction to exist) a substitutive interaction effect was shown to exist between international orientation and export market orientation, in which firms with higher values of export market orientation achieve higher export market performance when their international orientation is lower, whilst vice versa for firms with lower export market orientation. Second, in line with our expectation, a synergistic interaction effect between international orientation and international entrepreneurial orientation has been revealed in that international orientation was found to positively associate with export performance for higher values, whilst vice versa for lower values of international entrepreneurial orientation. Third, no significant interaction effect was found between export market orientation and international entrepreneurial orientation.

Chapter 5 presented the results of the analysis of the role of organizational learning orientation in the relationship between the various interactions of the focal IBCs and export performance. The results of the three-way interaction analysis demonstrated that under the condition of higher levels of organizational learning orientation, a positive association between international orientation and export performance was shown for firms with low levels of export market orientation, whilst vice versa for firms with high levels of export market orientation. Also, under the condition of higher levels of organizational learning orientation, a positive association between a firm's international orientation and export performance was shown for firms with higher levels of international entrepreneurial orientation. In the contrary, firms possessing higher levels of both international orientation and international entrepreneurial orientation, but lower levels of organizational learning orientation seem to be less able to leverage the full potential of their international and entrepreneurial-oriented capabilities, and as a result export market success is less likely.

\subsection{Major Conclusions}

Cognizant of the inherent complexity of operating in an increasingly global business environment, recent literature in international business, international marketing, and international entrepreneurship point to factors that contribute to successful export 
performance. This stream of literature tells that IBCs are fundamental capabilities of an organization that facilitate foreign market entry and operations, which suggests that firms who have better developed such competencies perform better in export (Kabagambe et al., 2012; Knight and Kim, 2009). The literature also tells that IBC is a multidimensional concept that reflects the extent to which the firm adopts a bundle of international competencies to carry out international business activities in foreign markets in an effective way (Knight and Kim, 2009). However, since different IBCs are studied in isolation from one another, the literature does not provide us a comprehensive framework for studying how IBC relates to export performance and contextual factors. More importantly, despite export performance is vital to economic growth of developing countries, majority of prior studies on IBC were focused on Western and advanced economies, hence, an understanding of the relationship between different sets of IBCs and export performance in the developing economies' contexts is still lacking (Boso et al., 2012; Kabagambe et al., 2012). This is exactly what this thesis has attempted to do. This thesis consisted of three main studies including a review study and two empirical studies, one of which was exploratory and the other a quantitative survey study, both conducted in a developing country context, Ethiopia.

\subsubsection{Identification and validation of IBCs}

The results of the review study presented in Chapter 2 synthesized the substantive contributions in a coherent framework of IBC and associated factors linked with export performance. The results of the review study showed that whereas IBC comprises a number of specific competence domains that account for export success, the discussion of such competencies in the literature is in its early stages, as evidenced by the fact that the majority of studies set out to investigate the effect of small sets of competences on firm's export performance. Moreover, the results suggested that the relationships between IBCs and export performance do not hold homogeneously for all contexts. Rather, there are always likely to be multiple environmental, organizational, and personal-level factors that play roles in that relationship (Murray et al., 2011; Cadogan et al., 2009). Thus explicit attention should be paid to the identification of the contextual factors that, in one or another way, affect the relationship between IBC and export performance, and the need to use vigorous conceptual and measurement frameworks when evaluating IBC and corresponding performance outcomes. This is because an attempt to simply examine the relationship between IBCs of choice and export performance by excluding the importance of contextual factors in the 
examination provides an incomplete and simplistic picture of the relationship (Murray et al., 2011; Cadogan et al., 2009; Mavrogiannis et al., 2008). The results of the review study of this thesis also suggested that export performance is a multifaceted concept and that the use of single-item measures is insufficient for reliable assessment (Leonidou et al., 2002). Furthermore, based on the limitations identified in the reviewed literature, the review study of this thesis provided suggestions for the subsequent empirical studies. First, in the light that the importance of each set of IBCs depends on the specific situation in which it is utilized, it is essential to start with the exploration of sets of IBC that are thought to be vital for export within the context of where the study is conducted instead of trying to investigate the relationship between IBCs of choice and export performance (Lisboa et al., 2011; Knight and Kim, 2009). Secondly, different sets of competencies possessed by the firm are likely to interact and complement each other to influence the firm's performance (Sørensen and Madsen, 2012; King, et al. 2008; Sanchez and Heene 2004; Winter 2003); thus, explicitly attention should be paid to the interaction between IBCs when examining the relationship of IBCs and export performance. Lastly, firms' competencies are not fixed structures but dynamic capabilities that can be improved through the firm's learning efforts and experiences (Prahalad and Hamel, 1990); hence, attention needs to be paid to the role of organizational learning-oriented values in the relationship between IBCs and export performance.

The results of the exploratory study presented in Chapter 3 confirmed the importance of the IBC framework extracted from the literature for the Ethiopian context and expanded it with three additional IBCs that did not emerge from the literature. However, international orientation, export market orientation, and international entrepreneurial orientation are most important IBCs for the contemporary Ethiopian exporting firms that are characterized by mostly SMEs, poor local business conditions, resource scarcity, and little international experience. This suggests that regardless of the importance of the presented IBCs and that a firm might possess all or more of these IBCs, the contexts in which it operates will require it to draw on some of these competencies more than the other. Hence, proper identification, development, and use of competencies vital for internationalization in a specific context are of great importance for firms to create competitive advantages in their export markets. Furthermore, the results suggest that the key combination of IBCs that firms need for successful export performance can change over time, depending on the evolving contexts and the fact that firms learn from their experiences. 


\subsubsection{Relationships between IBCs and export performance}

The results of the quantitative survey study of this thesis showed that different sets of IBC influence each other's performance effects and should always be examined in combination (Chapter 4). This, notwithstanding, the nature of the interactive relationships between IBCs is not always complementary, as one might expect. For instance, the results presented in Chapter 4 showed a trade-off between investing scarce time, energy and resources on developing becoming a highly internationally-oriented firm or on retrieving and managing export market information; thereby suggesting a substitutive interaction relationship between international orientation and export market orientation. This is due to the resource limitations inherent in firms operating in a resource-constrained environment, like Ethiopia. Such firms are not able to invest equally on all competencies required for their internationalization activities, as doing so depletes their already limited resources and negatively affects their performance. For research, this suggests that ignoring the interactive effects and reporting only on the direct relationship of each IBC with export performance does not show a realistic relationship between IBCs and export performance on the one hand, and an overgeneralization of the performance enhancing benefits of each IBC examined on the other hand.

Finally, the results of the quantitative survey study presented in Chapter 5 showed that organizational learning orientation strengthens the relationship between the various interactions among a firm's international business competencies and export performance. The results particularly showed that an organizational learning orientation strengthens the relationship between international orientation and export performance for lower levels of export market orientation as well as for higher levels of international entrepreneurial orientation. This means that firms possessing higher level of organization's learning-oriented values are able to perform better even when they are less able to gather, disseminate and respond to export market intelligence. An interesting conclusion that can be drawn from this result is that for resource-constrained exporting firms, the critical appraisal and the ability to make sense of export market intelligence guarantees their export performance rather than the efforts they made on gathering, disseminating and responding such intelligence. Firms with higher levels of organizational learning-oriented values have view the organization and the surrounding environment through a wider-angled lens, and consequently they are more likely 
able to leverage and utilize their performance-enhancing strategic resources better than those firms that don't have such values.

To sum up, IBC comprises a number of specific competence domains; hence, in order to strengthen their competitive advantages and achieve enhanced export performance, firms need to properly identify, develop and use suitable IBCs to the context in which they are operating. Firms operating in resource-constrained environments of developing economies have much to gain by focusing on the development of orientation-based IBCs such as international orientation, export market orientation, and international entrepreneurial orientation. These competencies are interrelated and applied in an integrated manner in practice; consequently, they have interaction effects on export performance and such effects are strengthened by learning-oriented values of the firm. However, for resource-constrained firms, not all interactions between these competencies have synergistic effects; a substitutive interaction effects was seen between international orientation and export market orientation. This hints the limitations of the dominant position that holds possession of higher levels of intention and motivation to export accompanied by higher levels of export market orientation and international entrepreneurial orientation together always lead to successful export performance.

\subsection{Strengths, weaknesses, and suggestions for future research}

The overall strength of this thesis lies in the use of mixed methods in examining the topic, which has enhanced the robustness of our study findings and compensated in part for limitations associated with using a single method. The thesis has attempted to straddle international business, international marketing, and international entrepreneurship literature in looking at international business competencies essential for export performance and their interplay in influencing export performance. More importantly, the thesis identifies two matters of crucial importance in examining international business competencies and corresponding export performance in a developing country context, Ethiopia: (1) datasets of previous studies are typically from developed rather than developing countries, and (2) contextual embeddedness matters in identifying, developing and interpreting how different sets of international business competence play out in influencing export performance. By doing so, the thesis sought to extend knowledge about a category of firms that deserve more research attention. Furthermore, its anchor mainly in the resource-based view of the firm 
provides a strong argument for firms with international activities to develop capabilities, such as international business competencies, as they appear to be a source of competitive advantage if managed at the right level. In the following, some of the strengths and weaknesses inherent to literature and empirical studies in this thesis are discussed.

A clear strength of the literature study is that recent articles published in international journals were systematically searched from multiple bibliographical databases and analysed. Nonetheless, although every effort was made to include all the relevant articles, literature review studies inherently risk excluding some pertinent publications. Future review studies could also make use of more sophisticated meta-analytic methods. The empirical studies included in this review, however, used a wide variety of methodologies and measures. Hence, owing to the incompatible and inconstant nature of the reported results, these studies could not be subjected to a formal meta-analysis. Nonetheless, improved reporting of descriptive statistics in future studies could be one step in the right direction to facilitate the use of more sophisticated meta-analytical methods. With respect to IBCs linked with export performance identified in the literature review, even though every effort was made to be as exhaustive as possible, additional research will be carried out and, quite possibly, reveal still IBCs that should be added to those already identified in this thesis. Moreover, while an attempt was made to include effects of intervening and contextual variables that either inspire the development of IBC or moderate the IBC-export performance relationship, future review studies could extend this study by focusing on and identifying more of such variables. Despite these concerns, this work provides substantive results and suggestions that need to be considered and addressed by future researchers studying determinants of export performance and their interplay in influencing export performance.

Regarding the empirical studies, the fact that survey study was preceded by a qualitative study aimed at identifying international business competencies relevant in a specific context of Ethiopia, and the insights provided by a simultaneous analysis of the direct and interactive effects could offer valuable contributions to the advancement in the field. Despite these issues, this work provides substantive results and suggestions that need to be considered and addressed by future researchers studying export performance. The main limitation of this study is caused by the characteristics of data collected: data collected from single respondents in the firm i.e., the individual responsible for international marketing activities (e.g. export manager or CEO); and use of subjective perceptual data. Although using data from a single 
respondent is a common practice in export studies in view that the information sought is so unique to the export function that there is only one person, or a small number of people, with access to the appropriate data (Sousa et al., 2008), and previous studies have shown correlation between subjective and objective performance measures (Ren et al. 2009), they are associated with a number of limitations. These limitations include common method bias that induces artificial covariance between the items because they are collected from the source with the same method; respondent characteristics such as memories and perceptions affecting the response style such as the tendency to perceive things negatively or to agree irrespective of the content; social desirability due to respondents' willingness to create a positive image of themselves or of their firm; item and scale characteristics such as common scale format; the context in which the items are presented and measured (Podsakoff et al., 2012; Chang et al., 2010). Future research may benefit from gathering data from more than one representative of the same firm. This may mean that multiple informants can be used either to obtain the same data from more than one person or to get different bits of the data from different people. Some data could be collected from secondary sources, either to be used to provide information on informant reliability (by comparing the secondary data with the same data provided by the single informant), or simply to introduce multi-source data to reduce problems relating to correlated systematic errors. Generally, this may suggest the need to move away from questionnaire-based data, which are provided by those who have an interest in the outcomes to researcher-based data.

In addition, the findings presented in Chapter 4 and 5 should be regarded with caution, given the cross-sectional nature of the data collected from single country. Where possible, researchers should be looking to reduce problems that may stem from the cross-sectional nature of the data by carrying out longitudinal surveys. More importantly, exploring the model empirically in other developing economies is another aspect that future researchers should consider in order to assess the stability and generalizability of the research findings.

\subsection{Practical implications}

The results have important practical implication for business practitioners in Ethiopia and other developing countries with similar contextual characteristics. The results from the three studies suggest the crucial roles that international business competencies have for the achievement of successful export performance. Exporting firms operating from developing 
countries often lack tangible resources to build up advanced technologies, to produce superior products for highly competitive international markets. For such firms, international business competencies could be their highly competitive strategic resources that enable firms overcome their limitations in tangible resources. For effective export performance, firms need to prepare for international ventures by properly identifying, prioritizing and developing an appropriate set of competencies necessary for their internationalization process in the contexts in which they are operating. However, if competence development would be solely based on the direct relationships between the competencies and export performance, results may be suboptimal. Thus, such resource-constrained firms need to maintain optimal balance among different sets of international business competencies they need for their internationalization activities. Our study has also verified the role of organizational learning orientation in strengthening the various interaction effects of international business competencies. Thus, firms can benefit by establish and maintain higher levels of organizational learning orientations. The results also provide policy-makers and export promotion support organizations with insights concerning focus areas in order to better facilitate improvements in the country's export performance. 


\section{REFERENCES}

Acikdilli, G. (2015). Marketing Capabilities-Export Market Orientation and Export Performance Relationship: Establishing an Empirical Link. Advances in BusinessRelated Scientific Research Journal, 6(1), 49-62.

Aiken, L.S. and West, S.G. (1991). Multiple Regression: Testing and Interpreting Interactions. London: Sage.

Akyol, A. and Akehurst, G. (2003). An investigation of export performance variations related to corporate export market orientation. European Business Review, 15(1), 5-19.

Al-Aali, A., Lim, J.S., Khan, T., and Khurshid, M. (2013). Marketing capability and export performance: The moderating effect of export performance. South African Journal of Business Management, 44(3), 59-69.

Alvi, F.H. (2012). Rethinking the institutional contexts of emerging markets through metaphor analysis. Management International Review, 52(4), 519-539.

Andersén, J., Jansson, C. and Ljungkvist, T. (2015). Resource Immobility and Sustained Performance: A Systematic Assessment of How Immobility Has Been Considered in Empirical Resource-based Studies. International Journal of Management Reviews, 10.1111/ijmr.12067.

Andersson, U., Cuervo-Cazurra, A., and. Nielsen B.B. (2014). From the Editors: Explaining interaction effects within and across levels of analysis. Journal of International Business Studies, 45, 1063-1071.

Autio, E., Sapienza, H., and Almeida, J. (2000). Effects of age at entry, knowledge intensity, and imitability on international growth. Academy of Management Journal, 43(5), 909924.

Awuah, G. B. (2007). A professional services firm's competence development. Industrial Marketing Management, 36, 1068-1081.

Baker, T. and Nelson R.E. (2005). Creating something from nothing: resource construction through entrepreneurial bricolage Administrative Science Quarterly, 50(3), 329-366.

Baker, W.E. and Sinkula, J.M. (2009). The complementary effects of market orientation and entrepreneurial orientation on profitability in small businesses. Journal of Small Business Management, 47(4), 443-464.

Baker, W.E., and Sinkula J.M. (1999). The Synergistic Effect of Market Orientation and Learning Orientation on Organizational Performance Journal of the Academy of Marketing Science, 27(4), 411-427. 
Balabanis, G.I. and Katsikea, E.S. (2003). Being an entrepreneurial exporter: does it pay? International Business Review, 12(2), 233-252.

Baldauf, A., Cravens, D.W., and Wagner, U. (2000). Examining determinants of export performance in small open economies. Journal of World Business, 35(1), 61-79.

Barney, J. (1991), Firm resources and sustained competitive advantage. Journal of Management, 17(1), 99-121.

Barrales-Molina, V., Martínez-López, F.J. and Gázquez-Abad, J.C. (2014). Dynamic Marketing Capabilities: Toward an Integrative Framework. International Journal of Management Reviews, 16(4), 397-416.

Becker, T.E. (2005). Potential problems in the statistical control of variables in organizational research: a qualitative analysis with recommendations. Organizational Research Methods, 8(3), 274-289.

Bereiter, C., and Scardamalia, M. (1993). Surpassing ourselves. An inquiry into the nature and implications of expertise. Chicago: Open Court.

Bianchi, M. (2010). Credit constraints, entrepreneurial talent, and economic development. Small Business Economics, 34(1), 93-104.

Biemans, H., Nieuwenhuis, L., Poell, R., Mulder, M. and Wesselink, R. (2004). Competencebased VET in the Netherlands: background and pitfalls. Journal of Vocational Education and Training, 56(4), 523-38.

Birru, W.T. (2011). Horizontal inter-firm cooperation in Ethiopian small and medium enterprises: evidence from leather shoe manufacturing firms in Addis Ababa. Journal of Small Business and Enterprise Development, 18(4), 806-820.

Blesa, A., and Ripollés, M. (2008). The influence of marketing capabilities on economic international performance. International Marketing Review, 25(6), 651-673.

Boreham, N. (2004). A theory of collective competence: Challenging the neo-liberal individualisation of performance at work. British Journal of Educational Studies, $52(1), 5-17$.

Boso, N., Cadogan, J.W. and Story, V.M. (2012). Entrepreneurial orientation and market orientation as drivers of product innovation success: A study of exporters from a developing economy, International Small Business Journal, 31(1), 57-81.

Boyatzis, R.E. (1982). The competent manager: A model for effective performance. New York: Wiley. 
Brockman, B.K. and Morgan, R.M. (2003). The Role of Existing Knowledge in New Product Innovativeness and Performance. Decision Sciences, 34 (2), 385-419.

Brouthers, K.D., Nakos, G. and Dimitratos, P. (2015). SME Entrepreneurial Orientation, International Performance, and the Moderating Role of Strategic Alliances. Entrepreneurship Thoery and Practice, 39(5), 1161-1187.

Brouthers, L.E. and Nakos, G. (2005). The role of systematic international market selection on small firms' export performance. Journal of Small Business Management, 43(4), $363-381$.

Burpitt, W.J. and Rondinelli, D.A. (2000). Small firms' motivations for exporting: to earn and learn? Journal of Small Business Management, 38(4), 1-14.

Cadogan J.W., Sundqvist, S., Salminen, R.T., and Puumalainen K. (2005). Export marketing, inter-functional interactions, and performance consequences. Journal of the Academy of marketing science, 33 (4), 520-535.

Cadogan, J.W. and Cui, C.C. (2004). Chinese export agents' adoption of export marketoriented behaviours: Measurement and performance relationship. Journal of Asia Pacific Marketing, 3(2), 21-37.

Cadogan, J.W., Cui, C.C., and Li, E.K.Y. (2003). Export market-oriented behaviour and export performance: the moderating roles of competitive intensity and technological turbulence. International Marketing Review, 20(5), 493-513.

Cadogan, J.W., Diamantopoulos, A., and Siguaw, J.A. (2002). Export market-oriented activities: their antecedents and performance consequences. Journal of International Business Studies, 33(3), 615-626.

Cadogan, J.W., Kuivalainen, O., and Sundqvist, S. (2009). Export market-oriented behaviour and export performance: Quadratic and moderating effects under differing degrees of market dynamism and internationalization. Journal of International Marketing, 17(4), 71-89.

Calantone, R. and Knight, G. (2000).The critical role of product quality in the international performance of industrial firms. Industrial Marketing Management, 29(6), 493-506.

Cavusgil, T. and Zou S. (1994). Marketing Strategy-Performance Relationship: An Investigation of the Empirical Link in Export Market Ventures. Journal of Marketing, $58(1), 1-21$.

Cepeda, G. and Vera, D. (2007). Dynamic capabilities and operational capabilities: A knowledge management perspective. Journal of Business Research, 60(5), 426-437. 
Chandra, Y., Styles, C., and Wilkinson I. (2009). The Recognition of First Time International Entrepreneurial Opportunities. Evidence from Firms in Knowledge-Intensive Industries. International Marketing Review, 26(1), 30-61.

Chang, S.J., Van Witteloostuijn, A., and Lorraine, E. (2010). From the Editors: Common Method Variance in International Business Research. Journal of International Business Studies, 41(2), 178-184.

Cheetham, G., and Chivers, G. (1996). Towards a holistic model of professional competence. Journal of European Industrial Training, 20(5), 20-30.

Chetty, S.K., and Hamilton, R.T. (1993). Firm-level determinants of export performance: a meta-analysis. International Marketing Review, 10(3), 26-34.

Christoffersen, J. (2013). A Review of Antecedents of International Strategic Alliance Performance: Synthesized Evidence and New Directions for Core Constructs. International Journal of Management Reviews, 15(1), 66-85.

Clarke, J.E., Tamaschke, R., and Liesch, P.W. (2013). International Experience in International Business Research: A Conceptualization and Exploration of Key Themes. International Journal of Management Reviews, 15(3), 265-279.

Covin, J.G. and Miller, D. (2014). International Entrepreneurial Orientation: Conceptual Considerations, Research Themes, Measurement Issues, and Future Research Directions. Entrepreneurship Theory and Practice, 38(1), 11-44.

Covin, J.G. and Slevin, D.P. (1989). Strategic Management of Small Firms in Hostile and Benign Environments. Strategic Management Journal, 10(1), 75-87.

Czinkota, M.R. and. Ronkainen, I.A (2007). International Marketing (8 ed.). United States of America: Thomson, South-Western.

Dacin, M.T., Ventresca, M.J, and Beal, B.D. (1999). The embeddedness of organizations: Dialogue and Directions. Journal of Management, 25(3), 317-356.

Damijan, P.J and Kostevc, Č. (2006). Learning-by-exporting: continuous productivity improvements or capacity utilization effects? Evidence from Slovenian firms. Review of World Economics, 142(3), 599-614.

Day, G.S. (1994). The Capabilities of Market-Driven Organizations. Journal of Marketing, 58(4), 37-52.

De Clercq, D., Sapienza, H.J., Yavuz, R.I. and Zhou, L. (2012). Learning and knowledge in early internationalization research: past accomplishments and future directions. Journal of Business Venturing, 27(1), 143-165. 
De Vita, G., Tekaya, A. and Wang, C.L. (2011). The Many Faces of Asset Specificity: A Critical Review of Key Theoretical Perspectives. International Journal of Management Reviews, 13(4), 329-348.

Delery, J.E. (1998). Issues of fit in strategic human resource management: Implications for research. Human Resource Management Review, 8(3), 289-309.

Delgado-García, J.B., De Quevedo-Puente, E., and Mazagatos, V.B. (2015). How Affect Relates to Entrepreneurship: A Systematic Review of the Literature and Research Agenda. International Journal of Management Reviews, 17(2), 191-211.

Deligianni, I., Dimitratos, P., Petrou, A., and Aharoni, Y. (2015). Entrepreneurial Orientation and International Performance: The Moderating Effect of Decision-Making Rationality. Journal of Small Business Management, 54(2), 462-480.

Dimitratos, P., Lioukas, S., and Carter, S. (2004). The relationship between entrepreneurship and international performance: the importance of domestic environment. International Business Review, 13(1), 19-41.

Du Chatenier, E. (2009). Open innovation competence. Towards a competence profile for inter-organizational collaboration in innovation teams. $\mathrm{PhD}$ dissertation: Wageningen University.

Dunning, J.H., and Lundan, S.M. (2008). Institutions and the OLI paradigm of the multinational enterprise. Asia Pacific Journal of Management, 25(4), 573-594.

Eisenhardt, K.M. (1989). Building theories from case study research. Academy of Management Review, 14(4), 532-50.

Eisenhardt, K.M. and Martin J.A. (2000). Dynamic capabilities: what are they? Strategic Management Journal, 21(10-11), 1105-1121.

Ellis, P.D. (2007). Distance, dependence and diversity of markets: effects on market orientation. Journal of International Business Studies, 38(3), 374-386.

Eraut, M. (1994). Developing professional knowledge and competence. London: The Falmer Press.

Felzensztein, C., Ciravegna, L., Robson, P., and Amorós, J.E. (2015). Networks, Entrepreneurial Orientation, and Internationalization Scope: Evidence from Chilean Small and Medium Enterprises. Journal of Small Business Management, 53(S1), 145160. 
Fernández-Mesa, A. and Alegre, J. (2015). Entrepreneurial orientation and export intensity: Examining the interplay of organizational learning and innovation. International Business Review, 24(1), 148-156.

Francis, J. and Collins-Dodd, C. (2000). The impact of firms' export orientation on the export performance of high-tech small and medium-sized enterprises. Journal of International Marketing, 8(3), 84-103.

Gerschewski, S., Rose, E.L., and Lindsay, V.J (2015). Understanding the drivers of international performance for born global firms: An integrated perspective. Journal of World Business, 50(3), 558-575.

Global Entrepreneurship Monitor (2014). Global Report. Retrieved from http://www.gemconsortium.org/report

Gonczi, A. (1994). Developing a competent workforce. Adelaide: National Centre for Vocational Education Research.

Granovetter, M. (1985). Economic action and social structure: the problem of embeddedness. American Journal of Sociology, 91(3), 481-510.

Gries, T. and Naude, W. (2010). Entrepreneurship and structural economic transformation. Small Business Economics, 34(1), 13-29.

Guan, J. and Ma, N. (2003). Innovative capability and export performance of Chinese firms. Technovation, 23(9), 737-747.

Haahti, A., Madupu, V., Yavas, U., and Babakus, E. (2005). Cooperative strategy, knowledge intensity and export performance of small and medium sized enterprises. Journal of World Business, 40(2), 124-138.

Hadida, A.L., Tarvainen, W., and Rose, J. (2015). Organizational Improvisation: A Consolidating Review and Framework. International Journal of Management Reviews, 17(4), 437-459.

Hager, P., Gonczi, A., and Athanasou, J. (1994). General issues about assessment of competence. Assessment and Evaluation in Higher Education, 19(1), 3-16.

Hair, J.F., Anderson, R.E., Tatham, R.L., and Black, W.C. (1998). Multivariate Data Analysis, (5 $5^{\text {th }}$ Edition). Upper Saddle River, New Jersey: Prentice Hall.

Hakala, H. and Kohtamäki, M. (2011).Configurations of entrepreneurial customer- and technology orientation. Differences in learning and performance of software companies. International Journal of Entrepreneurial Behaviour and Research, 17(1), $64-81$ 
Hamel, G. and Prahalad, C.K. (1994). Competing for the future. Harvard Business School Press, Boston.

Hartsfield, S., Johansen, D. and Knight, G. (2008). Entrepreneurial orientation, strategy, and marketing capabilities in the performance of born-global firms. International Business: Research Teaching and Practice, 2(1), 12-38.

He, X. and Wei, Y. (2011). Linking market orientation to international market selection and international performance. International Business Review, 20(5), 535-546.

Helfat, C.E., and Peteraf M.A. (2003). The dynamic resource-based view: capability lifecycles. Strategic Management Journal, 24(10), 997-1010.

Heugens, P.P.M.A.R. (2006). Environmental Issue Management: Towards a Multi-Level Theory of Environmental Management Competence. Business Strategy and the Environment, 15(6), 363-376.

Hoang, B.P. (2015). Relationship of Export Market Orientation, Selected Export Strategy, and Export Performance: An Empirical Study. Global Journal of Management and Business Research, 15(6), 2249-4588.

Huang, S.K. and Wang, Y-L (2011). Entrepreneurial orientation, learning orientation, and innovation in small and medium enterprises. Procedia Social and Behavioural Sciences, 24, 563-570.

Hultman, M., Katsikeas, C.S., and Robson, M.J. (2011). Export Promotion Strategy and Performance: The Role of International Experience. Journal of International Marketing 19(4), 17-39.

Hutzschenreuter, T., Kleindienst, I. and Lange, S. (2015). The Concept of Distance in International Business Research: A Review and Research Agenda. International Journal of Management Reviews, DOI: 10.1111/ijmr.12065.

Ibeh, K.I.N. (2003). Toward a Contingency Framework of Export Entrepreneurship: Conceptualizations and Empirical Evidence. Small Business Economics, 20(1), 49-68.

Ibeh, K.I.N., and Young, Y. (2001). Exporting as an entrepreneurial act: an empirical study of Nigerian firms. European Journal of Marketing, 35(5/6), 566-586.

Javalgi, R.G. and Todd, P.R. (2011). Entrepreneurial orientation, management commitment, and human capital: the internationalization of SMEs in India. Journal of Business Research, 64(9), 1004-1010.

Jaworski B., Kohli, A.K., and Sahay, A. (2000). Market-driven versus driving markets. Journal of the Academy of Marketing Science, 28(1), 45-54. 
Jeong, I., Pae, J., and Zhou, D. (2006). Antecedents and consequences of the strategic orientations in new product development: The case of Chinese manufacturers. Industrial Marketing Management, 35, 348-358.

Jiang, K., Lepak, D.P., Han, K., Hong, Y., Kim, A., and Winkler A.L. (2012). Clarifying the construct of human resource systems: Relating human resource management to employee performance. Human Resource Management Review, 22(2), 73-85

Johns, G. (2006). The essential impact of context on organizational behaviour. Academy of Management Review, 31(2), 386-408.

Jones, M.V., Coviello, N. Tang, Y.K. (2011). International entrepreneurship research (19892009): a domain ontology and thematic analysis. Journal of Business Venturing, 26(6), $632-659$.

Julian. C.C., Mohamad, O., Ahmed, Z.U. and Sefnedi, S. (2014). The Market OrientationPerformance Relationship: The Empirical Link in Export Ventures. Thunderbird International Business Review, 56(1), 97-110.

Julien, P.A. and Ramangalahy, C. (2003). Competitive strategy and performance of exporting SMEs: an empirical investigation of the impact of their export information search and competencies. Entrepreneurship Theory and Practice, 27(3), 227-245.

Kabagambe, L.B., Ogutu, M., and Munyoki, J.M. (2012). Firm competencies and export performance: a study of small and medium manufacturing exporters in Uganda. European Scientific Journal 8(12), 48-67.

Kaleka, A. (2012). Studying resource and capability effects on export venture performance. Journal of World Business 47(1), 93-105.

Karbasioun, M., Mulder, M., and Biemans, H. (2007). Towards a job competency profile for agricultural extension instructors: A survey of views of experts. Human Resource Development International, 10(2), 137-151.

Ketchen, D.J., Jr., Hult, G.T.M., and Slater, S.F. (2007). Toward greater understanding of market orientation and the resource-based view. Strategic Management Journal, 28(9), 961-964.

Kimhi, A. (2009). Entrepreneurship and income inequality in southern Ethiopia. Small Business Economics 34(1), 81-91.

King, D.R., Slotegraaf, R.J., and Kesner, I. (2008). Performance Implications of Firm Resource Interactions in the Acquisition of R\&D-Intensive Firms. Organization Science 19(2), 327-340. 
Knight, G. and Daekwan, K. (2009). International business competence and the contemporary firm. Journal of International Business Studies, 40(2), 255-264.

Knight, G., and Cavusgil, S.T. (2004). Innovation, organizational capabilities, and the bornglobal firm. Journal of International Business Studies, 35(2), 124-141.

Kohli, A.K. and Jaworski, B.J. (1990). Market orientation: the construct, research propositions, and managerial implications. Journal of Marketing, 54, 1-18.

Korneliussen, T. and Blasius, J. (2008). The effects of cultural distance, Free Trade Agreements, and Protectionism on perceived export barriers. Journal of Global Marketing, 21(3), 217-230.

Kropp, F., Lindsay, N.J. and Shoham, A. (2006). Entrepreneurial, market, and learning orientations and international entrepreneurial business venture performance in South African firms. International Marketing Review, 23(5), 504-523.

Kuivalainen, O., K. Puumalainen, S. Sintonen, and K. Kylaheiko, (2010). Organizational Capabilities and Internationalization of The Small and Medium-Sized Information and Communications Technology firms. International Journal Entrepreneurship 8(2), 135-155.

Kuivalainen, O., Sundqvist, S. and Servais, P. (2007). Firms' degree of born-globalness, international entrepreneurial orientation and export performance. Journal of World Business, 42, 253-267.

Lages, L.F, Silva, G., and Styles, C. (2009). Relationship capabilities, quality, and innovation as determinants of EP. Journal of International Marketing, 17(4), 47-70.

Lages, L.F. and Lages, C.R. (2004). The STEP Scale: A Measure of Short-Term Export Performance Improvement. Journal of International Marketing, 12(1), 36-56.

Laghzaoui, S. (2011). SMEs' internationalization: an analysis with the concept of resources and competencies. Journal of Innovation Economics and Management, 1(7), 181-196.

Lampel, J., Honig, B., and Drori, I. (2014). Organizational ingenuity: concept, processes and strategies. Organization Studies, 35(4), 465-482.

Lans, T. (2009). Entrepreneurial competence in agriculture. Identification, development and the role of the work environment. PhD dissertation: Wageningen University.

Le Deist, F.D., and J. Winterton (2005). What is competence? Human Resource Development International, 8(1), 27-46. 
Leonidou, L.C. (1998). Organizational determinants of exporting: conceptual, methodological, and empirical insights. (Challenges and solutions for international marketing management) Management International Review, 38(SI), 7-52.

Leonidou, L.C., Katsikeas, C.S. and Samiee, S. (2002). Marketing Strategy Determinants of Export Performance: A Meta-analysis. Journal of Business Research ,55(1), 51-67.

Li, Y., Sun, Y., and Liu, Y. (2006). An empirical study of SOEs' market orientation in transitional China. Asia Pacific Journal Management, 23(1), 93-113.

Li, Y., Wei, Z., and Liu, Y. (2010). Strategic orientations, knowledge acquisition, and firm performance: The perspective of the vendor in cross-border outsourcing. Journal of Management Studies, 47(8), 1457-1482.

Ling-yee, L. and Ogunmokun, G.O. (2001). The influence of inter-firm relational capabilities on export advantage and performance: an empirical analysis. International Business Review, 10(4), 399-420.

Lisboa, A., Skarmeas, D., and Lages, C. (2011). Entrepreneurial orientation, exploitative and explorative capabilities, and performance outcomes in export markets: a resource based approach. Industrial Marketing Management, 40(8), 1274-1284.

Liu B., Fu Z. (2011). Relationship between Strategic Orientation and Organizational Performance in Born Global: A Critical Review, International Journal of Business and Management, 6(3), 109-115

Lukas, B., Tan, J., and Hult, G. (2001). Strategic fit in transitional economies: The case of China's electronics industry. Journal of Management, 27(4), 409-429.

Lumpkin, G.T., and G.G. Dess (1996). Clarifying the Entrepreneurial Orientation Construct and Linking It to Performance. Academy of Management Review 21(1), 135- 172.

López-Duarte, C. Vidal-Suárez, M.M. and González-Dĺaz, B. (2015). International Business and National Culture: A Literature Review and Research Agenda. International Journal of Management Reviews, 00, pp. 1-20.

Macpherson, A., Herbane, B. and Jones, O. (2015). Developing dynamic capabilities through resource accretion: expanding the entrepreneurial solution space. Entrepreneurship and Regional Development, 27(5/6), 259-291.

Mainela, T., Puhakka, V. and Servais, P. (2014). The Concept of International Opportunity in International Entrepreneurship: A Review and a Research Agenda. International Journal of Management Reviews, 16(1), 105-129. 
Manolova, T., Manev, I. M. and Gyoshev, B. S. (2010). In good company: The role of personal and inter-firm networks for new venture internationalization in a transition economy. Journal of World Business, 45(3), 257-265.

Martins, P. and Yang, Y. (2009). The impact of exporting on firm productivity: a metaanalysis of the learning-by-exporting hypothesis. Review of World Economics, 145, $431-445$.

Mavrogiannis, M., Bourlakis, M.A., Dawson, P.J. and Ness, M.R. (2008). Assessing export performance in the Greek food and beverage industry: an integrated structural equation model approach. British Food Journal, 110(7), 638-654.

McClelland, D.C. (1973) Testing for Competence Rather Than for 'Intelligence'. American Psychologist, 28(1), 423-447.

McDougall, P.P., Oviatt, B.M ,and Shrader ,R.C. (2003). A comparison of international and domestic new ventures", Journal of International Entrepreneurship, 1(1), 59-82.

McGrath, R.G., MacMillan, I.C., and Venkataraman, S. (1995). Defining and developing competence: a strategic process paradigm. Strategic Management Journal, 16, 1995, 251-275.

Miesenböck, K.J. (1988). Small businesses and exporting: a literature review. International Small Business Journal, 6(2), 42-61.

Miocevic, D. and Crnjak-Karanovic, B. (2011). Cognitive and information-based capabilities in the internationalization of small and medium-sized enterprises: the case of Croatian exporters. Journal of Small Business Management, 49(4), 537-557.

Moen, Ø., Heggeseth, A.G,. and Lome, O. (2015). The Positive Effect of Motivation and International Orientation on SME Growth” Journal of Small Business Management, 119. doi: $10.1111 /$ jsbm.12163.

Montealegre, R. (2002). A process model of capability development: Lessons from electronic commerce strategy at bolsa de valores de guayaquil. Organizational Science, 13(5), $514-531$.

Morgan, N.A., Kaleka, A. and Katsikeas, C.S. (2004). Antecedents of export venture performance: a theoretical model and empirical assessment. Journal of Marketing 68(1), 90-108.

Mort, G.S. and Weerawardena, J. (2006). Networking capability and international entrepreneurship how networks function in Australian born global firms. International Marketing Review, 23(5), 549-572. 
Mulder, M. (2007). Competence: the essence and use of the concept in ICVT. European Journal of Vocational Training, 40(5), 5-22.

Mulder, M. (2014). Conceptions of Professional Competence. In: S. Billett, C. Harteis, and H. Gruber (Eds.), International handbook on research into professional and practicebased learning. Dordrecht: Springer, 107-137.

Murray, J., Gao, G.Y,. and Kotabe, M. (2007). Assessing measurement invariance of export market orientation: A study of Chinese and non-Chinese firms in China. Journal of International Marketing, 15(4), 41-62.

Murray, J.Y., Gao, G.Y., and Kotabe, M. (2011). Market Orientation and Performance of Export Ventures: The Process through Marketing Capabilities and Competitive Advantages. Journal of the Academy of Marketing Science ,39(2), 252-269.

Nalcaci, G. and Yagci, M.I. (2014). The effects of marketing capabilities on export performance using resource-based view: assessment on manufacturing companies. Procedia - Social and Behavioural Sciences, 148, 671-679.

Narver, J.C. and Slater, S.F. (1990). The effect of a market orientation on business profitability. Journal of Marketing, 54(4), 20-34.

Navarro, A., Losada, F., Ruzo, E., and Diez, J.A., (2010). Implications of perceived competitive advantages, adaptation of marketing tactics and export commitment on export performance. Journal of World Business, 45, 49-58.

Navarro-García, A., Arenas-Gaitán, J. and Rondán-Cataluña, J. (2014). External environment and the moderating role of export market orientation. Journal of Business Research, 67(5), 740-745.

Neter, J., Wasserman, W., and Kutner, M.H. (1985). Applied linear statistical models (2nd ed.). Homewood, IL: Richard D. Irwin, Inc.

Newbert, S.L., Gopalakrishnan, S., and. Kirchhoff., B.A (2008). Looking Beyond Resources: Exploring the Importance of Entrepreneurship to Firm-Level Competitive Advantage in Technologically Intensive Industries. Technovation 28 (1), 6-19.

Niesten, E. and Jolink, A. (2015). The Impact of Alliance Management Capabilities on Alliance Attributes and Performance: A Literature Review. International Journal of Management Reviews, 17(1), 69-100.

Nummela, N., Saarenketo, S., and Puumalainen, K. (2004). A Global Mindset - A Prerequisite for Successful Internationalization? Canadian Journal of Administrative Sciences, 21, 51-64. 
O'Cass, A. and Weerawardena, J. (2009). Examining the role of international entrepreneurship, innovation and international market performance in SME internationalization. European Journal of Marketing, 43(11/12), 1325-1348.

Okhmatovskiy, I. (2010). Performance Implications of Ties to the Government and SOEs: A Political Embeddedness Perspective. Journal of Management Studies, 47(6), 10201047.

Okpara, J.O. (2009). Entrepreneurial orientation and export performance: evidence from an emerging economy. International Review of Business Research Papers, 5, 195-211.

Oviatt, B. and McDougall, P. (2005). Defining international entrepreneurship and modelling the speed of internationalization. Entrepreneurship Theory and Practice, 29(5), 537548 .

Papadopoulos, N., and Martín M.O. (2010). Toward a model of the relationship between internationalization and export performance. International Business Review, 19, 388406.

Peng, M.W., Wang, D., and Jiang, Y. (2008). An institution-based view of international business strategy: A focus on emerging economies. Journal of International Business Studies, 39(5), 920-936.

Perri, A. and Peruffo, E. (2014). Knowledge Spillovers from FDI: A Critical Review from the International Business Perspective. International Journal of Management Reviews, doi: $10.1111 /$ ijmr.12054

Porter, M. (1980) Competitive Strategy. New York: The Free Press

Prahalad, C.K. and Hamel, G. (1990). The core competence of the corporation. Harvard Business Review, 68(3), 79-91.

Prasad, V. K., Ramamurthy, K. and Naidu, G. M. (2001). The influence of internetmarketing integration on marketing competencies and export performance. Journal of International Marketing, 9(4), 82-110.

Priem, R.L., and Butler, J.E. (2001). Is the resource-based "view" a useful perspective for strategic management research? Academy of Management Review, 26(1), 22-40.

Racela, O.C., Chaikittisilpa, C., and Thoumrungroje, A. (2007). Market orientation, international business relationships and perceived export performance. International Marketing Review, 24(2), 144-163. 
Real, J.C., Roldán, J.L. and Leal, A. (2012) From entrepreneurial orientation and learning orientation to business performance: analysing the mediating role of organizational learning and the moderating effects of organizational size. British Journal of Management, 25(2), 186-208.

Ren, H., Gray, B. and Kim, K. (2009). Performance of international joint ventures: what factors really make a difference and how? Journal of Management, 35(3), 805-832.

Reuber, A.R. and Fischer, E. (1997). The influence of the management team's international experience on the internationalization behaviours of SMEs. Journal of International Business Studies, 28(4), 807-25.

Rhee, J., Park, T. and Lee, D.H. (2009). Drivers of Innovativeness and Performance for Innovative SMEs in South Korea: Mediation of Learning Orientation. Technovation, $30(1), 65-75$.

Rialp, A., Rialp, J. and Knigh A. (2004). The phenomenon of early internationalizing firms: what do we know after a decade (1993-2003) of scientific inquiry? International Business Review, 14(2), 147-166.

Ritter, T. and Gemünden, H.G. (2003). Network competence: its impact on innovation success and its antecedents. Journal of Business Research, 56(9), 745-55.

Rodriguez, C.M, Wise, J.A. and Martinez, C.R. (2013). Strategic capabilities in exporting: an examination of the performance of Mexican firms. Management Decision, 51(8), $1643-1663$.

Rose, G.M. and Shoham, A. (2002). Export performance and market orientation: establishing an empirical link. Journal of Business Research, 55(3), 217-225.

Sanchez, R. and Heene, A. (2004). The New Strategic Management: Organizations, Competition and Competence. John Wiley and Sons.

Santos-Vijande, M., Sanzo-Pirez, M., Plvarez-Gonzalez, L., and Casielles, R.V. (2005) Organizational learning and market orientation: interface and effects on performance. Industrial Marketing Management, 34(3), 187-202.

Scott, W. R. (2008). Institutions and organizations: Ideas and interests. Thousand Oaks, CA: Sage Publications.

Senge, P. M. (1990). The Fifth Discipline: The Art and Practice of the Learning Organization. New York: Doubleday. 
Shamsuddoha, A.K., Ali, M.Y. and Ndubisi, N.O. (2009). Impact of government export assistance on internationalization of SMEs from developing nations Journal of Enterprise Information Management, 22(4), 408-422.

Shavazi, E.T, Moshabaki, A., K. Hosseini, S.H., and Kordnaeij, A. (2015). Designing Export Performance Model based on Organizational Orientations. Iranian Journal of Management Studies, 8(2), 265-285.

Shepherd, N.G. and Rudd, J M. (2014). The Influence of Context on the Strategic DecisionMaking Process: A Review of the Literature. International Journal of Management Reviews, 16(3), 340-364.

Short, J.C., Ketchen, D.J., Schook, C.L. and Ireland, R.D., (2010). The concept of "opportunity" in entrepreneurship research: past accomplishments and future challenges. Journal of Management, 36(1), 40-65.

Sigglekow, N. (2002). Misperceiving interactions among complements and substitutes: Organizational consequences. Management Science 48(7), 900-916.

Singh, H., and Mahmood, R. (2013). Determining the Effect of Export Market Orientation on Export Performance of Small and Medium Enterprises in Malaysia: An Exploratory Study. Advances in Management and Applied Economics, 3(6), 223-232.

Sinkula, J.M., Baker, W.E., and Noordeweir, T. (1997). A framework for market-based organisational learning: Linking values, knowledge, and behaviour. Journal of the Academy of Marketing Science, 25(4), 305-318.

Sirmon, D.G., Hitt, M.A., and Ireland, R.D. (2007). Managing firm resources in dynamic environments to create value: Looking inside the black box. Academy of Management Journal, 32(1), 273-292.

Slater, S.F. and Narver, J.C. (1994) Does competitive environment moderate the market orientation-performance relationship? Journal of Marketing, 58 (1),46-55.

Slater, S.F., and Narver, J.C. (1995). Market orientation and the learning organization. Journal of Marketing, 59(3), 63-74.

Slater, S.F., Olson, E.M., and Sørensen H.E., (2012). Creating and exploiting market knowledge assets", Journal of Business Strategy 33(4), 18 - 27.

Sørensen, H.E. and Madsen, T.K. (2012). Strategic orientations and export market success of manufacturing firms. The role of market portfolio diversity. International Marketing Review, 29(4), 424-441. 
Souchon, A.L., Sy-Changco, J.A., and Dewsnap, B. (2012). Learning orientation in export functions: impact on export growth. International Marketing Review, 29(2), 175 - 202

Sousa, C. M. P., F. J. Martínez-López, and F. Coelho, (2008). The determinants of export performance: a review of the research in the literature between 1998 and 2005. International Journal of Management Reviews, 10(4), 343-374.

Swoboda, B., and E. Olejnik (2016). Linking Processes and Dynamic Capabilities of International SMEs: The Mediating Effect of International Entrepreneurial Orientation. Journal of Small Business Management, 54(1), 139-161.

Tang, Y.K. (2011). The Influence of networking on the internationalization of SMEs: evidence from internationalized Chinese firms. International Small Business Journal, 29(4), 374-398.

Tanriverdi, H., and Venkatraman, N. (2005). Knowledge relatedness and the performance of multibusiness firms. Strategic Management Journal 26(2), 97-119.

Teece, D.J., Pisano, G., and Shuen, A. (1997). Dynamic Capabilities and Strategic Management. Strategic Management Journal 18(7), 509-533.

Tesfom, G., and C. Lutz (2006). “A classification of export marketing problems of small and medium sized manufacturing firms in developing countries", International Journal of Emerging Markets 1(3), 262-281.

Toften, K. (2005). The influence of export information use on export knowledge and performance: some empirical evidence. Marketing Intelligence and Planning, 23(2), 200-219.

Ural, T. (2009). The effects of relationship quality on export performance: a classification of small and medium-sized Turkish exporting firms operating in single export-market ventures. European Journal of Marketing, 43(1/2), 139-168.

Van de Ven, A.H. (2004). The Context-Specific Nature of Competence and Corporate Development. Asia Pacific Journal of Management 21(1), 123-147

Vogel, R. and Güttel, W.H. (2013). The Dynamic Capability View in Strategic Management: A Bibliometric Review. International Journal of Management Reviews, 15(4), 426446.

Voss, G.B., Godfrey, A., and Seiders, K. (2010). How Complementarity and Substitution Alter the Customer Satisfaction-Repurchase Link. Journal of Marketing, 74(6), 111127. 
Wang, C., Hong, J., Kafouros, M., and Boateng, A. (2012). What drives outward FDI of Chinese firms? Testing the explanatory power of three theoretical frameworks. International Business Review, 21(3), 426-438.

Wang, C.L. (2008). Entrepreneurial Orientation, Learning Orientation, and Firm Performance. Entrepreneurship Theory and Practice., 32 (4), 635-657.

Wang, C.L., Hult, G.T., Ketchen Jr, D.J., Ahmed, P.K. (2009). Knowledge management orientation, market orientation, and firm performance: An integration and empirical examination. Journal of Strategic Marketing, 17(2), 99-122.

Weerawardena, J., Mort, G.S., Liesch, P.W., and Knight, G. (2007). Conceptualizing accelerated internationalization in the global firm: A dynamic capabilities perspective. Journal of World Business, 42(3), 294-306.

Wesselink, R., De Jong, C. and Biemans, H.J.A. (2010). Aspects of competence-based education as footholds to improve the connectivity between learning in school and in the workplace. Vocations and Learning, 3(1), 19-38.

White, R. (1959). Motivation reconsidered: The concept of competence. Psychological Review, 66(5), 297-333.

Winter, S.G. (2003). Understanding dynamic capabilities. Strategic Management Journal, 24(10), 991-995.

World Bank Group (2014). Third Ethiopia Economic Update: Strengthening export performance through Improved Competitiveness. Retrieved from https://openknowledge.worldbank.org/handle/10986/20026

Wu, F., Sinkovics, R., Cavusgil, S.T., and Roath, A. (2007). Overcoming export manufacturers' dilemma in international expansion. Journal of International Business Studies, 38(2), 283-302.

Yeoh, P.L. (2000). Information acquisition activities: a study of global start-up exporting companies. Journal of International Marketing, 8(3), 36-60.

Yi, J., Wang, C. and Kafouros, M. (2013). The effects of innovative capabilities on exporting: Do institutional forces matter? International Business Review, 222), 392-406.

Yli-Renko, H., Autio, E. and Sapienza, H. J. (2001). Social capital, knowledge acquisition, and knowledge exploitation in young technology-based firms. Strategic Management Journal, 22(6/7), 587-613.

Zahra, S.A. (2005). A theory of international new ventures: a decade of research. Journal of International Business Studies, 36(1), 20-28. 
Zahra, S., and George, G. (2002). International entrepreneurship: the current status of the field and future research agenda, in: Hitt, M.A., Ireland, R.D., Sexton, D., Camp, M. (Eds.), Strategic Entrepreneurship: Creating an Integrated Mindset. Blackwell Publishers, Malden, MA.

Zahra, S., Ireland, R.D., and Hitt, M. (2000). International expansion by new venture firms: international diversity, mode of market entry, technological learning, and performance. Academy of Management Journal, 43(5), 925-950.

Zahra, S.A., Korri, J.S. and Yu, J.F. (2005). Cognition and international entrepreneurship: implications for research on international opportunity recognition and exploitation. International Business Review 14(2), 129-146.

Zhang, J. and Zhu, M. (2015). Market orientation, product innovation and export performance: evidence from Chinese manufacturers. Journal of Strategic Marketing, DOI: 10.1080/0965254X.2015.1052538.

Zhou, K. Z. and Li, C. B. (2007). How does strategic orientation matter in Chinese firms? Asia Pacific Journal of Management, 24, 447-466.

Zhou, K.Z., Gao, G.Y., Yang, Z.L., and Zhou, N. (2005a). Developing strategic orientation in China: Antecedents and consequences of market and innovation orientations. Journal of Business Research, 58, 1049-1058.

Zhou, L. (2007). The effects of entrepreneurial proclivity and foreign market knowledge on early internationalization. Journal of World Business, 42(3), 281-293.

Zhou, L.X., Wu, W.P., and Luo, X.M. (2007). Internationalization and the performance of born-global SMEs: the mediating role of social networks. Journal of International Business Studies, 38(4), 673-690.

Zou, S. and Cavusgil, S. T. (2002). The GMS: a broad conceptualization of global marketing strategy and its effect on firm performance. Journal of Marketing, 66(4), 40-56.

Zou, S. and Stan, S. (1998). The determinants of export performance: a review of the empirical literature between 1987 and 1997. International Marketing Review, 15(5), $333-356$.

Zou, S., Fang, E. and Zhao, S. (2003). The effect of export marketing capabilities on export performance: an investigation of Chinese exporters. Journal of International Marketing, 11(4), 32-55. 


\section{SUMMARY}

\section{Introduction}

With the expansion of globalization and economic integration among countries, exporting has become an important internationalization strategy for firms and national economies, especially for developing countries, where opportunities for domestic market growth are limited (Boso et al., 2012). Thus, a better understanding of the determinant factors for export performance of the firm is of great importance for firms' success and expansion in the export markets (Johansen and Knight, 2010; Knight and Kim, 2009). In this context, international business competence is essential intangible strategic resource that engenders export performance of the firm (Knight and Kim, 2009). This thesis studies the relationships between international business competence and export performance in a developing country context

\section{Problem and objective of the study}

Previous empirical studies established a persuasive link between different sets of IBC and export performance; consequently, IBC has shown to explain the observed differences in export performance among firms (e.g., Brouthers et al., 2015; Kabagambe et al., 2012; Knight and Kim, 2009). However, despite the number of academic exchanges on IBCs that underpin a firm's EP is growing, studies have commonly focused on a specific set of such competencies; thereby disregarding other possible competence domains on the one hand and contextual factors on the other hand. As a result there is no comprehensive framework for studying how IBC relates to export performance and contextual factors. More importantly, the majority of the extant studies are based on Western and advanced economies datasets; thus, an understanding of the relationship between IBC and export performance in developing economies' contexts is still lacking (Boso et al., 2012; Kabagambe et al., 2012; Okpara, 2009). With the claim that contextual embeddedness matters in interpreting how different competencies play out to influence performance (Mulder, 2014; Okhmatovskiy, 2010), more study and data is needed from the context of developing economies to broaden knowledge on the subject (Boso et al., 2012; Kabagambe et al., 2012. In this thesis, we sought to shed some light on this issue by providing evidence from Ethiopia. 
This thesis has three key objectives. The first objective is to synthesize the literature in order to identify IBCs and associated factors that are linked with export performance and develop a tentative framework for analysing the relationship between IBC and export performance. The second objective is to validate and expand the literature-based IBC framework in the specific context of Ethiopia, identify those forms of IBC, which are considered most important for Ethiopian exporting firms, and develop IBC framework for use in Ethiopia. The reason for this objective is because the importance of each set of IBCs depends on the specific situation in which it is utilized (Lisboa et al., 2011; Knight and Kim, 2009). The third objective is to investigate how the identified IBCs and their interactions relate to export performance and to explore the role of learning-orientated values of the firms in that relationship. This objective is because in accordance with the competence-based strategic management theory a firm's competencies are interdependent and likely to interact to influence the firm's performance (Sanchez and Heene 2004). Also, competencies are learning construct that can be improved through learning efforts and experiences (Prahalad and Hamel,1990); thus the performance impact of a firm's competencies and their interactions can be contingent on the level of its learning-oriented values (Huang and Wang 2011; Newbert et al., 2008). The first aim was achieved by performing a literature study; the second aim was achieved by conducting an exploratory study (experts' interview), and the third aim was achieved by conducting a quantitative study based on data collected from exporting firms in different economic sectors in Ethiopia.

\section{Overview of the studies}

The first chapter sets the stage for the thesis. It describes the context of the study, introduces key concepts and theoretical foundations of the research topic, and outlines problem statement, research questions and overview of the thesis.

Chapter 2 provides an overview of this field of research, synthesizes the findings, proposes a tentative framework for studying the IBC-export performance relationship, and suggests areas for the subsequent empirical studies. The review of the literature was based on specific inclusion criteria, and input received from a total of 58 articles, which were selected for the systematic analysis. The results revealed that more than two-third of the articles reviewed were published during the last decade and over 39 percent have appeared in the last five years; suggesting that scientific interest into aspects of IBC and corresponding performance outcomes is a growth area from a research standpoint. The study also revealed that the 
majority of studies are based on datasets of advanced and emerging economies; SMEs, bornglobal entrepreneurial firms, and new ventures are firms studied most; and Resource Based View (RBV) of the firm is a theoretical paradigm used by most recent publications to explain IBC as an important internal firm-specific resource that leads to success in export. The synthesis of the review of IBC leading to successful export performance resulted in eight sets of competencies which, based on the substantive conceptual meanings of the underlying constructs examined in the studies, can be categorized into three inter-related domains: Orientation-based, Marketing/sales-based, and Networking-based competencies.

Chapter 3 validates and expands the IBCs framework reported in Chapter 2 using an experts' interview. The results confirm the importance of the IBCs, which were identified from the literature and expand with three additional competencies, which didn't emerge from the literature. International orientation, export market orientation, and international entrepreneurial orientation are identified as most important IBCs for Ethiopian exporting firms that are characterized by mostly SMEs, poor local business conditions, resource scarcity, and little international experience. Furthermore, contextual variables - market dynamism, competitive intensity, and size and export experience of the firm - are identified as factors determining in what ways and to what extent the identified IBCs affect export performance of the firm.

Chapter 4 focuses on the relationships between export performance and international business competencies, which were identified as most important for Ethiopian exporting firms in Chapter 3 and their interactions. Based on data from on-site structured interviews with 159 owners and managers of exporting firms, we found the direct relationships between each of the competencies and export performance, whilst we found mixed results of the effects of interactions between the competencies. While the findings suggest that IBCs enhance export performance, an attempt to simply report the individual impact of these IBCs by ignoring their interactive effects provides an incomplete and simplistic picture of determinants of export performance, on one hand, and an over-generalization of their benefits on the other hand.

Chapter 5 extends the results presented in Chapter 4 and explores the role of organizational learning orientation in strengthening the performance impact of the interaction between the competencies. We found evidence that indicate higher level of organizational learning orientation helps the firm benefit from its international orientation when it has lower level of 
export market orientation and higher levels of international entrepreneurial orientation. For firms operating in the resource-constrained environments, which are not able to invest equally on all the required competencies, higher level of learning-orientated values enable the firms evaluate outside opportunities more favourably than do firms without such values. More importantly, firms with higher levels of organizational learning orientation benefit more from their critical appraisal and the ability to make sense of export market intelligence rather than the amount of efforts they made on gathering, disseminating and responding such intelligence.

\section{Main conclusions}

Overall, the results reported in this thesis support the notion that IBCs are important strategic resources of the firm that provide the owning internationalizing firms with substantial competitive advantages in the foreign markets and subsequently, successful export performance. However, this research shows that IBC comprises a number of specific competence domains; hence, in order to strengthen the said competitive advantages and achieve enhanced export performance, firms need to have suitable IBCs to the context in which they are operating. Furthermore, evidence was found that IBCs influence each other's' effects. It was also found that organizational learning orientation strengthens the effects of the various interactions between IBCs. Firms, particularly those operating in resourceconstrained environments need to develop the required competencies in their context to increase export performance. Nevertheless, if competence development would be solely based on the direct relationships between the competencies and export performance, results may be suboptimal. Thus, they need to maintain the optimal balance between their competencies on the one hand, and establish and maintain higher levels of organizational learning orientations on the other hand. The results also have implication for research that ignoring the interaction between different competencies and not including an organizational learning orientation in the examination provide an incomplete and simplistic picture of the relationship between international business competencies and export performance. 


\section{APPENDIX}

\section{Questionnaire Items (Chapter 4 And 5)}

\section{Export performance}

Please state below your opinion about the success of your export activities in the last three years measured in financial and strategic terms on scale: 1 = "strongly disagree" and 7 = "strongly agree"

\section{Financial export performance}

1. We are satisfied with the export turnover achieved through our export activities.

2. We are satisfied with the export market share achieved through our export activities.

3. We are satisfied with the export growth achieved in recent years.

4. We are satisfied with the export profit achieved through our export activities.

\section{Strategic export performance}

1. Exporting has contributed to the overall quality of the firm's management.

2. Exporting has enhanced the relative position of the firm in our home market by making it more competitive.

3. Exporting has helped our firm in gaining access to new technology.

4. Our firm is better able to build brand awareness by exporting.

5. Exporting has helped our firm in reducing market dependency.

6. Exporting has helped our firm in improving response to competitive pressure.

\section{International orientation (IO)}

With regard to your company situation please indicate perceived possession of IOC on scale: $1=$ "strongly disagree" and 7 = "strongly agree"

1. Top management tends to see the world, instead of just the Ethiopia, as our firm's marketplace.

2. The prevailing organizational culture at our firm (management's collective value system) is conducive to active exploration of new export opportunities.

3. Management continuously communicates its mission to succeed in international markets to firm employees.

4. Management develops human and other resources for achieving our goals in international markets.

5. Top management is willing to go to great lengths to make our products succeed in foreign markets.

6. Vision and drive of top management are important in our decision to enter foreign markets. ${ }^{\mathbf{b}}$

\section{Export market orientation (EMO)}

With regard to your company situation please indicate perceived possession of EMO on scale: $1=$ "strongly disagree" and 7 = "strongly agree"

1. We periodically review the likely effect of changes in our export environment (e.g., technology and regulation).

2. In this company, we generate a lot of information concerning trends (e.g., regulation, technological developments, politics, and economy) in our export markets.

\begin{tabular}{|l|l|l|l|l|l|l|l|} 
& 1 & 2 & 3 & 4 & 5 & 6 & 7 \\
\hline in & & & & & & & \\
\hline int & & & & & & & \\
\hline ls & & & & & & & \\
\hline
\end{tabular}


3. We generate a lot of information in order to understand the forces that influence our overseas customers' need and preferences.

4. We constantly monitor our level of commitment and orientation to serving export customer needs. ${ }^{\mathbf{c}}$

5. Information about our export competitors' activities often reaches relevant personnel too late to be of any use. ${ }^{\text {a }}$

6. Too much information concerning our export competitors is discarded before it reaches decision makers. ${ }^{\text {a }}$

7. Information that can influence the way we serve our export customers takes forever to reach export personnel. ${ }^{\text {a }}$

8. Important information concerning export market trends (regulation, technology) is often discarded as it makes its way along the communication chain. ${ }^{\text {a }}$

9. If a major competitor were to launch an intensive campaign targeted at our foreign customers, we would implement a response immediately.

10. We are quick to respond to significant changes in our competitors' price structures in foreign markets. ${ }^{\mathrm{c}}$

11. Several departments get together periodically to plan a response to changes taking place in our export environment. ${ }^{\mathbf{b}}$

12. We rapidly respond to competitive actions that threaten us in our export markets.

13. When we find out that our export customers are unhappy with the quality of our product, we take corrective action immediately.

14. When we find that our export customers would like us to modify a product, the departments involved make concerted efforts to do so. ${ }^{\mathrm{c}}$

\section{International entrepreneurial orientation (IEO)}

With regard to your company situation please indicate perceived possession on scale: 1 = "strongly disagree" and 7 = "strongly agree"

\begin{tabular}{|c|c|c|c|c|c|c|c|}
\hline & 1 & 2 & 3 & 4 & 5 & 6 & \\
\hline $\begin{array}{l}\text { 1. In the design and manufacture of our product, we employ some of the most } \\
\text { skilled specialists in the industry. }\end{array}$ & & & & & & & \\
\hline $\begin{array}{l}\text { 2. Compared with local competitors, we're often first to introduce product } \\
\text { innovations or new operating approaches in international markets. }{ }^{\mathbf{c}}\end{array}$ & & & & & & & \\
\hline $\begin{array}{l}\text { 3. Over the past } 3 \text { years, our firm has marketed very many products in foreign } \\
\text { markets. }\end{array}$ & & & & & & & \\
\hline $\begin{array}{l}\text { 4. Our top management always encourages new product ideas or operating } \\
\text { approach for international markets. }{ }^{\text {c }} \text {. }\end{array}$ & & & & & & & \\
\hline 5. Our top managers have regularly attended local/foreign trade fairs. ${ }^{\mathrm{c}}$ & & & & & & & \\
\hline $\begin{array}{l}\text { 6. Our top management actively seeks contact with suppliers or clients in } \\
\text { international markets. }\end{array}$ & & & & & & & \\
\hline 7. Our top managers have usually spent some time abroad to visit. ${ }^{b}$ & & & & & & & \\
\hline 8. Our top management regularly monitors the trend of export markets. ${ }^{\mathrm{c}}$ & & & & & & & \\
\hline 9. Our top management continuously searches for new export markets. & & & & & & & \\
\hline 10. Our top management focuses more on opportunities than risks abroad. & & & & & & & \\
\hline $\begin{array}{l}\text { 11. When confronted with decisions about exporting or other international } \\
\text { operations, our top management is always tolerant to potential risks. }\end{array}$ & & & & & & & \\
\hline 12. Our top managers have shared vision towards the risks of foreign markets. ${ }^{\mathbf{c}}$ & & & & & & & \\
\hline 13. Our top management values risk-taking opportunities abroad. & & & & & & & \\
\hline
\end{tabular}

\section{Organizational learning orientation (OLO)}

With regard to your company situation please indicate perceived possession on scale: 1 = "strongly disagree" and $7=$ "strongly agree"

1. Managers basically agree that our organization's ability to learn (modification of one's behaviour as a result of some experience or even before a certain event takes place) is one of the essential keys to the achievement of competitive advantage.

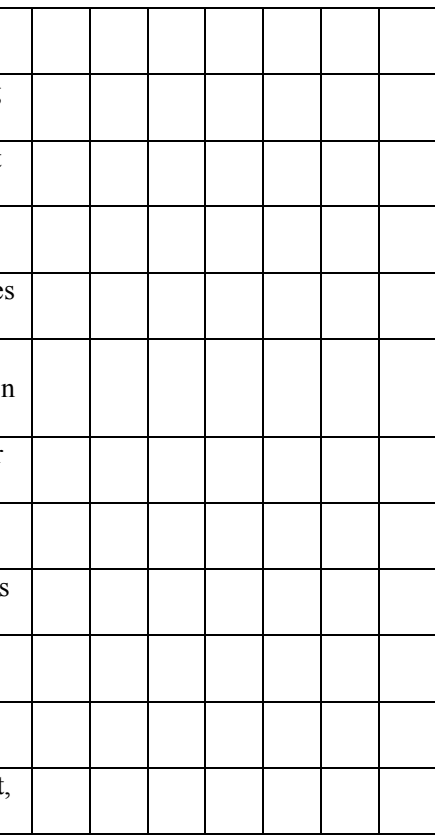




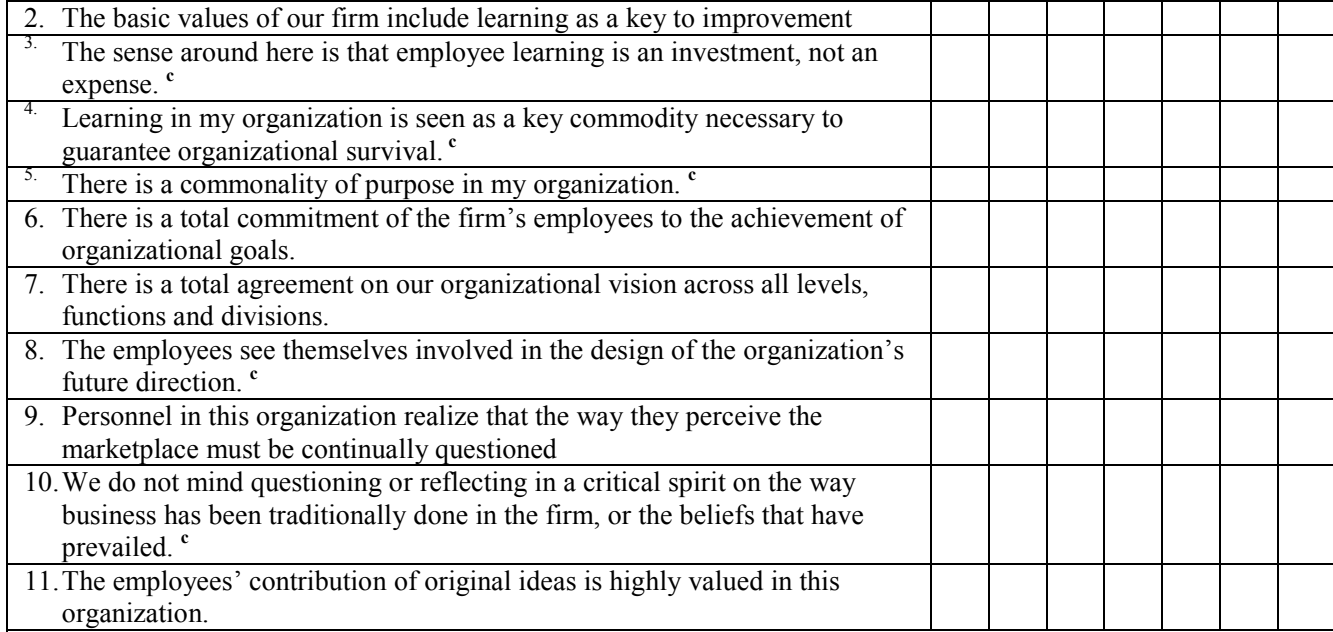

\section{Environmental factors}

On scale: 1 = "not at all," and 7 = "to an extreme extent", please state below your opinion about market turbulence and competitive intensity in your export market in the last three years

\begin{tabular}{|c|c|c|c|c|c|c|c|}
\hline Export market dynamism & 1 & 2 & 3 & 4 & 5 & 6 & 7 \\
\hline 1. Our export customers' product preferences change quite rapidly & & & & & & & \\
\hline $\begin{array}{l}\text { 2. New export customers tend to have product-related needs that are different } \\
\text { from those of our existing export customers }\end{array}$ & & & & & & & \\
\hline 3. Our export customers tend to look for new products all the time & & & & & & & \\
\hline $\begin{array}{l}\text { 4. We are witnessing changes in the type of products/services demanded by } \\
\text { our export customers }\end{array}$ & & & & & & & \\
\hline 5. Market competitive conditions highly unpredictable ${ }^{\mathbf{b}}$ & & & & & & & \\
\hline 6. $\quad$ Customer product demands and preferences highly uncertain ${ }^{b}$ & & & & & & & \\
\hline 7. Difficult to predict changes in customer needs and preferences ${ }^{\mathbf{b}}$ & & & & & & & \\
\hline Competitive intensity & 1 & 2 & 3 & 4 & 5 & 6 & 7 \\
\hline Competition in our export market is cutthroat & & & & & & & \\
\hline 1. There are many "promotion wars" in our export market & & & & & & & \\
\hline $\begin{array}{l}\text { 2. Anything that one competitor can offer in our export market, others can } \\
\text { match readily }\end{array}$ & & & & & & & \\
\hline 3. Price competition is a hallmark of our export market & & & & & & & \\
\hline $\begin{array}{l}\text { 4. One hears of a new competitive move in our export markets almost every } \\
\text { day }\end{array}$ & & & & & & & \\
\hline
\end{tabular}

Notes: ${ }^{a}$ Reverse-coded item

${ }^{b}$ Indicates items that were dropped during pilot reading of the questionnaire by experts;

${ }^{c}$ Indicates items that were dropped in the initial EFA

Firm size: the number of employees

\section{Experience in Exporting:}

Duration: Number of years the firm has been exporting

Number of markets in which the firm has regular exporting operations 


\section{ACKNOWLEDGEMENTS}

Though it will not be enough to express my gratitude in words to all people who helped me during this research trajectory, I would still like to give my many thanks to all these people.

First of all, I am deeply grateful to my promotor Professor dr. Martin Mulder for the continuous support of my $\mathrm{PhD}$ study, for his patience, motivation, and immense knowledge. His guidance helped me in all the time of research and writing of this thesis. I could not have imagined having a better advisor and mentor for my $\mathrm{PhD}$ study.

My sincere gratitude also goes to my co-promotors, Dr. Piety Runhaar and Dr. Thomas Lans for their guidance and advice. Thanks to Piety, she was always patient and willing to spend time and effort in reading and critically commenting on all chapters of my thesis. Without her help I could not have finished my thesis successfully. I would also like to thank Thomas for his valuable suggestions and critical remarks, which always encouraged me to get the best of my intelligence and potential.

I am profoundly grateful to those who contributed to the chapters of this thesis, either by collaborating on co-authoring papers or giving their insightful comments. I cheerfully acknowledge Prof. David Rae and Dr. Ruud Zaalberg. Special thanks go to Eghe, Hasse, Nienke, George, Getachew, Wudu, and Yalemzewd who have been nice colleagues over the years. Many of these colleagues, were of great value, not only for discussions about the research topics addressed in this thesis, but also in terms of further development of ideas about research. I would also like to cordially thank all my fellow $\mathrm{PhD}$ students, colleagues and the admin staff of the Chair Group of Education and Competence Studies.

I am thankful to Sam, Babette, Lissane, and Erik my nice roommates during my stay in Wageningen. I thank Sam also for language editing one of the chapters of my thesis.

I would like to express my appreciation to all companies and experts who have offered me their time when I collected necessary data for my empirical studies.

I am also indebted to Yonas Solomon and Samuel Sada for their kindness for allowing me to work in their barbershop during several times of power outages in my area.

I am thankful to my mother, and my brothers and sisters for supporting me spiritually throughout writing this thesis and my life in general. Their firm and kind-hearted personality 
had affected me to be steadfast and never bend to difficulties. They always let me know that they are proud of me, which motivates me to work harder and do my best.

Last but not least, I am greatly indebted to my beloved wife Tsehay. Her understanding and her love encouraged me to work hard and to continue pursuing a $\mathrm{PhD}$ study abroad. During the time I was writing my thesis at home, she spent sleepless nights with and was always my support in the moments when there was no one to answer my queries. I am also very grateful for my children Yordanos, Yonas and our new born Rodas for always making me smile and for not demanding my attention while I wrote my thesis. They form the backbone and origin of my happiness. 
Worku Tuffa Birru

Wageningen School of Social Sciences (WASS)

Completed Training and Supervision Plan

\section{Name of the learning activity}

Department/Institute Year

ECTS*

A) Project related competences

Project proposal writing

WASS

$2011-2012 \quad 6$

Competence theory and research

WASS

2012

4

Static \& Dynamic Analysis

WASS

2012

1.5

Dynamic Efficiency and Productivity Analysis

WASS

2012

B) General research related competences

Introduction course

WASS

WGS

2012

2012

1

Techniques for Writing and Presenting a

Scientific Paper

Project and Time Management

WGS

RME-WUR

2012

2012

1.5

Quantitative data analysis Multivariable

Techniques (YRM 60306)

Qualitative data analysis Procedures \&

RME-WUR

2012

6

Strategies (YRM 60806)

\section{C) Career related competences/personal development}

Information literacy including Endnote

Library-WUR

2012

0.6 introduction

Scientific publishing

Library-WUR

2011

0.3

Mobilising your scientific network

Editorship: book review editorial assistant and

ECS

2012

$2012-2015$

1

journal review editor, Journal of Agricultural Education and Extension (JAEE)

Short stay and teaching at foreign university, Lincoln Business School

University of Lincoln,

2014

4

Total

*One credit according to ECTS is on average equivalent to 28 hours of study load 